\section{LA-UR-}

PRECONCEPTUAL ABC DESIGN DEFINITION AND SYSTEM CONFIGURATION LAYOUT

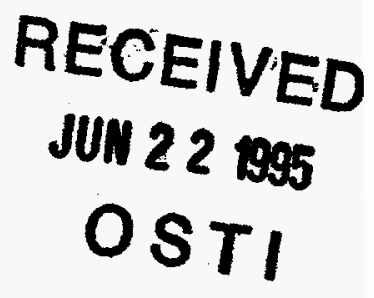

Submitted to:

Wolfgang Barthold

Barthold \& Associates, Inc.

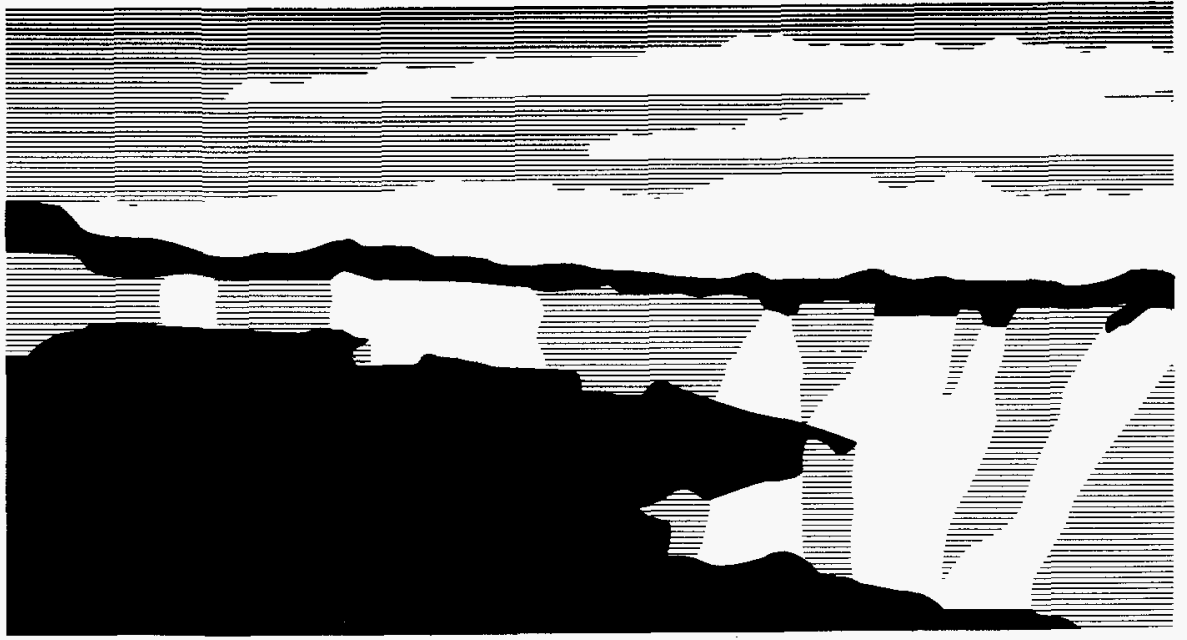

Los Alamos National Laboratory, an affirmative action/equal opportunity emplöyer, is operated by the University of California for the U.S. Department of Energy under contract W-7405-ENG-36. By acceptance of this article, the publisher recognizes that the U.S. Government retains a nonexclusive, royalty-free license to publish or reproduce the published form of this contribution, or to allow others to do so, for U.S. Government purposes. The Los Alamos National Laboratory requests that the publisher identify this article as work performed under the auspices of the U.S. Department of Energy. 


\title{
PRECONCEPTUAL ABC DESIGN DEFINITION AND SYSTEM CONFIGURATION LAYOUT
}

\author{
March 1995
}

\author{
DISCLAIMER
}

This report was prepared as an account of work sponsored by an agency of the United States Government. Neither the United States Government nor any agency thereof, nor any of their employees, makes any warranty, express or implied, or assumes any legal liability or responsibility for the accuracy, completeness, or usefulness of any information, apparatus, product, or process disclosed, or represents that its use would not infringe privately owned rights. Reference herein to any specific commercial product, process, or service by trade name, trademark, manufacturer, or otherwise does not necessarily constitute or imply its endorsement, recommendation, or favoring by the United States Government or any agency thereof. The views and opinions of authors expressed herein do not necessarily state or reflect those of the United States Government or any agency thereof.

\section{Prepared by}

Barthold \& Associates, Inc. 132 Seven Oaks Drive Knoxville, TN 37922

for

Los Alamos National Laboratory under Subcontract 2254V0015-3Y 


\section{DISCLAIMER}

Portions of this document may be illegible in electronic image products. Images are produced from the best available original document. 


\section{PRECONCEPTUAL}

ABC DESIGN DEFINITION AND

SYSTEM CONFIGURATION LAYOUT

\section{LIST OF CONTENTS}

1.0 INTRODUCTION

1.1 MSBR as a Basis for Design

1.2 Changes in Reactor Design Approach Since the MSBR

1.3 Important Changes in the Regulatory Environment Since 1970

1.4 References

2.0 DESIGN FEATURES OF PAST MOLTEN SALT AND LIQUID METAL REACTORS

2.1 MSBR Design and Safety Features

2.1.1 design features

2.1.2 safety features

2.2 LMR Pool Design Features

2.3 Original ABC/ATW Design Features

2.4 New ORNL ABC Design Features

2.5 References

3.0 PRECONCEPTUAL ABC DESIGN DEFINITION

3.1 Blanket Design Options

3.1.1 requirements

3.1.2 design options

3.1.2.1 fuel salt composition options

3.1.2.2 power density

3.1.2.3 moderator options

3.1.3 flow direction, inlet and outlet plena 
3.2 Primary, Secondary, Tertiary Systems, Components and System Layouts

3.2.1 requirements

3.2.2 design options

3.3 Containment Options

3.3.1 requirements

3.3.2 design options

3.4 Off-gas Systems

3.4.1 requirements

$$
\begin{array}{ll}
3.4 .1 .1 & \text { fuel } \\
3.4 .1 .2 & \text { coolant }
\end{array}
$$

3.4.2 design options

3.5 Drainage Systems

3.5.1 requirements
3.5.1.1
fuel drainage system
3.5.1.2
coolant drainage system

3.5.2 design options for drainage systems

$$
\begin{array}{ll}
\text { 3.5.2.1 } & \text { fuel drainage system } \\
\text { 3.5.2.2 } & \text { coolant drainage system }
\end{array}
$$

3.6 Freeze Plugs, Melt Plugs and Mechanical Valves

3.7 Fuel and Salt Processing

3.8 Approach to Shielding

3.8.1 maintenance personnel

3.8.2 systems, structures and components

\subsection{References}




\subsection{RECOMMENDED REFERENCE CONFIGURATION}

4.1 Considerations for the Selection of the Reference Configuration

4.2 Recommended Primary System

\subsection{1 blanket}

4.2.3 core support plate

4.2.4 fuel and coolant salt pumps

4.2.5 gas sparging system

4.2.6 blanket vessel

4.3 Secondary system
4.3.1 $\mathrm{IHX}$

4.3.2 coolant drain system

4.3.3 coolant off-gas system

4.3.4 isolation valves

4.4 Steam System

4.3.1 operating conditions

4.3.2 steam generator

4.3.3 isolation valves

4.5 Auxiliary Systems

4.5.1 fuel drainage system

4.5.2 off-gas system

4.5.3 fuel salt processing

4.6 Containment System

4.7 References 


\section{PRECONCEPTUAL}

\section{ABC DESIGN DEFINITION AND SYSTEM CONFIGURATION LAYOUT}

OBJECTIVE: Define Preconceptual ABC Design and System Configuration Layout That Meets ABC Safety and Performance Requirements.

\subsection{INTRODUCTION}

\subsection{MSBR as a Basis for Design}

In 1971, ORNL published a conceptual design of a molten salt breeder reactor (MSBR) ${ }^{1}$ that has been used extensively in this report in guiding the development of the $A B C$ plant layout. The ORNL design is based on an extensive experience base in molten salt reactor technology and molten salt reactor design and, for all practical purposes, has to be the point of reference (and departure) for any new molten salt system layout. Such a decision is also supported by the fact that since the termination of the molten salt reactor program in the 1970's, no more molten salt reactor design and technology development work has been conducted in the U.S.'

\subsection{Changes in Reactor Design Approach Since the MSBR}

While the stoppage of the molten salt reactor program two decades ago froze the molten salt reactor technology base to that of the mid 1970's, changes in the approaches to reactor design, safety and licensing happened since that time that have

(i) Under the NASAP Program during the late 1970's, ORNL developed the conceptual design characteristics of a denatured molten salt reactor with once-through fueling (ORNLTM-7207) that was based on the earlier MSBR design. However, no follow-up design was conducted, and the technology development program has been dormant since. 
a significant impact on the design of a future molten salt system, in particular the ABC system:

- the approach to reactor design has changed significantly in that reactor safety considerations govern the reactor design from the very beginning and are not added anymore as an afterthought;

- the licensing approach has become more demanding in that extensive experimental data bases are required to substantiate performance claims and assure that all of NRC's qualitative and quantitative safety criteria are meti;

- NRC's Advanced Reactor Policy Statement emphasizes passive and inherent safety features as well as monitoring of the operational status of all advanced reactors.

There are important differences in regard to the mission of the ABC vis-a-vis the MSBR as well as changes in reactor technology:

- the objective of the $A B C$ system is the safe, efficient, environmentally benign and cost-effective destruction of fissile plutonium and not the production (breeding) of fissile material;

- the component and system designs of the MSBR reflect to a large extent the technology status of the 1960's; operating experience with LWRs has shown that many of the systems that were viewed as essentially conventional power plant systems had to be modified to suit the nuclear power plant application;

- the nuclear reactors that were sold during the 1960's and 70's were expected to achieve lifetime capacity factors of $80 \%$ or better; after gaining many years of reactor operating experience, incorporating design changes, system and component modifications, improved maintenance, inspection and repair procedures, this availability goal is finally achieved by an increasing number of reactors albeit only on an annual basis and not as a lifetime average, and not for the majority of nuclear reactors.

(ii) It is important to note that neither the MSRE nor the MSBR underwent a licensing review. 
For these reasons it is prudent to develop an $A B C$ system layout that takes those experiences into consideration. To a limited extent this has been done in the new ORNL ABC design ${ }^{2}$ that, in several instances, goes beyond a mere scale-up of the original MSBR. However, the ORNL ABC layout is still a loop design and safety considerations did not play a major role in its development. The level of safety expected for the MSBR was viewed as sufficient for an ABC system except for adding an additional barrier to radionuclide releases.

\subsection{Important Changes in the Regulatory Environment Since 1970}

In the aftermath of the Three Mile Island accident the NRC issued a series of policy statements regarding unresolved safety issues that began with a notice in the Federal Register ${ }^{3}$, leading to an attempt to implement the generic issues program ${ }^{4}$ largely based on engineering judgement, and culminating in a prioritization of generic safety issues $^{5}$ and even the inclusion of lessons learned from the Chernobyl accident ${ }^{6}$. Of particular importance for any new reactor design ${ }^{\mathrm{iii}}$ is the Advanced Nuclear Power Plant Policy Statement ${ }^{7}$. This Policy Statement states:

"Regarding advanced reactors, the Commission expects, as a minimum, at least the same degree of protection of the public and the environment that is required for current generation LWRs. Furthermore, the Commission expects that advanced reactors will provide enhanced margins of safety and/or utilize simplified, inherent, passive or other innovative means to accomplish their safety functions."

While the $A B C$ facility is not a commercial nuclear power reactor it is prudent to assume that such a facility would have to adhere to NRC safety and design requirements as any new type of nuclear reactor.

In its Policy Statement, the Commission listed a series of attributes that should be considered in advanced reactor design:

- Highly reliable and less complex shutdown and decay heat removal systems. The use of inherent or passive means to

(iii) The terms "reactor", "core", and "blanket" are used in this report to describe an accelerator-driven subcritical configuration that multiplies spallation neutrons and destroys plutonium in the process.

REVISION 0 
accomplish this objective is encouraged (negative temperature coefficient, natural circulation)."

- $\quad$ "Longer time constants and sufficient instrumentation to allow for more diagnosis and management prior to reaching safety systems challenge and/or exposure to vital equipment to adverse conditions."

- $\quad$ "Simplified safety systems which, were possible, reduce required operator actions, equipment subjected to severe environmental conditions, and components needed for maintaining safe shutdown conditions. Such simplified systems should facilitate operator comprehension, reliable system function, and more straightforward analysis."

- $\quad$ "Designs that minimize the potential for severe accidents and their consequences by providing sufficient inherent safety, reliability, redundancy, diversity and independence in safety systems."

- "Designs that provide reliable equipment in the balance of plant, (or safety-system independence from balance of plant) to reduce the number of challenges to safety systems."

- $\quad$ "Designs that provide easily maintainable equipment and components."

- "Designs that reduce potential radiation exposures to plant personnel."

- $\quad$ "Designs that incorporate defense-in-depth philosophy by maintaining multiple barriers against radiation release, and by reducing the potential for and consequences of severe accidents."

- $\quad$ Design features that can be proven by citation of existing technology or which can be satisfactorily established by commitment to a suitable technology development program."

The regulatory review of evolutionary and passive light-water reactors led to the identification of LWR certification issues ${ }^{8}$ and in 1993 to recommendations by the NRC staff to the Commission on positions for issues pertaining to evolutionary LWR 
designs 9 . Of particular interest here is the use of a "conditional containment failure probability (CCFP)" of 0.1 as a basis for establishing regulatory guidance for the evolutionary ALWRs. Furthermore, the Commission states that the use of a CCFP of 0.1 should not discourage accident prevention. This is consistent with the requirement for a defense-in-depth philosophy that in regard to radionuclide releases requires that a reactor should not excessively rely on a single barrier.

It is also important to consider the NRC General Design Criteria where the Code of Federal Regulations (CFR) in General Design Criterion 11 requires $^{10}$ :

"Reactor inherent protection: The reactor core and associated coolant systems shall be designed so that in the power operating range the net effect of the prompt inherent nuclear feedback characteristics tends to compensate for a rapid increase in reactivity".

For all practical purposes this requires a negative Doppler coefficient. Furthermore, in a memorandum on policy issues for advanced reactors ${ }^{11}$ the issue of positive void reactivities is addressed and it is recommended:

"In order for the existence of a positive void coefficient to be acceptable, the probability of a core disruptive accident caused by voiding would have to be shown to be markedly less than $1 \times 10^{-6} /$ year."

In Chapter 2 of this report, design features of past molten salt and liquid metal reactors will be discussed. First, design and safety features of the MSBR will be evaluated in detail and the compliance of the MSBR with NRC advanced reactor safety policy requirements will be assessed.

Next, Liquid Metal Reactor (LMR) design and safety features will be briefly discussed because they have greater relevance to the molten salt reactor that those of gascooled or water-cooled reactors.

This is followed by a brief review of the original ABC/ATW design features.

Chapter 2 concludes with a brief discussion of the new ORNL ABC design features ${ }^{\mathrm{iv}}$.

(iv) The design described in Reference 2 is the design status as of December 1, 1995 and might have changed since that time.

REVISION 0

$1-5$

MARCH 1995 
Chapter 3 deals with a preconceptual $A B C$ design definition. The important $A B C$ systems and subsystems are addressed in regard to requirements and design options, their pluses and minuses. The level of detail in those discussions is consistent with the pre-conceptual nature of the design definition, although some of the discussion are very detailed.

Chapter 4 describes the recommended reference configuration for the important systems and subsystems.

It was intended to broaden the scope of this effort in regard to $A B C$ operating conditions, including steam cycle conditions, and to provide drawings of design options and the proposed reference system and subsystem designs. However, for reasons of contractional arrangements these topics will be addressed later in a sepatate report. 


\subsection{References}

1. R. C. Robertson (Editor) "Conceptual Design Study of a Single-Fluid Molten Salt Breeder Reactor", ORNL-4541 (1971)

2. ORNL presentation of ABC design at LANL, November 30-December 1, 1994

3. Federal Register Notice 54 FR 24432, "Program for Resolution of Generic Issues Related to Nuclear Power Plants", January 10, 1978

4. NUREG-0410, "NRC Program for the Resolution of Generic Issues Related to Nuclear Power Plants", U.S. Nuclear Regulatory Commission, January 1978

5. NUREG-0933, "Prioritization of Generic Safety Issues", U.S. Nuclear Regulatory Commission, July 1991

6. NUREG-1251, "Implications of the Accident at Chernobyl for Safety Regulation of Commercial Nuclear Power Plants in the United States", U.S. Nuclear Regulatory Commission, Vol. 1 (April 1989) and Vol. 2 (April 1989)

7. 10 CFR Part 50, "Regulation of Advanced Nuclear Power Plants; Statement of Policy", Federal Register Vol. 51, No. 130, July 8, 1988

8. SECY-90-016, "Evolutionary Light-Water Reactor (LWR) Certification Issues and Their Relationship to Current Regulatory Requirements", January 12, 1990

9. SECY-93-087, "Policy, Technical, and Licensing Issues Pertaining to Evolutionary and Advanced Light-Water Reactor (ALWR) Designs", April 2, 1993

10. Code of Federal Regulations (CFR) Part 50, Appendix A: General Design Criteria for Nuclear Power Plants, January 1, 1992

11. Memorandum, D. M. Crutchfield (NRC) to Distribution, "Policy Issues for Advanced Reactors", March 10, 1992 


\subsection{DESIGN FEATURES OF PAST MOLTEN SALT AND LIQUID METAL REACTORS}

The MSRE ${ }^{1}$ and MSBR $^{2}$ designs developed by ORNL during the 1960's and 70's, the denatured molten salt reactor ${ }^{3}$ developed for proliferation resistance, and the LANL $A B C$ design studies ${ }^{4}$ provide points of reference and departure for the development of new $A B C$ systems designs. Advantage will also be taken of the design efforts by the KFA Juelich ${ }^{5}$ and INTERATOM ${ }^{6}$ (Germany) on the development of epithermal and fast molten salt reactors, although these designs were only developed up to the early preconceptual level. Benefits can also be derived from the Clinch River Breeder Reactor Plant design and licensing experience ${ }^{7}$, the Advanced Liquid Metal Reactor (ALMR) design $^{8}$, the design and licensing experience of Advanced Light Water reactors, and a system evaluation for the CANDU 3 reactor ${ }^{9}$.

\subsection{MSBR Design and Safety Features}

Starting in 1960, the Molten Salt Reactor Program at ORNL focused on the breeding potential of molten salt systems leading to the design of the Molten Salt Breeder reactor (MSBR), that was based on the design of and operating experience with the Molten Salt Reactor Experiment (MSRE) and its technology support programs. In 1974, ORNL proposed a major technology development program ${ }^{10}$ that would have culminated in the construction and operation of a demonstration reactor called the Molten Salt Breeder Experiment, at a total cost over 11 years of $\$ 350$ million. Such a program had both industrial and utility support ${ }^{11}$ claiming that the existing technology was sufficient to justify construction of a molten salt demonstration planti.

While the MSBR responded to the performance requirements and safety concerns at that time, its concept evolution goes back to the early 1960's. It was expected that the MSBR could match or even exceed the level of safety achieved by any other reactor. However, upon completion of the MSBR design it was also recognized that a molten salt reactor had never been subjected to a licensing review and that design modifications might be necessary to pass regulatory review.

(i) The McPherson article (Reference 11) contradicts directly the notion that the molten salt reactor program died because of a lack of industry support. Two industry-utility working groups had recommended to the AEC to proceed to a molten salt reactor demonstration plant. 
In the following, several important MSBR design and safety features will be discussed that in many instances differ from today's reactor design and safety approach.

\subsection{2 design features}

Loop Design: The MSBR is a loop design just as the PWRs and BWRs and the LMFBR concepts of the 1970's (FFTF, CRBRP). Nowhere in the literature is an explicit justification presented as to why a loop design would be more beneficial than a pool design. It seems liklely that a loop conept was selected because it resembled more closely a conventional power plant with a boiler and an energy conversion unit. For circulating fuel reactors, it seemed easier to minimize the out-of-core fuel inventory which is always a concern for those reactors. A large out-of-core fuel inventory increases inventory cost and increases fuel doubling time which is a particular concern for a breeder reactor.

Molten Salt Pumps and IHX: Experience with molten salt pumps and IHX was gained from earlier ARE and in particular MSRE operation. However, it is important to note that the MSRE fuel pump had a capacity of only $1200 \mathrm{gpm}$ and was driven by a 75 hp motor, whereas the MSBR fuel pump design shows a capacity of $16,000 \mathrm{gpm}$ with a brake horsepower of about $2350 \mathrm{hp}$; the corresponding data for the secondary pumps are $850 \mathrm{gpm}$ and $20,000 \mathrm{gpm}$, respectively. The MSRE IHX was capable of transferring $8 \mathrm{MW}$ of heat whereas the MSBR IHX design had a capacity of 556.5 MW. Going from the MSRE to the MSBR represented a substantial extrapolation in size but also changes in design.

While the ORNL design staff expressed confidence that there were only few development difficulties for the larger pumps, it was concluded that a lower bearing might be required, and noted that salt bearing development work was in progress at ORNL at that time and looked very promising. However, the use of salt-lubricated bearings would not allow the pump to circulate gas during warmup of the system before it is filled with salt. This would require a change in startup equipment and procedures.

The MSBR IHX design is not unlike other IHX designs but used special tubing in certain portions to enhance heat transfer. This enhancement consisted of indenting a shallow spiral groove in the tube wall that, based on water tests, was expected to improve the heat transfer coefficient inside by a factor 2 and outside by a factor 1.3.

The main reason for using special tubing in the MSBR, in spite of increased cost for the tubing, was the estimated reduction in the total fuel salt inventory in the primary 
system by $5 \%$ which reduced the fuel doubling time. With breeding not being an issue for the $A B C$ system, it would not be advisable to engage in a development program for such tubing with extensive (and expensive) in-pile and out-of-pile testing.

Valves: All valves in the MSRE were freeze valves. In case of the MSRE fuel-salt drain valve, a flattened section of the 2-inch drain line was equipped with external heaters and coolers. For as long as this section of the pipe was cooled, the fuel salt inside remained frozen and did not permit any flow through this section. However, in case the cooling ceased, the freeze plug began to melt and flow could pass through this section. Restarting cooling would lead to a freezing of this section and "close the valve".

Using a single drain line for the MSBR would require a 6-inch line which in turn would require a significant refrigeration plant to keep the valve closed during normal operation. A shell-and-tube heat exchanger was considered to control thawing and freezing, where the salt flows through the tubes. Mechanical valves where also considered where the seat was chilled to provide positive shutoff.

No assessment has been made for the MSBR of the safety implications of any of the valve types.

Graphite /ssues: The main function of the graphite in the MSBR core was to provide neutron moderation. This graphite had no structural function.

Concerns were expressed about seepage of fuel salt into small cracks in the graphite that can lead to local overheating and crack propagation. There are no data to show that significant salt entrainment took place or, in case of salt entrainment, that this can lead to pieces of graphite breaking off.

It was recognized for the MSBR that the in-core graphite structures would have to be replaced every four years because of radiation damage. Such replacements would require extensive shutdown periods. No considerations were given at that time to (graphite) waste management and disposal.

Any concerns about graphite performance in an $A B C$ system are greatly reduced by going to an unmoderated system (during the early 1960's, the German MOSEL system was developed in part to avoid the periodic graphite replacements).

Gas Sparging: For the MSBR it was vitally important to remove fission gases from the primary system to enhance breeding. Because fission gases collect in pores in the graphite where they and their decay products represent strong neutron absorbers, 
helium bubbles were introduced into the fuel salt to offer additional places for fission gas collection. The helium bubbles were introduced in a side stream off the pump bowl, and they were removed from the pump bowl and directed to the off-gas system.

For the $A B C$ system a gas sparging system is of lesser importance because breeding is not an issue. Therefore, any requirements in regard to effective fission gas removal by a gas sparging system are more relaxed than for the MSBR. In case a graphite moderator is not used in the core region, there would be a further relaxation of the gas removal requirements, and it might even be sufficient to remove the fission gases from the pump bowl without introducing helium as a sparging gas but just relying on the helium sweep gas flow in the pump bowl.

Metals and Graphite Performance: One of the problems discovered after completion of the MSRE operation was the damage to the Hastelloy $N$ (embrittlement) caused by $(n, a)$ reactions in ${ }^{10} \mathrm{~B}$ and in a two-step reaction in nickel, and the embrittlement caused by the fission metal tellurium that diffused a short distance into the metal along the grain boundaries. The development of a modified Hastelloy $N$ was called for using niobium as a modifier, and initial irradiation data showed a good resistance to irradiation embrittlement.

In regard to the Te embrittlement it was noted ${ }^{12}$ that it might be possible to operate the reactor in a regime (i.e., in a reducing environment) where tellurium might not even embrittle standard Hastelloy $N$. The embrittlement due to neutron damage, however, was more difficult to control in the MSBR because of the need to breed effectively.

It was estimated for the MSBR that the core graphite was exposed to about the same neutron flux as the fuel salt and the power density in the core $(22.2 \mathrm{~kW} / /$ average, $70.4 \mathrm{~kW} /($ peak) had to be selected to ensure at least a four-year graphite lifetime (a life-limiting graphite damage fluence of $3.0 \times 10^{22} \mathrm{n} / \mathrm{cm}^{2}$ has been assumed). ${ }^{i "}$

To achieve a 30-year lifetime for the reactor vessel (made of Hastelloy N), the core region was surrounded by a $2 \frac{1}{2} \mathrm{ft}(0.762 \mathrm{~m})$ thick graphite reflector region to keep the vessel fluence below the limiting fast fluence of $1 \times 10^{21} \mathrm{n} / \mathrm{cm}^{2}(E>1 \mathrm{MeV})$. No poison materials were added to the reflector because this would have diminished the breeding potential of the MSBR in spite of the resulting benefits for vessel lifetime.

(ii) There are other more important constraints on power density, among them the requirement to keep low the absorptions in ${ }^{233} \mathrm{~Pa}$, which decays into ${ }^{233} \mathrm{U}$, because any absorption in ${ }^{233} \mathrm{~Pa}$ significantly diminishes the breeding potential of the MSBR. 
Coolant Drainage: Drainage of both fuel salt and coolant salt was done passively by gravity. iii In case of the coolant drainage, however, the MSBR design did not permit complete coolant drainage of the IHX by gravity. For a complete removal of coolant, a gas pressurization of the shell side of the IHX was required. The consequences of not being able to drain all the coolant in the MSBR have not been assessed.

Steam System: The MSBR used a very advanced supercritical steam cycle 13800 psig steam) based on the design of the coal-fired Bull Run Steam Plant. It was recognized in reference 2 that there might be problems (see p.74 of reference 2: "Use of subcritical steam pressures, although less efficient, may prove desirable from other standpoints"). While the feasibility of these steam conditions has been amply demonstrated in the coal-fired Bull Run steam plant just outside of Oak Ridge, Tennessee, there is no nuclear reactor that uses such high steam pressures. The highest pressures in the steam cycle of nuclear power plants are in the range of 2200 psig, but those pressures are matched by very high primary system pressures which leaves rather small pressure differentials between the steam pressure and the primary coolant pressures. In a low pressure system like the early PRISM design, the saturated steam pressure is only 1000 psia. The PRISM IHX had to be designed to withstand only a 1000 psia pressure, and the containment design pressure was only 5 psig. ${ }^{i v}$

(iii) Note: for drainage to be passive in the MSBR design, freeze valves have to be used. While reference 2 only addresses the fuel drain valve and is ambiguous on the reference valve design, passive drainage for both fuel and coolant salts requires freeze valves or valves that are activated by thawing of frozen salt.

(iv) The following are the IHX and steam pressure conditions for the MSBR:

IHX:

$\begin{array}{lll}\text { fuel salt (tube side) } & \begin{array}{l}\text { entrance pressure: } \\ \text { pressure drop: }\end{array} & \begin{array}{l}180 \mathrm{psi} \\ 130 \mathrm{psi}\end{array} \\ \text { coolant (shell side) } & \begin{array}{l}\text { exit pressure: } \\ \text { pressure drop: }\end{array} & \begin{array}{l}34 \mathrm{psi} \\ 115.7 \mathrm{psi}\end{array} \\ & & \\ \text { Steam Generator: } & & \\ \text { coolant (shell side) } & \text { entrance pressure: } & 233 \mathrm{psia} \\ & \text { exit pressure: } & 173 \mathrm{psia} \\ \text { supercritical fluid } & \text { entrance pressure: } & 3752 \mathrm{psia} \\ \text { (tube side) } & \text { exit pressure: } & 3600 \mathrm{psia}\end{array}$

The impact of a main steam line break or a steam generator tube rupture is not discussed in the conceptual MSBR design report. 
The MSBR designers were aware that these steam conditions were very severe. In reference 2 on page 68 is stated:

"The -3750 psia fluid pressure on the inside of the tubes imposes relatively severe requirements on the heads and tube sheets. This factor was considered in selecting the number of steam generator units used in the MSBR, since the relatively small diameter of 18 in. selected for the shell allows stresses to be kept within more tolerable limits". (emphasis added)

Each of these steam generators was designed for only $121 \mathrm{MWt}$.

Based on this experience it seems that using the same steam conditions as in the MSBR but for a significantly larger-size steam generator would have to be justified.

Power Density: The power density in the MSBR fuel salt has an average value of 74 $\mathrm{kW} / \mathrm{l}$ and a peak value of $492 \mathrm{~kW} / \mathrm{l}$. Because of the large amount of graphite in the core, the average core power density is only $22.2 \mathrm{~kW} / \mathrm{I}$ with a peak value of 70.4 $\mathrm{kW} / \mathrm{l}$. The fuel volume fraction in the inner and outer core zones are $13 \%$ and $37 \%$ respectively. While the power density values are higher than in the MSRE, they are still conservative ${ }^{v}$.

\subsection{2 safety features}

Passive Safety Features: The most important inherent safety feature for the MSBR is the overall negative temperature coefficient of reactivity. While some of the components are positive, the overall temperature coefficient is negative (Table 2.1):

The void coefficient (assuming bubble expansion and salt expansion) is positive albeit very small. In case of the MSBR, an increase in void fraction from $1 \%$ to $2 \%$ would yield a reactivity change of +0.00039 ; analogously, a bubble collapse from $2 \%$ to $1 \%$ would yield a reactivity change of -0.00039 .

Placing a large amount of graphite in the core and operating at a low power density provides for a large heat sink in case of a loss of flow accident.

(v) It should be noted that the MHTGR has a core average power density of $5.9 \mathrm{~kW} / \mathrm{w}$ with helium as a coolant. A molten salt coolant is far more effective in removing heat than helium. LWRs have significantly higher power densities that, depending on the design, are in the 60$80 \mathrm{~kW} / \mathrm{l}$ range. LMRs have power densities in the $300 \mathrm{~kW} / \mathrm{l}$ range.

REVISION 0

$2-6$

MARCH 1995 
TABLE 2.1: ISOTHERMAL REACTIVITY COEFFICIENTS FOR THE MSBR

\begin{tabular}{|c|c|}
\hline COMPONENT & 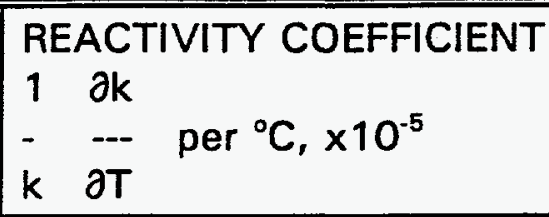 \\
\hline $\begin{array}{l}\text { Doppler } \\
\text { Salt thermal base } \\
\text { Salt density }\end{array}$ & $\begin{array}{l}-4.37 \\
+0.27 \\
+0.82\end{array}$ \\
\hline Total Salt & -3.22 \\
\hline $\begin{array}{l}\text { Graphite thermal base } \\
\text { Graphite density }\end{array}$ & $\begin{array}{l}+2.47 \\
-0.12\end{array}$ \\
\hline Total Graphite & +2.35 \\
\hline Total Core & -0.87 \\
\hline
\end{tabular}

The MSRE operation was found to be stable and self-regulating with regard to changes in heat load. Responsible in large part for this behavior are the strong negative temperature coefficients of the fuel salt and the graphite moderator ${ }^{\text {vi. The MSRE was }}$ simple to control. In over 14,000 hours of critical operation, not once has the nuclear power, period, or fuel temperature gone out of limits so as to cause a control-rod scram. A similar operational characteristics could have been expected for the MSBR even though the temperature coefficients were not as stronlgly negative as for the MSRE. Both reactors, however, were equipped with control rods.

Two types of rods were planned for the MSBR core: (1) control rods which have both regulating and shimming functions for normal load following and shutdown, and (2) safety rods which are primarily for backup to assure adequate negative reactivity for emergency situations. The control rods are movable graphite cylinders whose withdrawal from the core leaves an under-moderated region and causes a reduction in reactivity. Should any of these control rods ever break, they would float out of the

(vi) The MSRE temperature coefficient of reactivity for ${ }^{235} U$ fuel at operating loading was measured as $-8.1 \times 10^{-5}$, with the fuel contribution being $-4.1 \times 10^{-5}$. The measured total temperature coefficient for ${ }^{233} \mathrm{U}$ was $-8.5 \times 10^{-5}$.

REVISION 0

$2-7$

MARCH 1995 
core and cause the reactivity to decrease.

Common to all circulating fuel reactors with continuous refueling is the absence of the accidental control rod withdrawal event that is usually the main initiator for a transient overpower event, because these reactors operate with only an insignificant amount of excess reactivity.

Missing from the MSBR design are other major passive safety features, in particular in regard to decay heat removal, that all of today's advanced reactor possess.

Because of the limited extent to which inherent and passive safety features are built into the 1971 MSBR design, it would run today into licensing problems unless the design is modified. However, none of these deficiencies is a generic limitation but MSBR-design specific. If properly designed for passive and inherent safety, the molten salt reactor most likely will excced the level of safety that any other advanced reactor can provide.

Decay Heat Removal: Because the MSBR core is at the same elevation as the $\mathrm{IHX}$ and the steam generators, decay heat removal via natural convection in case of a loss of forced flow accident is very limited.

A loss of heat sink accident will lead to fuel overheating. If the fuel drainage system of the MSBR had been designed as a safety system then fuel drainage and subsequent passive decay heat removal from the drain tank would provide for the heat transport from the fuel salt to a heat sink. However, the MSBR design report (reference 2) states on page 85 :

"Although draining the fuel salt from the reactor is a positive shutdown mechanism, it is not necessary to rely on this as an emergency procedure, and rapid drainage is not a primary design criterion." (emphasis added)

Reference 2 reflects on the safety thinking at that time when the prime concern was with quickly shutting down the reactor and to a far lesser degree with assured decay heat removal.

The loop design and placement of the core system in a well-insulated, heated cell is not easily amenable to passive decay heat removal, similar to the Reactor Cavity Cooling System (RCCS) of the MHTGR or the Indirect Reactor Auxiliary Cooling System (IRACS) and Direct Reactor Auxiliary Cooling System (DRACS) of the Liquid Metal Reactor. 
Loss of Primary Coolant Accidents: A loss of primary coolant accident in the MSBR is the spillage of fuel salt. Some level of fuel salt leakage was expected for the MSBR and led to the placement of a catch basin under the primary system that was connected to the primary salt drain tank. However, while the concern with a primary system pipe break accident in an LWR is the loss of coolant that can lead to a fuel overheating and, under severe conditions, to a gaseous fission product release that can later lead to a fuel melting, a primary system pipe break in the MSBR leads to the spillage of molten salt fuel. In term of radionuclides releases, this is the equivalent to a partial fuel meltdown and breach of the primary system boundary in a solid fuel reactor. The remedy available in the MSBR, namely to catch the molten salt fuel in a catch basin would be the subject of significant regulatory scrutiny even though the primary system is contained inside a containment-like cell, which is surrounded by a containment building. While MSBR proponents have argued that in such an accident the fuel would immediately freeze and most likely retain the fission products, it will be difficult to convince the NRC that the remedy for such an accident is cleanup of the contaminated areas and then a restart of the reactor.

It should be noted that the concern with a loss of coolant accident in a loop-type LMFBR led strong support to the selection of a pool design concept.

IHX Tube Failure: Because the MSBR primary system pressure is higher than the secondary system pressure, any IHX tube failure would lead to an out-leakage of fuel salt. This would lead to fuel salt spilling into the coolant salt that moves to the steam generator. A coincidental failure of a steam generator tube could lead to a release of fuel salt, loaded with fission products, to the outside environment ${ }^{\text {vii. }}$.

There are questions about the licensability of such a configuration today. Considering that the tube failure probabilities are in the $10^{-1}$ to $10^{-2}$ range, in the absence of adequate isolation capabilities this would lead to a major release of radionuclides with a probability in the range of $10^{-3}$ to $10^{-4}$. The NRC requirement for a large release of radioactivity is in the $10^{-7}$ range.

Steam Pressure: The steam pressure for the MSBR is 3800 psig which is by far the highest steam pressure in any nuclear reactor system. To prevent overpressurization of the intermediate loop in the event of a failure in the barrier between the coolant salt and the steam system (e.g., a steam generator tube rupture), the secondary circulating loops have been equipped with a pressure-relief system. A rupture disk had been located at the secondary salt outlet of each steam generator. It had been estimated

(vii) The MSBR had no isolation valves for the IHX; however, the MSBR design called for thecapability to isolate the steam generator.

REVISION O

$2-9$

MARCH 1995 
that failure of a single tube in the steam generator would increase the pressure at the coolant-salt outlet of the steam generator from a "normal value of 130 psi to about $200 \mathrm{psi}$ in less than $1 \mathrm{sec} " .{ }^{\text {viii }}$ In calculating the pressure-containing requirements for the MSBR steam cells it was assumed that the six tubes surrounding the failed tube will also fail in the estimated $5 \mathrm{sec}$ required to close the steam-system block valves at the inlet and outlet of the steam generator. This action was expected to prevent a pressure buildup on the primary heat exchanger tubes. The pressure relief in the steam system through the rupture disks together with these quick-acting stop valves on the steam generators were expected to limit the pressure buildup in the steam cells to 50 psig.

No analysis details are available for review. However, considering the pressure differential in the steam generator between the steam inside the tubes and the coolant salt on the outside of over 3600 psi, it is quite conceivable that any tube failure will rapidly lead to other tube failure (e.g., due to impact failure) with the result that the coolant salt will be suddenly and severely overpressurized.

While lowering the steam pressure tends to lower the energy conversion efficiency, one of the advantages of lower steam pressures is the decreased severity of main steam line breaks that determine the design pressures for the containment. Furthermore, the $\mathrm{IHX}$ design is simplified because of the lowered pressure in the steam generator and the less severe pressurization of the $\mathrm{IHX}$ in case of a steam generator tube rupture. While pressure relief valves and rupture disks can be used to control slow pressurization accidents, less assurance of their effectiveness can be provided in case of rapid pressurization accidents.

Furthermore, from an investment protection as well as a safety point of view, it would be imprudent to rely solely for the protection of plant integrity on two so far unproven assumptions, namely (1) not more than six steam generator tubes could ever fail at one time, and (2) the steam generator isolation through stop valves can be accomplished within five seconds with nearly $100.00 \%$ certainty.

Other Consequences of Coolant System Overpressurization: The possibility exists that the coolant system, including the pump and $\mathrm{IHX}$ can be suddenly overpressurized due to a sudden steam generator tube failure. This can lead to mechanical failures of these components. This in turn can affect the other three steam generators that are

(viii) It should be noted that there is an inconsistency in the pressures cited in reference 2 on page 72 that describes the steam generator tube failure, and the data in Table 4.1, MSBR steam generator design data, on page 67. The pressure at the coolant salt outlet of the steam generator is stated as 130 psi on page 72 , but as 172 psi in table 4.1 .

REVISION 0

$2-10$

MARCH 1995 
fed by the same $\mathrm{IHX}$ due to coolant flow interruptions to those steam generators (the MSBR uses $4 \mathrm{IHX}$ and 16 steam generators). Furthermore, in anticipation of such steam generator tube ruptures overpressure protection is also required for the off-gas and drainage systems.

Natural Convection Capability: The MSBR core and IHX, and also the steam generator, are all at about the same elevation, i.e., there is little difference in the elevation of the respective thermal centers. Such a configuration is not very conducive to natural convection as a means of heat transport in case of a loss of forced flow.

Shutdown Capability: Because the MSBR operates with only a very small amount of excess reactivity that has to be compensated by external control, the shutdown rods placed in the core are sufficient.

As stated earlier, fuel drainage was not relied upon to shut down the reactor.

Loop Isolation: Loop isolation is not addressed explicitly in the MSBR design except in regard to an isolation of the steam generator in case of a steam generator tube rupture. There is no capability to isolate the intermediate heat transfer loop between the secondary circuit pump and the core.

Safety Classifications: Systems, structures and components have not been classified in regard to their importance to safety. For example, the pressure relief system in the intermediate loop, represented by the rupture disks, and the fast-acting block valves used to isolate the steam generator, are described only in very general terms even though they are of extreme importance in mitigating the consequences of a steam generator tube rupture accident. If those isolation devices are not extremely reliable ${ }^{\mathrm{ix}}$ the containment integrity would be relied upon too heavily.

\section{Compliance of MSBR with NRC Advanced Reactor Safety Policy Requirements}

Table 2.2 summarizes the MSBR safety characteristics in relation to the NRC Advanced Reactor Policy. An overall rating is listed using the following symbols:

(ixi) Assuming a steam generator tube failure probability and a containment failure probability of $10^{-1}$ each, these isolation devices must have a reliability of $99.999 \%$ to ensure that the primary and secondary systems are not damaged due to overpressurization by the steam and radionuclides in unacceptably high concentrations are not released to the environment (consistent with the $10^{-7}$ probability limit for large radionuclide releases). 
TABLE 2.2: NRC-PROPOSED SAFETY ATTRIBUTES VS MSBR RESPONSE

\begin{tabular}{|c|c|c|}
\hline $\begin{array}{l}\text { NRC-PROPOSED SAFETY ATTRIB- } \\
\text { UTE }\end{array}$ & MSBR RESPONSE & RATING \\
\hline $\begin{array}{l}\text { Use of inherent and passive means } \\
\text { for: } \\
\begin{array}{l}\text { Reliable and less complex } \\
\text { shutdown system }\end{array} \\
\text { - decay heat removal }\end{array}$ & $\begin{array}{l}\text { Working with a very small excess } \\
\text { reactivity is a generic feature of } \\
\text { MSRs and leads to less complex } \\
\text { shutdown systems; the overall } \\
\text { temperature coefficient is negative } \\
\text { active systems except in the fuel } \\
\text { drainage system; however, fuel drai- } \\
\text { nage is not relied upon }\end{array}$ & $\theta$ \\
\hline $\begin{array}{l}\text { Long time constants, sufficient in- } \\
\text { strumentation and diagnostics }\end{array}$ & MSBR meets all those requirements & $\oplus$ \\
\hline $\begin{array}{l}\text { Simplified safety systems to reduce } \\
\text { required operator action }\end{array}$ & $\begin{array}{l}\text { Normal operation of the MSBR re- } \\
\text { quires little operator action }\end{array}$ & $\oplus$ \\
\hline $\begin{array}{l}\text { Provide sufficient inherent safety, } \\
\text { reliability, redundancy, diversity and } \\
\text { independence to minimize severe } \\
\text { accidents }\end{array}$ & $\begin{array}{l}\text { Inherent and passive safety have not } \\
\text { guided the design of the MSBR. Re- } \\
\text { dundancy has been largely achieved; } \\
\text { diversity and independence have not } \\
\text { been set as goals; reliability is largely } \\
\text { unknown }\end{array}$ & $\theta$ \\
\hline Reliable balance of plant equipment & $\begin{array}{l}\text { MSBR report focuses on NSSS with } \\
\text { little details on the BOP (pre-concep- } \\
\text { tual design) }\end{array}$ & O \\
\hline $\begin{array}{l}\text { Easy maintenance of equipment and } \\
\text { components }\end{array}$ & $\begin{array}{l}\text { MSBR was specifically designed for } \\
\text { remote maintenance and repair, but it } \\
\text { is not easy }\end{array}$ & 0 \\
\hline $\begin{array}{l}\text { Reduce radiation exposure to plant } \\
\text { personnel }\end{array}$ & $\begin{array}{l}\text { The MSBR uses heavy shielding } \\
\text { around all cells that contain radio- } \\
\text { active material }\end{array}$ & $\oplus$ \\
\hline $\begin{array}{l}\text { Defense-in-depth philosophy by: } \\
\text { - } \quad \text { use of multiple barriers } \\
\text { reduce potential for severe } \\
\text { accidents }\end{array}$ & $\begin{array}{l}\text { Defense in depth has not guided } \\
\text { MSBR design. Insufficient isolation } \\
\text { capabilities; steam tube rupture acci- } \\
\text { dent is severe. }\end{array}$ & $\theta$ \\
\hline $\begin{array}{l}\text { Rely to large extent on existing } \\
\text { technology }\end{array}$ & $\begin{array}{l}\text { Broad technology bases exists from } \\
\text { ANP and MSRE Programs }\end{array}$ & $\oplus$ \\
\hline $\begin{array}{l}\text { In case existing technology is } \\
\text { insufficient, commit to suitable te- } \\
\text { chnology development program }\end{array}$ & $\begin{array}{l}\text { An extensive technology develop- } \\
\text { ment program plan had been written } \\
\text { in } 1974\end{array}$ & $\oplus$ \\
\hline
\end{tabular}


overall positive

overall negative

cannot be rated due to preconceptual nature of design

\subsection{LMR Pool Design Features}

LMRs started out as pool designs (e.g., EBR-II, as well as an early GE design) that, however, were soon changed to loop designs. The reasons cited at that time for these changes were (1) easier inspectability, maintainability and repair, (2) easier extrapolations to larger sizes, and (3) use of PWR and BWR experience in plant design $\times$.

However, in the mid-1980's with increasing emphasis on passive and inherent safety, LMRs were designed as pool configurations where in the beginning, a large sodiumfilled tank contained the reactor core, primary pumps, the IHXs and possibly also the steam generators. With the advent of modular designs, the large tank was replaced by a steel vessel that contained the core, primary pumps and IHX with penetrations for the secondary coolant that is directed to the steam generators.

There are many advantages for these pool configurations: (1) primary system leaks are essentially eliminated or at the least greatly reduced and whatever leak can occur does not lead to radionuclide releases; i.e., a loss of coolant accident is eliminated for all practical purposes; (2) the pool provides a large heat sink in case of a loss of flow accident where heat is dissipated in the large pool of coolant outside the core; $(3)$ a pool configuration easily accommodates a passive decay heat removal system where decay heat is passively removed from the coolant surrounding the core, and transported to the outside environment.

Disadvantages of a pool configuration are: (1) a larger reactor vessel is required that can accommodate the primary system components; (2) leak detection is made more difficult; (3) remote maintenance is made more difficult because an inert environment has to be created/maintained for repair/maintenance work of systems, structures and components located inside the pool.

(x) Contrary to claims by DOE a few years ago, the selection of a loop concept over a pool concept was not based on an exhaustive assessment of these concepts but in essence a justification of a selection already made.

REVISION 0 
The ALMR Reference and Mod-B plant performance characteristics are briefly summarized in Table 2.3.

TABLE 2.3: REFERENCE AND MOD-B PLANT PERFORMANCE CHARACTERISTICS

\begin{tabular}{|c|c|c|}
\hline & $\begin{array}{l}\text { REFERENCE } \\
\text { PLANT }\end{array}$ & $\begin{array}{l}\text { MOD-B } \\
\text { PLANT }\end{array}$ \\
\hline $\begin{array}{l}\text { OVERALL PLANT: } \\
\text { reactor modules per block/plant } \\
\text { net station efficiency (\%) } \\
\text { net electrical output (MWe) } \\
\text { rating/module (MWe) } \\
\text { steam conditions (F/psia) }\end{array}$ & $\begin{array}{l}3 / 9 \\
35.1 \\
1488 \\
165 \\
830 / 1800\end{array}$ & $\begin{array}{l}2 / 4 \text { or } 2 / 6 \\
36.1 \\
1212 \text { or } 1818 \\
303 \\
850 / 2200\end{array}$ \\
\hline $\begin{array}{l}\text { REACTOR MODULE } \\
\text { core thermal power (MWt) } \\
\text { primary sodium inlet/outlet temp (F) } \\
\text { primary sodium flow rate (gpm) } \\
\text { intermediate sodium inlet/outlet (F) }\end{array}$ & $\begin{array}{l}471 \\
665 / 930 \\
46,000 \\
575 / 865\end{array}$ & \begin{tabular}{|l}
$840(178 \%)$ \\
$680 / 930$ \\
86,000 \\
$620 / 890$
\end{tabular} \\
\hline $\begin{array}{l}\text { REACTOR CORE } \\
\text { fuel ( } \% \text { Pu) } \\
\text { number of control/ultimate shutdown rods } \\
\text { number of gas expansion modules } \\
\text { refueling interval (months) } \\
\text { average breeding ratio }\end{array}$ & $\begin{array}{l}26 \\
6 / 1 \\
6 \\
24 \\
1.05\end{array}$ & $\begin{array}{l}23 \\
9 / 3 \\
6 \\
23 \\
1.059\end{array}$ \\
\hline
\end{tabular}

The LMR layout is shown in Fig 2.1. This is a classical pool design. For the LMR with a power output of $840 \mathrm{MWt}^{\times \mathrm{i}}$, core, four primary system EM pumps and two IHXs are located in the reactor (containment) vessel. The primary coolant flows through the core, the hot pool, the shell side of the IHXs, the cold pool, the EM pumps, and the core inlet plenum. There is no piping inside the reactor vessel that connects core, pumps and IHXs. The sodium inventory inside the vessel is large which provides for heat storage in case of an undercooling accident.

(xi) The reference LMR module power is $471 \mathrm{MWt}$. This design was to be replaced by the socalled "Mod-B" design with a module power of $840 \mathrm{MWt}$. Mainly cost optimization led to the increased module size. 


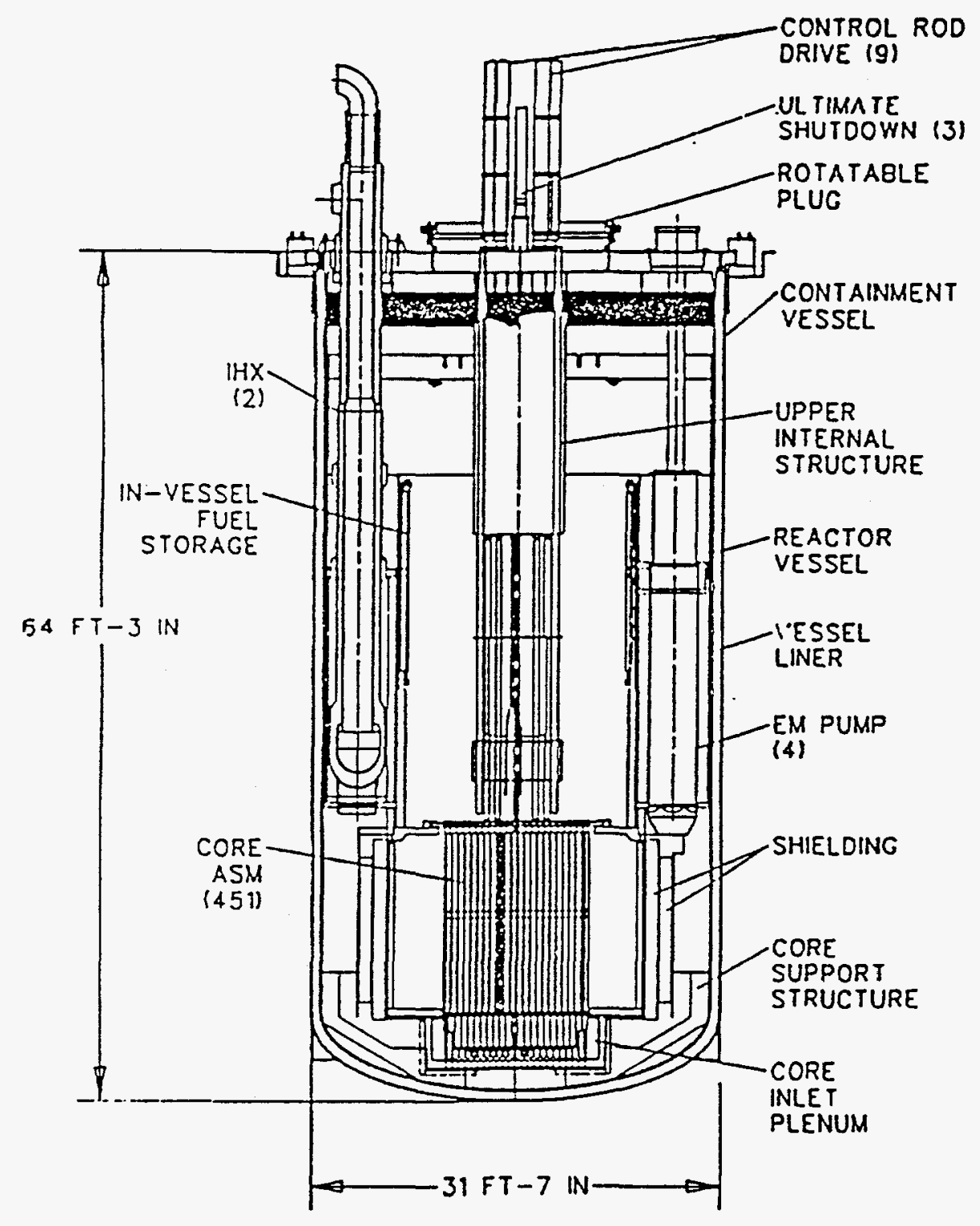

FIG. 2.1: ALMR Mod. B Primary Vessel Layout 
The reactor vessel sits inside a concrete vault. Through a system of ducts, outside air enters this vault and passively cools the reactor vessel (Reactor Vessel Auxiliary Cooling System RVACSI.

From the IHX, secondary sodium transports the heat to the steam generator. Between helical coil steam generator, on the inlet and outlet sides, are intermediate heat transport system (IHTS) isolation valves. The secondary sodium pump is in the cold leg.

The steam generator vessel is passively cooled by air that flows between a skirt surrounding the steam generator vessel and the steam generator vessel itself.

The reactor and the IHTS valves are located inside a safety-grade containment whereas the intermediate sodium EM pump and the steam generator and feedwater systems are located in a building that meets high quality industrial standards.

\subsection{Early ABC/ATW Design Features}

The early ATW/ABC design (Fig. 2.2) places the blanket region and six pumps and six IHXs in a vessel filled with graphite (reflector) blocks similar to the MHTGR fuel and reflector graphite blocks. In the blanket region, the graphite blocks contain $1 \mathrm{~cm}$ diameter holes drilled through the blocks to permit fuel flow passage. The flow channels from the blanket to the pumps and IHX and back to the inlet plenum are provided by open spaces in this graphite structure. This design approach aimed at a minimization of the fissile inventory by making extensive use of graphite to "fill" the space inside the vessel that otherwise would be occupied by fuel salt. An average blanket power density of only $6 \mathrm{MW} / \mathrm{m}^{3}$ was assumed which corresponds to a molten salt power density of $100 \mathrm{MW} / \mathrm{m}^{3}$.

This design (as described in Reference 13) had a very complex bottom plenum design similar to the MHTGR. However, the MHTGR has coolant downflow ${ }^{13}$ and the reason for combining first coolant flow channels from each graphite column and then, at a lower elevation, combining the flow channels from neighboring graphite columns, is to provide extensive coolant mixing to avoid hot streaks that can be damaging to the graphite core support posts and the IHX inlet plenum. The $A B C$ has upflow and, therefore, there is no need to mix the inlet flow because this is already at a constant temperature. There are benefits in having offset flow channels because this reduces neutron streaming through the lower axial reflector. 


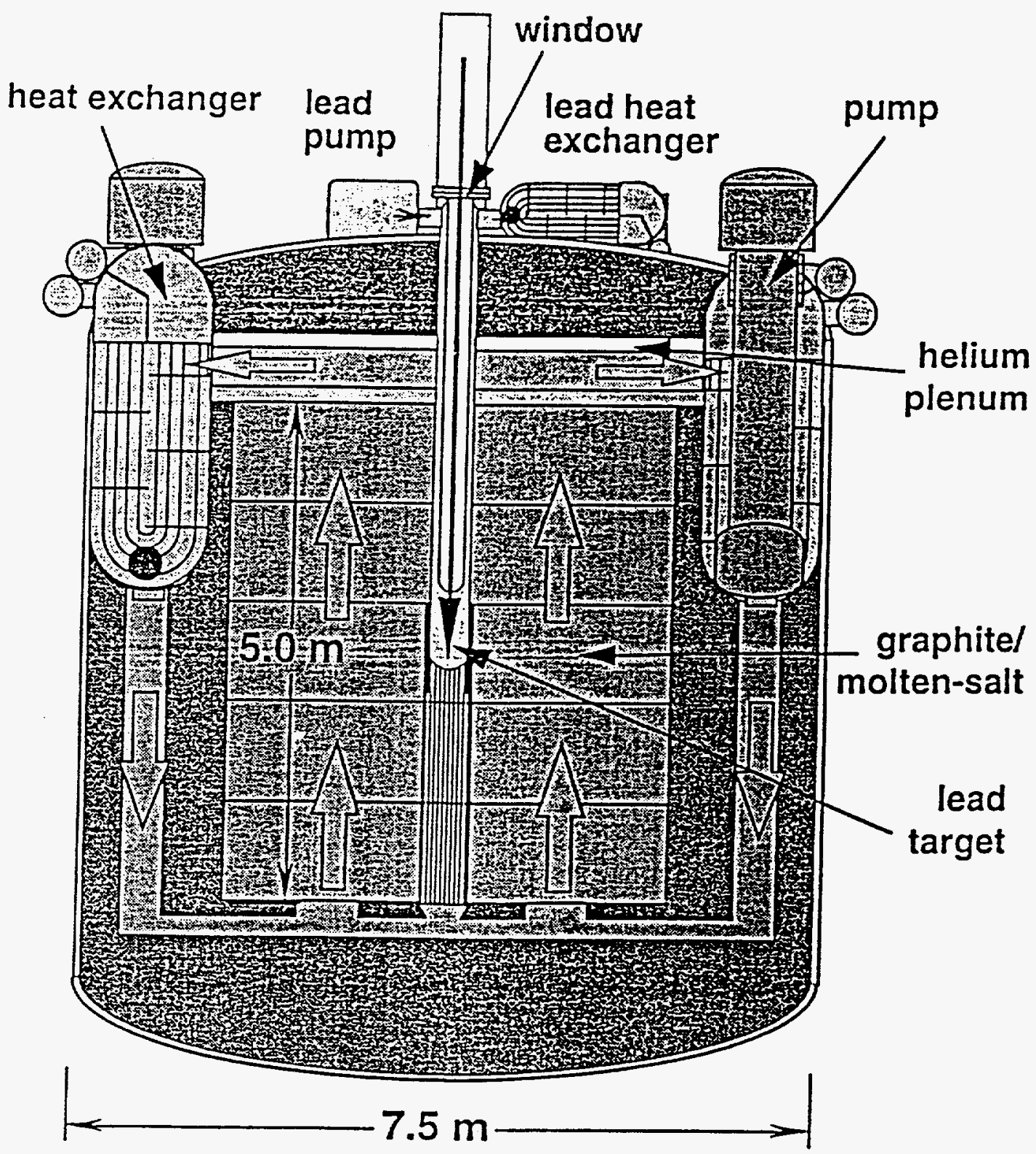

FIG. 2.2: Early Accelerator-Driven ABC System Primary System Layout 
The earlier ABC design has in common with the LMR design the placement of core, pumps and $\mathrm{IHXs}$ inside a vessel at different elevations to promote natural convection flow and the absence of metal piping to channel the (fuel) flow. It does not have the hot pool and cold pool regions of the LMR. Instead it simulates piping by providing openings in the graphite structures to channel the flow.

Because graphite undergoes dimensional changes due to thermal expansion and irradiation growth and shrinkage, the flow channel geometry can also undergo dimensional changes that could remain undetected. Furthermore, those dimensional changes could also be affected by the fact that graphite is expected to "float" in the fuel salt because of its lower density. This means the fuel flow path is not well defined under all conditions. An additional complication in this design was the proximity of pumps and IHXs to the blanket region that could lead to substantial fission rates in those components while at the same time exposing those components too high neutron fluxes.

\subsection{New ORNL ABC Design Features}

The ORNL ABC design was presented at the November 30-December 1, 1994 design review meeting ${ }^{\text {xii }}$. This design is in most areas a scale-down or scale-up of the MSBR design. Notable differences are:

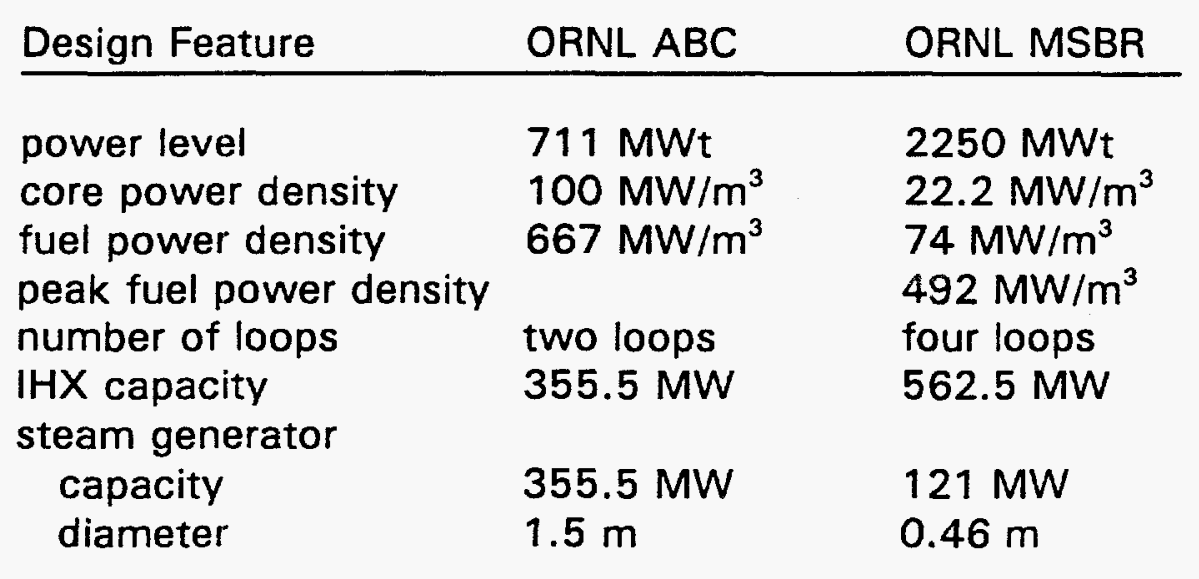

(xii) At the time of this writing the ORNL $A B C$ design has not been finalized. It is possible that changes in the design have been incorporated based on the discussions held at the review meeting on December 1, 1994. 
Due to the increase in power density and the absence of fertile materials in the fuel salt (that from a neutronics point of view represents parasitic absorptions) significantly higher neutron fluxes can be expected than in the MSBR that will affect both in-core graphite and vessel lifetimes.

It is also unknown how the fuel power density that on average is a factor 9 higher than in the MSBR will affect decay heat removal by passive means.

The new ORNL design employs the same steam conditions as the MSBR. As discussed earlier, the MSBR designers realized that these steam conditions might have to be changed due to the expected severity of steam generator tube failures which would result in a decrease in thermal efficiency but lead to design simplifications in other areas. Furthermore, the MSBR designers were concerned about the high stresses on the head and tube sheets and this led to the selection of the smalldiameter shell $(46 \mathrm{~cm})$ for the steam generator. The ORNL ABC design uses a shell diameter of $150 \mathrm{~cm}$ with an inlet and outlet plenum diameter of $200 \mathrm{~cm}$. A wall thickness of $24 \mathrm{~cm}$ is calculated for each plenum. The plena structures resembly very closely pressure vessels.

Before such a design can be adopted a thorough evaluation has to be conducted of the performance of such a pressure vessel under both normal and off-normal conditions.

The choice of these operating conditions for a much large steam generator represents a significant departure from MSBR design experience.

A steam generator for the MSBR has never been built and was always considered one of the question marks. To alleviate potential problems a relatively small steam generator was used (121 MW capability). The ORNL ABC steam generator is designed for $355.5 \mathrm{MW}$ and represents a significant increase above that for the MSBR. While the size itself is not a major concern, the combination of size, the extremely high pressures and severe operating conditions might introduce problems.

At the ORNL ABC design review meeting at LANL, November 30-December 1, 1994, a gas turbine cycle was accepted as a backup design to the steam cycle design. While a gas turbine cycle has certain advantages in regard to tritium trapping, it has significant disadvantages such as:

- in case no intermediate loop is used (as proposed by ORNL), the highpressure gas turbine circuit would interface directly with the very lowpressure fuel circuit; this would lead to the potential for large radionucli- 
de releases and a high likelihood for investment loss in case of a tube rupture in the fuel salt - gas heat exchanger. The probability for a tube rupture in the heat exchanger is typically $>10^{-2}$. Such a failure would lead to a sudden overpressurization of the (low-pressure) primary circuit with the potential for a catastrophic primary system failure. Furthermore, it would open a direct communication of the equivalent of a molten core with the gas turbine system.

- a gas turbine configuration with an intermediate loop would have to use a molten salt-He or $\mathrm{N}$ gas heat exchanger that can be expected to be of significant size and requires substantial development work.

- in case an intermediate loop is used, a significant reduction in overall energy conversion efficiency should be expected.

- a gas turbine cycle has not been used for a nuclear power reactor; currently in use by utilities are open-cycle gas turbine topping units using air as the heat transfer medium.

- while closed-cycle gas turbine technology would have been significantly advanced under the MHTGR program, this program is expected to be canceled by FY96. 


\subsection{REFERENCES:}

1. "The Status and Technology of Molten Salt Reactors: A Review of Molten Salt Reactor Work at the Oak Ridge National Laboratory", Molten Salt Reactor Information Meeting May 27-28, 1969, draft

2. R. C. Robertson (Editor), "Conceptual Design Study of a Single-Fluid MoltenSalt Breeder Reactor", ORNL-4541 (June 1971)

3. J. R. Engel, W. R. Grimes, et al., "Conceptual Design Characteristics of a Denatured Molten-Salt Reactor with Once-through Fueling", ORNL-TM-7207

4. C. D. Bowman, "Overview of the Los Alamos Accelerator-driven Transmutation Technology Program", International Conference on Accelerator-Driven Transmutation Technologies and Applications, Las Vegas, July 25-29, 1994

5. P. R. Kasten, U. Gat, S. Schultze Horn, H. Vornhusen, "Design Concepts for the Core Structure of a MOSEL (Molten Salt Experimental) Reactor", Nuclear Structural Engineering 2 (1965),p. 224-232

6. "Untersuchungen ueber die Verwendbarkeit von Fluoridsalzschmelzen als Kernbrennstofftraeger in epithermischen Thoriumreactores", internal INTERATOM report, INTAT-44 (June 1966)

7. NUREG-0968, "Safety Evaluation Report related to the construction of the Clinch River Breeder Reactor Plant", March 1983

8. SECY-89-197, "Issuance of Draft Safety Evaluation Report (SER) for the Power Reactor Inherently Safe Module (PRISM)", September 12, 1989

9. NUREG/CR-6065, "System Analysis of the CANDU 3 Reactor", July 1993

10. "Program Plan for Development of Molten-Salt Breeder Reactors", ORNL5018, (December 1974)

11. H. G. McPherson, "The Molten Salt Reactor Adventure", Nuclear Science and Engineering 90, 374-380 (1985)

12. see "ABC Technology Development Program", Barthold \& Associates, Inc., October 14,1994

13. A summary of the MHTGR is provided in NUREG-1338, "Draft Preapplication Safety Evaluation Report for Modular High-Temperature Gas-Cooled Reac- 
PRECONCEPTUAL ABC DESIGN DEFINITION AND SYSTEM CONFIGURATION LAYOUT

tor", March 1989 


\subsection{PRECONCEPTUAL ABC DESIGN DEFINITION}

To define the $A B C$ reference system design and layout, alternate paths were identified that identify alternate feasible $A B C$ configurations. To arrive at the reference configuration that is described in Chapter 4 the following approach was used:

- define a set of systems requirements

- identify design options

- $\quad$ perform qualitative tradeoff studies.

The various options differ in regard to reliability, maintainability, inspectability, performance, development status of materials, design approach, past experience with the systems, component, or structure under consideration, cost, and development needs.

The selection of alternate paths was guided by top level considerations such as:

- $\quad$ safety-first design rather than design first and confirm safety later

- ensure that all design options can meet the requirements

- use the design experience gained from the MSRE, MSBR, LMR, LWR, CANDU, and MHTGR in accepting and rejecting design options/features

- because of the significance of the MSBR design that is based on the most extensive experience with molten salt systems, use the MSBR as point of reference and departure instead of scaling up or down the MSBR design

- design for repair, maintenance and replacebability of major components

- use multiple modules instead of single large blanket

- $\quad k e e p$ in mind that a prototypical ABC module would have to be preceded by a molten salt reactor demonstration plant with a power output not more than a factor 10 above the MSRE and not less than $10 \%$ of the prototype module; this would place a demonstration plant power level at $<80 \mathrm{MWt}$ and that for a prototypical module at $<800 \mathrm{MWt}$.

- $\quad$ achieve at least 30-year major component lifetimes

- minimize size of the containment system

- keep cost in mind but do not constrain the design by cost considerations at this time

These evaluations lead ultimately to design recommendations that will be discussed in the next chapter.

For the development of the $A B C$ layout is assumed that the proton beam enters the blanket region from the top, after a horizontal beam is bent with a bending radius of 
$3 \mathrm{~m}$ and expanded over a distance $10 \mathrm{~m}$. No attempt was made here to design the beam expander or the target assembly.

Because of the safety advantages offered by a pool design as discussed earlier, a pool design was adopted here. This pool layout is somewhat different from the liquid metal reactor (LMR) layout' ${ }^{\prime}$ and the original ABC/ATW layout ${ }^{2,3}$.

No attempt was made to calculate the cost for this design because the emphasis here is on a preconceptual design definition and system layout. It is recommended not to unduly restrict the conceptual design efforts by preliminary cost estimates that could potentially lead to the exclusion of promising design features.

At this time, it is unknown how the goal availability of $75 \%$ can be achieved and which requirements in terms of system independence, redundancy and diversity have to be met to achieve this goal. It is not exactly known which systems and subsystems are needed, not only in the NSSS-equivalent but also in the BOP portion of the facility. Furthermore, it is conceivable that the ABC unavailability is driven more by the accelerator and target systems than the blanket systems ${ }^{4}$.

Only a cursory assignment can be made in terms of safety-related and non-safetyrelated structures, systems and components (SSC) for this facility at this time (and it is known that requirements for safety-related SSCs can dramatically increase cost). The focus in this effort was on providing a layout that is reasonable and has a good chance that it can work and meet the requirements.

Not addressed in this effort are all issues related to instrumentation, control and protection systems. This topic is very important and very complex because it deals with three major systems and their subsystems, namely the accelerator, the target system and the blanket system. It will require considerable efforts to even sketch out, for example, the trip logic for such a complex system under the constraint of a $75 \%$ capacity factor.

\subsection{Blanket Design Options}

\subsection{1 requirements}

Based on the proposed $A B C$ Requirements Document ${ }^{5}$ the $A B C$ blanket has to accomplish the following mission: 
Provide a weapon's grade plutonium disposition capability in a safe, economical, and environmentally sound manner on a prudent schedule for 50 tons of weapon's grade plutonium to be disposed of in 25 years.

It was determined earlier that such an $A B C$ design has to produce about $3000 \mathrm{MWt}^{\prime}$. To arrive at such a plant design, four modules of about $750 \mathrm{MWt}$ were selected.

\subsection{2 core design options}

\subsubsection{1 fuel salt composition options}

Currently favored is the following fuel salt composition:

$$
\mathrm{LiF}-\mathrm{BeF}_{2}-\mathrm{PuF}_{3}-\mathrm{ZrF}_{4}
$$

However, there are several other fuel salt compositions that should be evaluated:

$$
\begin{array}{ll}
\mathrm{LiF}-\mathrm{BeF}_{2}-\mathrm{PuF}_{3} & \text { (Option 1) } \\
\mathrm{NaF}-\mathrm{BeF}_{2}-\mathrm{PuF}_{3}-\mathrm{ZrF}_{4} & \text { (Option 2) } \\
\mathrm{NaF}-\mathrm{BeF}_{2}-\mathrm{PuF}_{3} & \text { (Option 3) }
\end{array}
$$

The reference fuel composition contains $\mathrm{ZrF}_{4}$ as an oxygen getter. However, it is not clear that this is required for a plutonium-bearing salt and, therefore, Option 1 is worth considering. Option 2 has a significant advantage over the reference fuel and Option 1 fuel in that it contains no lithium and, therefore, eliminates for all practical purposes the tritium problem. This would permit to use as a coolant NaF-BeF ${ }_{2}-\mathrm{LiF}$ which is fully compatible with the fuel salt, has a lower melting point than fluoroborate, and is thermally stable.

In Option 3, does not contain $\mathrm{ZrF}_{4}$, which might be acceptable.

\subsubsection{2 power density}

During the design of the $\mathrm{MSBR}^{6}$, a fuel power density of $72 \mathrm{~kW} / \mathrm{l}$ was considered acceptable. As mentioned earlier the choice of power density was based on considerations of system hydraulics, graphite lifetime and protactinium decay. However, ultimately, the power density for the fuel has to be compatible with the

(i) Such a configuration at $3000 \mathrm{MWt}$ will dispose of approximately half the goal amount of $50 \mathrm{MT}$; the disposal of the full goal amount requires two such systems.

REVISION 0 
following capabilities:

- heat removal (temperature rise, maximum fuel salt velocity, maximum pressure drop)

- $\quad$ achievement of the desired component lifetimes by limiting the damage neutron flux for graphite and vessel

- $\quad$ passive decay heat removal

\subsubsection{3 moderator options}

\section{moderator materials}

The Aircraft Reactor Experiment (ARE) used BeO as moderator and the MSRE used graphite. Both materials are compatible with molten salt fuel. As part of the HTGR program, graphite component technology has been greatly advanced so that the use of graphite as both moderator and reflector seems to be an acceptable choice. Chemistry considerations would also favor this choice.

It should also be noted that the fuel salt constituents fluorine, beryllium, and lithium also moderate neutrons, i.e., in a molten salt environment there is no real unmoderated system.

\section{configurations}

Fig. 3.1 shows schematically four different blanket configurations.

The first configuration uses graphite as moderator in the core. The moderated core region is surrounded by a reflector, and both regions are contained inside a vessel. This configuration has also been referred to as "internally moderated". It is well moderated.

The second configuration has been referred to as "externally moderated". The fuel salt is contained inside a metallic vessel which is surrounded by a graphite reflector. This configuration is not as well moderated as the first one.

A third configuration consists only of fuel salt contained inside a vessel without reflector. It also has been referred to as "unmoderated". The only moderation comes from the salt constituents $\mathrm{F}, \mathrm{Li}$, and Be. 


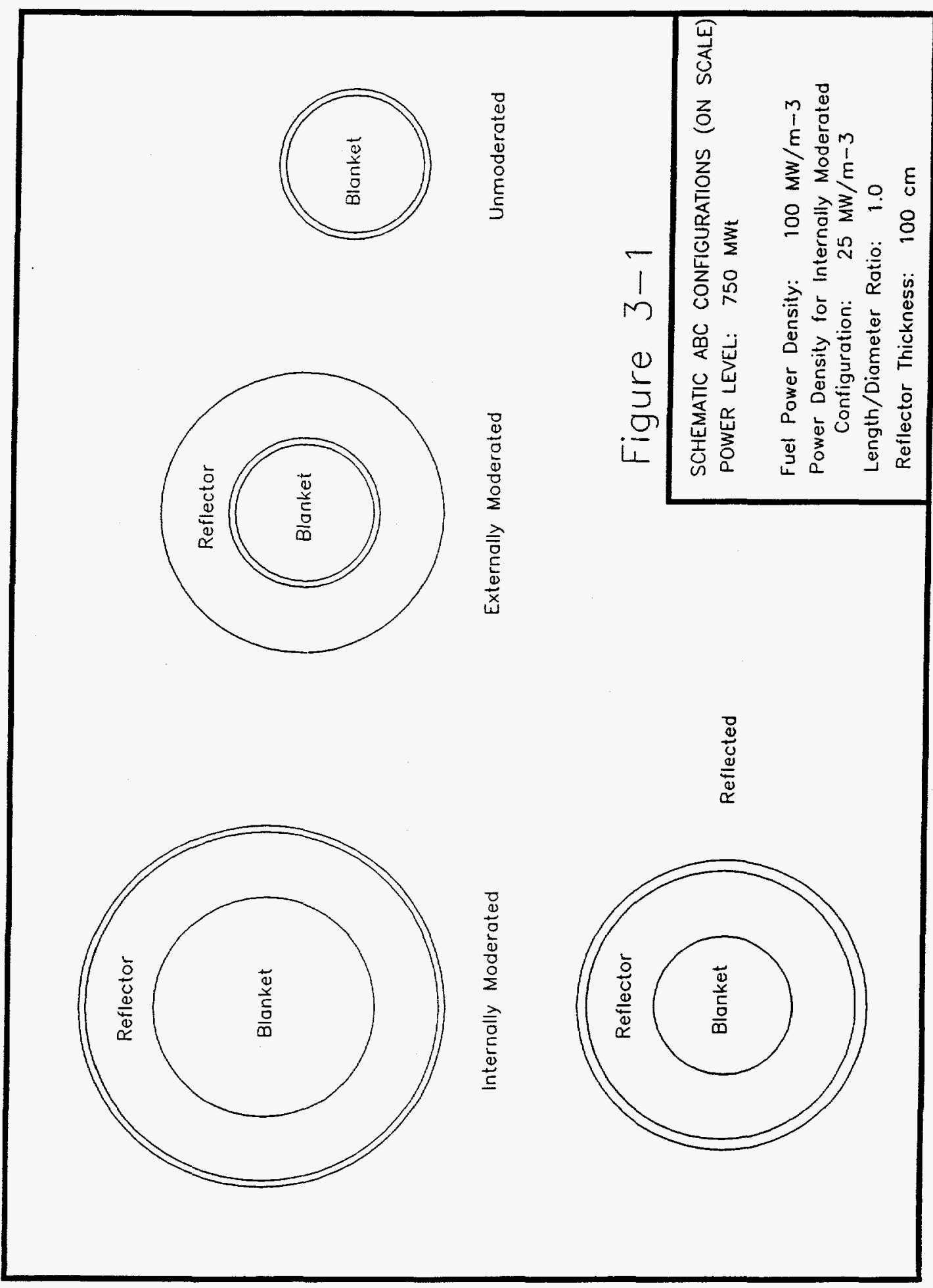

REVISION 0

$3-5$

MARCH 1995 
A fourth configuration has an unmoderated fuel region surrounded by a reflector/shield region, both of which are located inside a vessel. It is referred to as a "reflected" configuration. The advantages and disadvantages of these configurations can be summarized as follows:

\begin{tabular}{|c|c|c|}
\hline $\begin{array}{l}\text { CONFIGU- } \\
\text { RATION }\end{array}$ & ADVANTAGES & DISADVANTAGES \\
\hline $\begin{array}{l}\text { internally } \\
\text { moderated }\end{array}$ & $\begin{array}{l}\text { best moderation } \\
\text { flow orificing possible } \\
\text { MSRE experience }\end{array}$ & $\begin{array}{l}\text { large vessel size } \\
\text { fabrication of graphite elements } \\
\text { graphite lifetime limits } \\
\text { graphite waste } \\
\text { to shield the vessel will increase vessel } \\
\text { dimensions that are already the highest } \\
\text { of all options } \\
\text { gaseous fission product deposition in } \\
\text { moderator }\end{array}$ \\
\hline $\begin{array}{l}\text { externally } \\
\text { moderated }\end{array}$ & $\begin{array}{l}\text { small vessel } \\
\text { lower graphite damage fluence } \\
\text { no f.p. deposition in graphite } \\
\text { simple flow path in core } \\
\text { favorable BOL temperature coef- } \\
\text { ficient without burnable poison } \\
\text { (claimed) }\end{array}$ & $\begin{array}{l}\text { high vessel fluence resulting in short } \\
\text { vessel lifetime } \\
\text { spent vessel storage and disposal } \\
\text { graphite waste } \\
\text { fabrication of reflector elements }\end{array}$ \\
\hline $\begin{array}{l}\text { unmoderat- } \\
\text { ed }\end{array}$ & $\begin{array}{l}\text { small vessel/containment } \\
\text { reduces waste } \\
\text { no graphite fabrication cost } \\
\text { no f.p. deposition in graphite } \\
\text { simple flow path in core }\end{array}$ & $\begin{array}{l}\text { high vessel fluence resulting in short } \\
\text { vessel lifetime } \\
\text { spent vessel storage and disposal } \\
\text { regions outside the vessel are exposed } \\
\text { to very high fluences leading to signifi- } \\
\text { cant activations of other systems, } \\
\text { structures and components }\end{array}$ \\
\hline reflected & $\begin{array}{l}\text { small vessel } \\
\text { low vessel fluence } \\
\text { good moderation } \\
\text { less constrained by graphite life- } \\
\text { time limits } \\
\text { reduces waste } \\
\text { lower fabrication cost } \\
\text { simple flow path in core }\end{array}$ & $\begin{array}{l}\text { medium size vessel } \\
\text { fabrication cost for reflector elements } \\
\text { part of the reflector must be replaced } \\
\text { gaseous fission product deposition in } \\
\text { reflector }\end{array}$ \\
\hline
\end{tabular}


Not listed as a separate configuration is one where the target is surrounded by a graphite sleeve to enhance neutron moderation.

Weighing both advantages and disadvantages, the reflected configuration looks very attractive. For a power density in the fuel of $100 \mathrm{MW} / \mathrm{m}^{3}$, this results in a $7.5 \mathrm{~m}^{3}$ fuel salt blanket for a $750 \mathrm{MWt}$ module". Assuming a square cylindrical core, the core diameter is in the range of $2.2 \mathrm{~m}$ after the volume for the target assembly with a diameter of $0.6 \mathrm{~m}$ and extending to below the core midplane is accounted for.

For this configuration, the blanket region is surrounded by a sufficiently thick graphite reflector/shield to protect the vessel from neutron damage and to thermalize the fission and spallation neutrons. In the outer regions of the reflector, it is assumed that boronated iron pins are used to slow down fast neutrons via inelastic scattering in iron, and absorb the thermalized neutrons in the boron. Because the neutron flux in the fuel region can be expected to be very high, it is conceivable that the reflector/shield thickness is well in excess of $1 \mathrm{~m}$, to provide a more effective shielding of the vessel by being able to add more rows of boronated iron pins in the reflector/shield region.

\subsection{3 flow direction, inlet and outlet plena}

Fuel salt upflow in the core region is selected because it promotes natural convection flow. There is no compelling reason for downflow through the core region.

With this choice, the inlet plenum location is fixed at the bottom of the core, and the outlet plenum at the top. There are two options for bringing the fuel flow to the inlet plenum and from the outlet plenum to the IHX. One option brings the fuel flow to the inlet plenum from the IHX outlet via piping to the bottom of the vessel; the outlet plenum directs the fuel flow via a different piping to the IHX inlet (like the MSBR). This option requires two vessel penetrations for the inlet pipe and the outlet pipe. It is also possible to combine the inlet pipe with a fuel salt drain pipe by using doublewalled piping like in the MSBR design.

(ii) It should be noted that in the ORNL ABC design of December 1994, the average core power density was assumed to be $100 \mathrm{MW} / \mathrm{m} 3$; the core fuel salt fraction was assumed to be 0.15 which results in a fuel salt power density of $667 \mathrm{MW} / \mathrm{m}^{3}$. It is my understanding that the power density has been lowered since and brought in line with the MSBR. The average core power density for the MSBR was $22.2 \mathrm{MW} / \mathrm{m}^{3}$. 
For this option the vessel temperature distribution is very similar to the fuel temperature distribution with the maximum vessel temperature being close to the fuel outlet temperature.

In another option, two concentric pipes (vessels) are used to bring "cold" fuel salt to the core in the space between an inner and outer pipe from the IHX, and direct hot fuel to the $\mathrm{IHX}$ through the inner pipe. Such a configuration can be coupled with a core barrel that contains the blanket and reflector regions and creates a gap between barrel and vessel wall through which cold fuel salt entering the reactor vessel at the elevation of the upper plenum, is directed downward to the inlet plenum. The fuel salt leaves the reactor vessel from the outlet plenum through the inner pipe of the concentric pipes. In such a configuration, the vessel temperature is kept at the fuel inlet temperature. Furthermore, the use of concentric pipes requires only one penetration in the vessel and reduces the piping lengths which has the effect of reducing the external fuel inventory and the heating requirements when the primary system is filled with salt. A separate but much smaller vessel penetration is required at the bottom of the vessel for fuel drainage.

The use of a core barrel adds somewhat to the complexity of the vessel internals but brings additional advantages:

- the core barrel creates a space for the fuel salt to flow downward along the vessel wall to the inlet plenum

- it allows for the attachment of the metallic structures that keep the reflector blocks in their position (graphite that is placed in molten salt has to be held down because its density is lower than the fuel density)

- this structure is kept essentially at fuel inlet temperature and is subjected only to a very small pressure drop across the barrel wall thickness, i.e., this structure is not a pressure boundary and experiences only very small stresses

- it slightly reduces the vessel fluence

The lower axial reflector/shield has penetrations to allow the fuel salt to pass through on its way to the core region. If large holes are used the fuel salt will experience only a small pressure drop. However, neutron streaming in the direction of the lower vessel portion is significant and would render ineffective the other measures introduced to protect the vessel from high fluences. Therefore, neutron streaming has to be significantly reduced. This can be achieved by avoiding straight penetrations through this region but instead using a staggered pattern of penetrations, possibly with different hole diameters. 
A lower core support plate can be used to provide support for radial and axial reflector/shield regions and the moderator (if used).

The inlet plenum has to be large enough to reduce the pressure drop across the plenum to ensure that there is a flat inlet flow distribution, i.e., no channels receive more flow than others (this applies only to the internally moderated systems). The outlet plenum has to be large enough to ensure sufficient mixing to avoid hot streaking.

For the reflected blanket option, the upper dome of the vessel should be insulated to fully benefit from the low vessel temperatures that are kept at fuel inlet temperature.

\subsection{Primary, Secondary, Tertiary Systems, Components and System Layouts}

The fuel salt in the primary system transports the heat to the IHX where it is transferred to the coolant salt in the secondary system. The coolant salt transports the heat to the steam generator where it is transported to the feedwater and steam. The steam drives turbines and generators to produce electricity. For this study is assumed that the fuel salt is composed of $\mathrm{LiF}, \mathrm{BeF}_{2}, \mathrm{ZrF}_{4}$, and $\mathrm{PuF}_{3}$. However, a substitution of LiF by NaF should also be considered. The coolant choices are sodium fluoroborate, NaF-LiF-BeF ${ }_{2}$ and Hitec. Should a fuel salt composition of NaF-BeF $-\mathrm{PuF}_{3}$ be selected, a coolant salt composition of $\mathrm{NaF}_{-} \mathrm{BeF}_{2}$-(LiF) seems appropriate because tritium trapping is not an issue for such a fuel salt.

In an $A B C$ layout with a tertiary system, the secondary system is followed by an additional heat transfer loop before the heat is transferred to a steam generator. In this case, the secondary salt can be NaF-LiF-BeF ${ }_{2}$, and the tertiary salt can be Hitec.

\subsection{1 requirements}

The different heat transport systems are designed for enhanced natural convention in compliance with regulatory requirements. This requires to stagger the thermal centers from the blanket region outward (Fig. 3.2).

Spatial separation of the blanket from the pump and $\mathrm{IHX}$ is required, together with proper shielding inside and possibly also outside the blanket vessel, to significantly reduce fissions caused by neutrons leaking from the blanket vessel to these pumps and $\mathrm{IHX}$. 


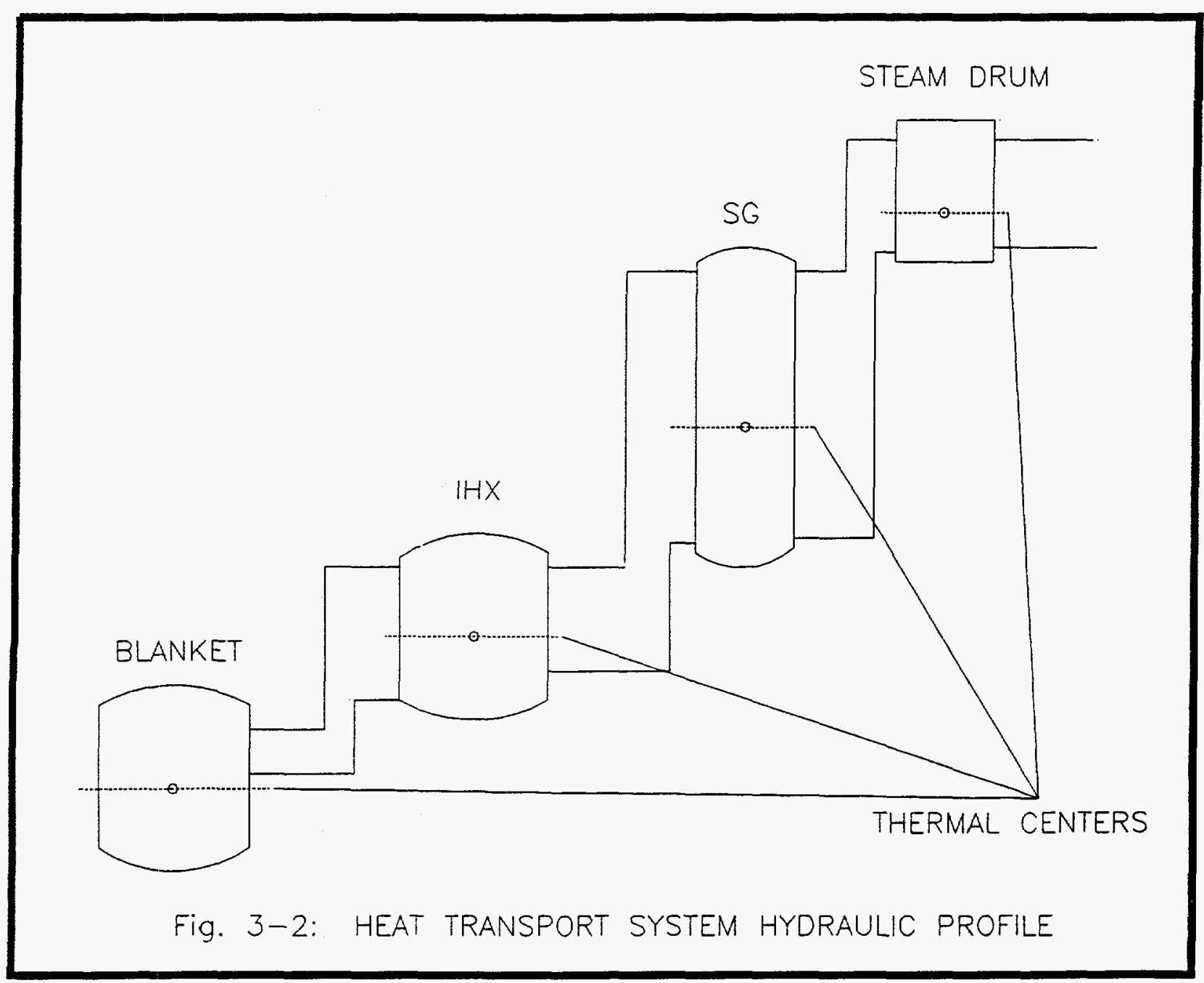


It must be possible to reliably isolate the different loops.

One of the advantages of molten salt systems is the fact that they can operate at low pressures. This advantage should be maintained.

In case of a IHX tube failure it is desirable to ensure that coolant will leak into the fuel salt rather than fuel salt leaking into the coolant. This is achieved by operating the secondary loop at a higher pressure than the primary system.

To avoid the complications coming from a superheated steam cycle (like that used for the MSBR which is based on the Bull Run Steam Plant with 3800 psi steam), the steam conditions should be similar to those used today in nuclear reactors, especially the advanced reactors. While lower pressure steam will reduce the energy conversion efficiency it is conceivable, and needs to be confirmed by analysis, that the advantages coming from lower-pressure designs that simplify the designs of the IHX, piping, coolant and fuel pumps, and increased reliability and reduced development cost, could easily offset thermal efficiency penalties.

Unless a different scheme can be devised for gaseous fission product removal from the salt, the fuel pump bowl has to provide for the removal of gaseous fission products.

\subsection{2 design options}

For the following discussions it is useful to remember the liquidus temperatures for various coolants:

LiF-BeF $F_{2}(66-34)$

$\mathrm{NaF}-\mathrm{NaBF}_{3}(8-92)$

$\mathrm{NaF}-\mathrm{BeF}_{2}$-LiF (45-33-22)

$\mathrm{KNO}_{3}-\mathrm{NaNO}_{2}-\mathrm{NaNO}_{3}(53-40-7)[\mathrm{Hitec}]$ $459^{\circ} \mathrm{C}\left(858^{\circ} \mathrm{F}\right)$

$384^{\circ} \mathrm{C}\left(723^{\circ} \mathrm{F}\right)$

$290-340^{\circ} \mathrm{C}\left(554-644^{\circ} \mathrm{F}\right)$

$109^{\circ} \mathrm{C}\left(228^{\circ} \mathrm{F}\right)$

coolant circuit configuration Option 1:

It is assumed that only one intermediate loop is used that contains sodium fluoroborate salt as coolant and is heated by the fuel salt. This coolant salt then transfers its heat to water/steam in a steam generator. The main reasons for using fluoroborate as an intermediate coolant are: 


\section{PRECONCEPTUAL ABC DESIGN DEFINITION AND SYSTEM CONFIGURATION LAYOUT}

- ability to trap tritium that is produced in the fuel salt;

- lower melting point than ${ }^{7} \mathrm{LiF}-\mathrm{BeF}_{2}$ and

- lower cost than that of enriched ${ }^{7} \mathrm{LiF}_{-} \mathrm{BeF}_{2}$

\section{coolant circuit configuration Option 2:}

In another configuration, NaF-LiF-BeF ${ }_{2}$ could be used as secondary coolant and Hitec as tertiary coolant. The advantages of $\mathrm{NaF}_{-} \mathrm{BeF}_{2}-\mathrm{LiF}$ are:

- compatibility with fuel salt,

- low cost and

- low melting point.

Hitec has an even lower melting point and can also trap tritium ${ }^{\mathrm{iii}}$. Such a design would also significantly lower the feedwater heating requirements that could at least partially offset the otherwise significant cost penalty of using an additional heat transfer loop.

\section{coolant circuit configuration Option 3:}

Still another choice is the use of NaF-BeF - LiF as secondary coolant and trying to find another means to trap the tritium. This would be an excellent choice if it were not for the trapping of tritium that is produced in large amounts in the $A B C$ system. The use of a NaF-BeF ${ }_{2}-\mathrm{PuF}_{3}$ fuel salt would permit the use of this coolant because tritium is produced only in very small quantities because of the absence of $\mathrm{Li}^{\mathrm{iv}}$.

\section{pump placement:}

The pumps can be placed either in the hot leg or the cold leg. Placing the pump in the cold leg has the advantage of the pump being in a low-temperature environment. However, in such a configuration (i.e., installing the pump in the piping coming from the IHX outlet) the core would be exposed to the highest pressure in the primary system.

Placing the pump in the section between core outlet and IHX inlet, would place the pump in a high-temperature environment but it is the $\mathrm{IHX}$ that would be exposed to

(iii) Using Hitec as secondary coolant is not recommended because in case of a tube leak Hitec could enter the blanket region where it reacts violently with graphite.

(iv) The use of NaF-BeF2-UF4 was not considered for the MSBR because it was a marginal thermal breeder that could not use sodium because of its neutron absorptions. 
the highest pressure in the primary system and not the core. Furthermore, fission gases that would have left the fuel salt could easily be removed without being reentrained in the IHX section.

Placing the pump in the hot leg at the highest elevation in the primary system (or the secondary system) would avoid a loss of coolant in case of a loss of suction due to a leak at the pump. If the pump were to be placed at a lower elevation, both the fuel inventories in the core and IHX could be drained in case of a pipe break near or at the pump.

\section{IHX options:}

A counterflow vertical shell-and-tube-type heat exchanger had been used for the MSBR, rated at $556.5 \mathrm{MW}$. Similar designs have been used in liquid metal reactors. Table 3.1 compares the IHX design data for the MSBR and the CRBRP.

The difference in lengths for the two designs is attributable to much larger outlet and inlet plena for the CRBRP and a cylindrical hanging support structure whose length is over $15 \mathrm{ft}$. Because primary inlet and intermediate outlet in the CRBRP IHX are on the side of the shell whereas the secondary salt enters and leaves the IHX through $U$ shaped double-walled tubing, the space required for the accommodation of the IHX in the MSBR is larger than the $24 \mathrm{ft}$ cited in the MSBR preconceptual design report.

There are no obvious advantages for developing an $\mathrm{IHX}$ different from the counterflow tube-and-shell heat exchanger. The use of special tubing in the IHX to improve the heat transfer, as explained in Section 2.1.2, does not have the significance as in case of the MSBR where a reduction of the external fuel inventory by $5 \%$ was significant the reduction in doubling time, despite of the cost increase for the special tubing. Such a strong incentive does not exists for the ABC system.

\section{steam generator options:}

The MSBR uses a horizontal U-tube, U-shell exchanger with cross-flow baffles. The CRBRP and ALMR use helical-coil steam generators with external steam drum. The CANDU-3 uses a vertical U-tube with integral steam drums (see Table 3.2).

The steam generator design and performance data have not been evaluated in sufficient detail due the scope for this work and due to lack of information. It is noteworthy that the MSBR uses a U-tube horizontal steam generator, and CANDU 3 uses a vertical steam generator with integrated steam drums. 
TABLE 3.1: IHX FEATURES FOR THE MSBR AND CRBRP

\begin{tabular}{||l|l|l||}
\hline IHX FEATURES & MSBR & CRBRP \\
\hline \hline thermal duty, MW & 556.5 & 325 \\
overall length, $\mathrm{ft}$ & 24 & 52.1 \\
shell diameter, ft & 5.7 & 8.8 \\
tube length, ft & 24.4 & 25.8 \\
\# of tubes & 5803 & 2850 \\
overall heat transfer area, ft-2 & 13.916 & 11.810 \\
overall heat transfer coefficient, Btu/hr-F-ft-2 & 784.8 & 1,374 \\
primary flow, 1OE +6 lb/hr & 23.4 & 13.82 \\
intermediate flow, 10E +6 lb/hr & 17.8 & 12.78 \\
primary system & & \\
hot leg temperature, F & 1300 & 995 \\
cold leg temperature, F & 1050 & 730 \\
intermediate system & 1150 & 936 \\
hot leg temperature, F & 850 & 651 \\
\hline cold leg temperature, F & \multicolumn{2}{|l}{} \\
\hline
\end{tabular}

TABLE 3.2: CHARACTERISTICS OF SOME STEAM GENERATOR DESIGNS

\begin{tabular}{|c|c|c|c|c|}
\hline FEATURE & MSBR & ALMR-REF & ALMR-MODB & CANDU 3 \\
\hline type & $\begin{array}{c}\text { horizontal U- } \\
\text { tube }\end{array}$ & helical coil & helical coil & $\begin{array}{l}\text { vertical U- } \\
\text { tube }\end{array}$ \\
\hline $\begin{array}{l}\text { capacity, MW } \\
\text { intermediate coolant } \\
\text { inlet temperature, } \mathrm{F} \\
\text { outlet temperature, F } \\
\text { feedwater/steam } \\
\text { inlet temperature, } F \\
\text { outlet temperature, } \mathrm{F} \\
\text { feedwater pressure, psia } \\
\text { SG outlet pressure, psia } \\
\text { tube bundle length, ft } \\
\text { \# tubes } \\
\text { overall HT surface, ft-2 } \\
\text { steam flow, } 10 \mathrm{O}+6 \mathrm{lb} / \mathrm{hr} \\
\text { efficiency, \% }\end{array}$ & $\begin{array}{r}121 \\
1150 \\
850 \\
700 \\
1000 \\
3752 \\
3600 \\
76.4 \\
393 \\
3929 \\
0.633 \\
44.4\end{array}$ & $\begin{array}{r}477 \\
\\
864 \\
573 \\
\\
380 \\
830 \\
2072 \\
1800 \\
27 \\
495 \\
31,102 \\
1.6 \\
35.1\end{array}$ & $\begin{array}{r}850 \\
890 \\
619 \\
420 \\
850 \\
2520 \\
2200 \\
40 \\
612 \\
64,089 \\
3.0 \\
36.1\end{array}$ & $\begin{array}{r}689.7 \\
587 \\
514 \\
369 \\
500 \\
667 \\
740\end{array}$ \\
\hline
\end{tabular}




\subsection{Containment Options}

\subsection{1 requirements}

The ABC containment system consists of a series of enclosures that are leak-tight and can withstand maximum pressures projected under design basis and beyond designbasis accidents. The ABC containment system must provide the same defense in depth as conventional reactors.

The containment building is expected to act as the final barrier to radionuclide releases. It has to be leak-tight and withstand the most severe pressures under design basis and beyond design basis accidents (usually a main steam-line break).

Because the fuel exists already in molten form it must be contained in a primary system containment and there also has to be a secondary system containment. The steam generators must also be in a safety-grade containment building.

Because there are unavoidable penetrations from one containment cell to another, those penetrations must be kept to a minimum, must be leak-tight and it must be possible to isolate the different loops.

\subsection{2 design options}

While a loop system can be built to high standards and afford a high degree of protection, a pool configuration where the core, primary pump and $\mathrm{IHX}$ are placed inside a reactor vessel that contains a coolant, and thus ensure containment of any primary system leaks, seems to be a configuration that is widely favored. For example, modern ALMRs are configured in a pool arrangement (see Fig. 2.1), and even the ABB-CE Safe Integral Reactor (SIR) design ${ }^{7}$, an evolutionary PWR, uses a pool configuration as shown in Fig. 3.3. The Westinghouse AP-600 design ${ }^{8}$ places the reactor and steam generator vessels inside a thick-walled steel containment vessel that is expected to safely isolate the reactor from the environment. This vessel sits inside a reactor shield building. Between the shield building and the steel containment is space for natural air circulation to cool the containment building (see Fig. 3.4).

In case of an IHX tube rupture, it is desirable to be able to isolate this loop. Because of the higher pressure on the secondary side, any tube rupture will result in an inleakage of coolant into the primary system until the pressures in the two systems are equalized. By this time but not later, the secondary side has to be isolated to avoid any transport of radionuclide into the steam generator. 

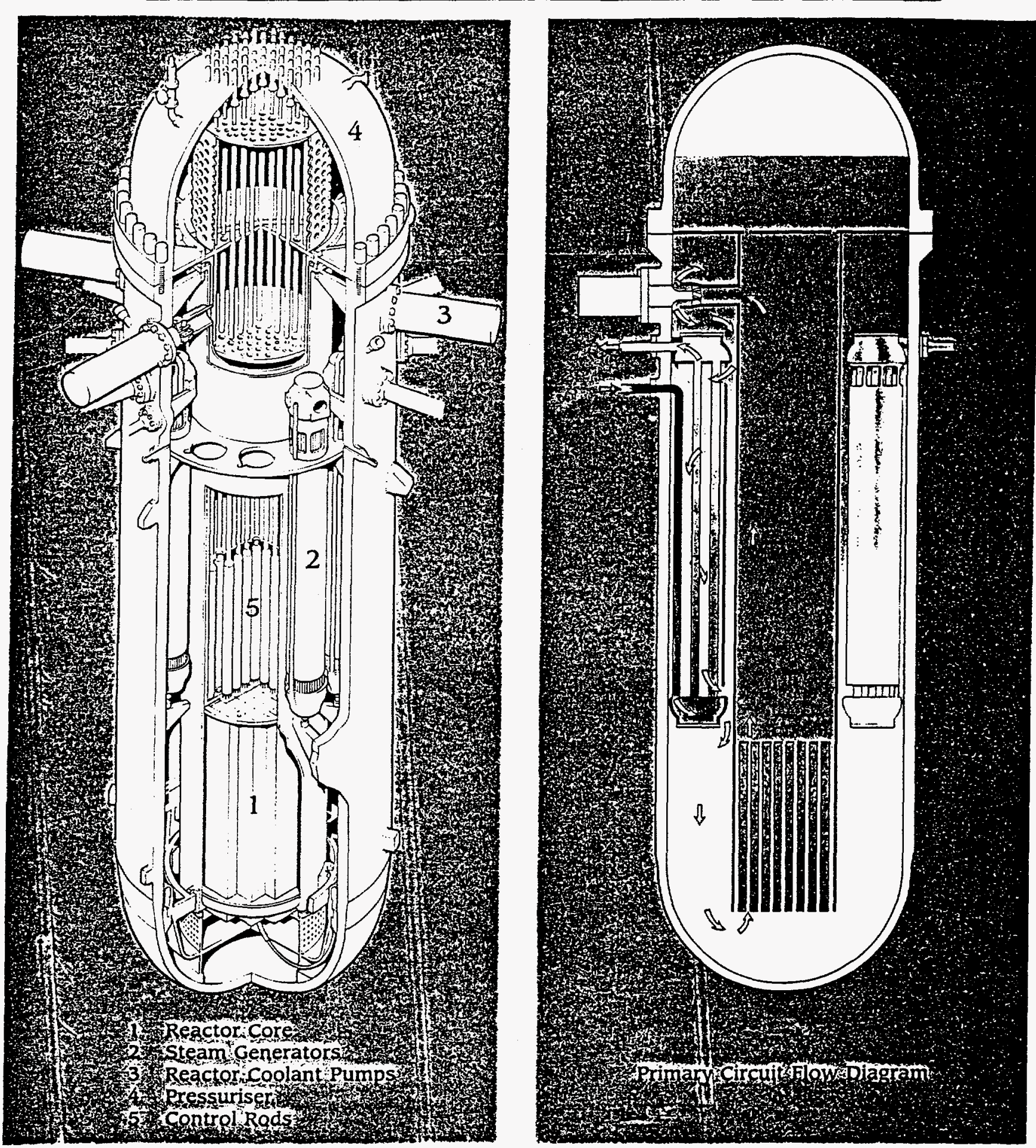

Fig. 3-3: ABB-CE Safe Integral Reactor (SIR) Design 


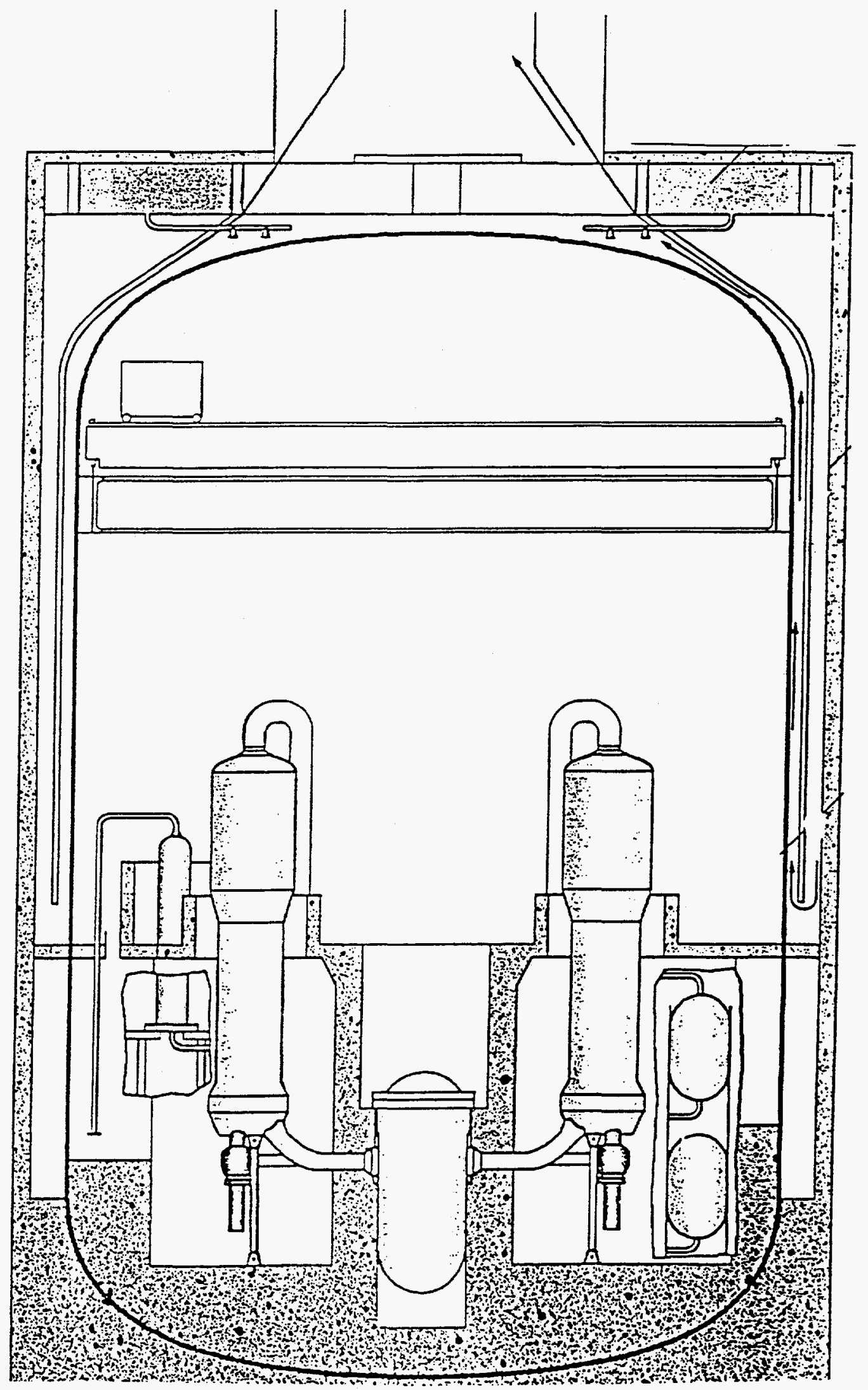

Fig. 3-4: Westinghouse AP-600 Design 
It is also necessary to be able to isolate the steam generator that is located in its own containment (cell, building)

\subsection{Off-gas Systems}

For the MSBR it was mandatory to remove gaseous fission products effectively and continuously to ensure effective breeding because the breeding gain for the MSBR is very small (a value of 0.06 was cited assuming continuous reprocessing, ${ }^{233} \mathrm{~Pa}$ isolation and effective removal of gaseous fission products). It had been estimated that the fission yields for krypton and xenon are such that nearly one atom of gas is produced for every atom of ${ }^{233} \mathrm{U}$ fissioned. This would yield nearly $1 \mathrm{~kg}$ of noble gas fission products per day for the 2250 MWt MSBR. About $15 \%$ of the gaseous fission products are short-lived and will decay in the fuel salt system. The remaining $85 \%$ are either stable or have half-lives long enough to allow their removal from the salt system.

To ensure an effective fission gas removal and avoid migration of fission product gases into the graphite pores, the MSBR was designed such that helium was continuously injected to gather fission gases. The helium and fission gases were extracted from the pump bowl and directed to a decay tank and subsequently to various charcoal beds and other separation steps to allow for fission product decay and recycle helium.

Such constraints do not exists for the $A B C$ system. The problem with gaseous fission product deposition in pores in the graphite where they represent significant neutron poisons is further mitigated when graphite is not used as a moderator but only as a reflector. For one, this would decrease the retention of fission gases in the core region, and secondly due to the harder neutron spectrum, fission products in general are decreased in absorber strength.

For the secondary system, in case sodium fluoroborate is used as a coolant, efforts have to be undertaken to maintain the composition of the coolant that thermally disintegrates continuously and releases gaseous $\mathrm{BF}_{3}$. This gas would migrate to the pump bowl and mix with the helium sweep gas. Because of its toxicity, it cannot be discharged from the plant continuously. 


\subsection{1 requirements}

Preliminary requirements will be cited for both a fuel and coolant loop off-gas system.

\subsubsection{1 fuel}

The main function of the off-gas system for the primary system is to reduce the concentrations of:

- $\quad$ gaseous and gas-borne fission products

- fission product daughters

- water, oxygen, hydrocarbons

Additional important functions for the off-gas system are:

- dissipation of decay heat

- collection and storage or disposal of stable and long-lived gases, liquids and solids, and

- recompression of the recycle gas

- collection and treatment of a salt mist

- adequate containment of the off-gas system, especially the banks of charcoal beds

The appropriate equipment has to be provided to handle all these functions.

In case of an internally moderated system, a gas sparging system might be used to increase the fission gas removal efficiency. For other systems lunmoderated, reflected, externally moderated) the need for a gas sparging system has to be evaluated.

\subsubsection{2 coolant}

The thermal decomposition of sodium fluoroborate into sodium fluoride and BF3 requires an off-gas system to perform the following functions:

- collect the $\mathrm{BF}_{3}$ together with the helium sweep gas from the pump bowl

- collect undesirable contaminants from the coolant salt that can include 


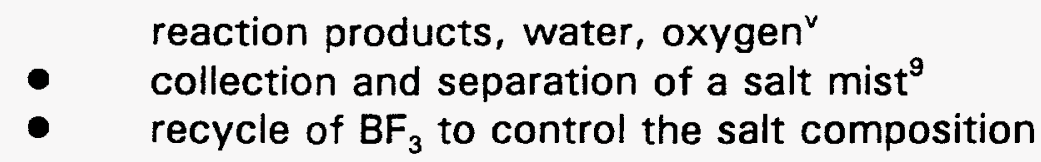

It should be noted that the use of NaF-LiF- $-\mathrm{BeF}_{2}$ as coolant would eliminate any need for an off-gas system for the coolant.

\subsection{2 design options}

The off-gas system schematics used for the MSBR is shown in Fig. 3.5. The gases removed from the pump bowl are first sent to the fuel-salt drain tank for a 2-hr decay. It is conceivable that the internal surfaces in the drain tank, especially those at lower temperatures, may act as sites for the deposition of particulate matter in the off-gas and thus eliminate the need for a filter (particle trap) at the drain tank outlet. The primary contaminants in the gas leaving the drain tank are $\mathrm{Kr}, \mathrm{Xe}$, and tritium. This gas passes first through the 47-hr xenon holdup system to permit the decay of ${ }^{135} \mathrm{Xe}$ to about $3 \%$ of the inlet amount. Charcoal is used for the dynamic adsorption and holdup of $\mathrm{Xe}$ and $\mathrm{Kr}$. The decay heat is transferred to boiling water which is condensed in a condenser outside the holdup charcoal bed. After leaving this charcoal bed, the gas stream is split into two streams. About $80 \%$ of the gas is sent to a chemical trap, a compressor and a surge tank. From the surge tank the gas is metered to the bubble generator and sent back to the reactor. The second stream which is about $20 \%$ of the gas leaving the $47-\mathrm{hr}$ charcoal bed, passes first through a long-delay (90 days) charcoal bed where all radioisotopes except the ten-year ${ }^{85} \mathrm{Kr}$ decay to insignificant levels. The gas then passes through a purification system which reduces the level of contaminants to an acceptable level, a surge tank, a compressor and is finally returned to the primary system.

The physical concept for the 47-hr charcoal bed consists of hairpin tubes filled with charcoal suspended in large tanks that contain water for cooling to keep the charcoal beds at acceptable temperatures. For the $2250 \mathrm{MWt}$ MSBR it has been estimated that $127,200 \mathrm{ft}$ of pipes would be required containing $82,400 \mathrm{lb}$ of charcoal. The pipes are suspended in cells about $25 \mathrm{ft}$ deep; the overall plan area is $32 \times 65 \mathrm{ft}^{2}$. The heat removal capability of the condenser is $2.7 \mathrm{MW}$, which is $25 \%$ over the maximum estimated decay heat level.

(v) To my knowledge there are only limited data on the off-gas system for ORNL's CoolantSalt Technology Facility (CSTF). They showed that a salt mist entered the off-gas system together with the helium and $\mathrm{BF}_{3}$.

REVISION 0

$3-20$

MARCH 1995 


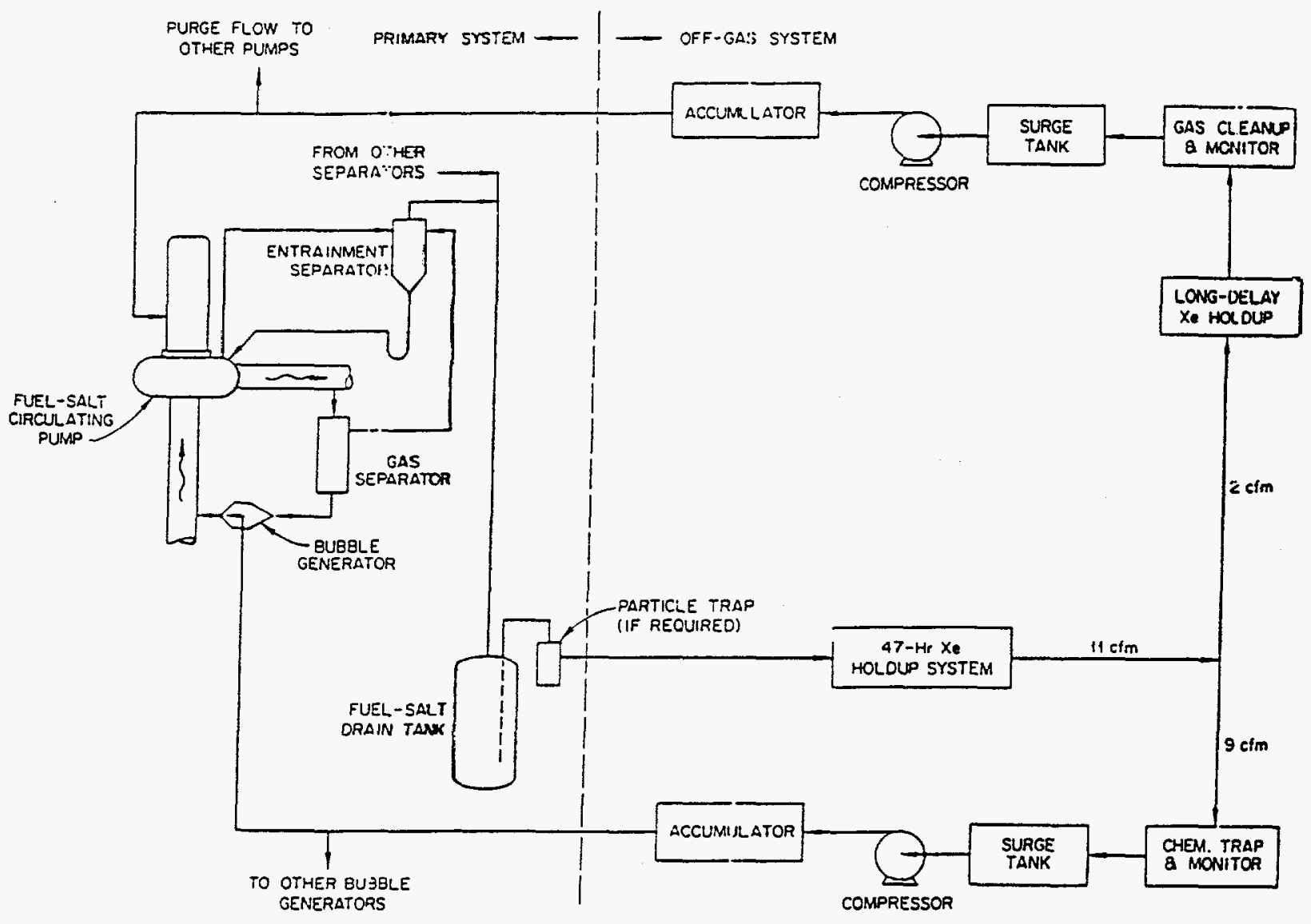

Fig. 3-5: Flow Diagram for the MSBR Off-Gas System 
The physical concept of the long-delay charcoal bed for the MSBR houses 18.5 tons of charcoal, contained in $1234 \mathrm{ft}^{3}$, with a pipe length of $24,060 \mathrm{ft}$. The overall dimensions of the charcoal bed are $25 \times 60 \times 25 \mathrm{ft}$ deep.

Some of the problems with these designs were recognized at the time the MSBR was designed and are cited from reference 5 , page 159:

"Means will have to be provided for the disposal of the collected radioactive materials. Although the MSRE provided considerable background of experience, additional development will be needed for the components in the MSBR off-gas system. The charcoal traps, helium compressors, particle traps, etc., must be effectively cooled to remove decay heat. All areas appear amenable to further study and development, however."

"The conceptual design proposes that the radioactive gaseous wastes from an MSBR be collected in gas-cylinders for long-term storage and decay. Whether the bottles are stored at the MSBR plant site or at other sites, approved equipment and procedures must be developed for handling them".

Depending on the need for effective fission gas removal that is different for internallymoderated systems and systems with no internal moderation, there are several design options that need to be explored:

- use of the fuel salt drain tank not only for short-time decay ( 2 hours) but also for long-term decay ( $47 \mathrm{hrs}$ ) of gaseous fission products. Gaseous fission product decay heat removal is not an issue for this option because the drainage systems (as will be shown later) is capable of passive cooling a discharged fuel inventory. However, charcoal beds cannot be used because their operation is typically limited to temperatures below $340^{\circ} \mathrm{F}$.

- remove gaseous fission products only with the sweep gas flow to the pump bowl

- eliminate the long-delay charcoal bed and recycle $100 \%$ (instead of $80 \%$ ) of the gas stream to the pump bowl via gas injection system (if needed)

- design off-gas system to serve several or all modules. 
- divert fission gases directly into storage (e.g., bottles) after helium separation (with helium coming either from sweep gas or sparging system);

Several of these options would eliminate to large extent the huge charcoal beds and the waste disposal problems they pose.

It should be noted that while the major MSRE components worked very well, the offgas system was one of the most troublesome systems of the MSRE. Within a few hours of operation, plugs had developed at several points in the fuel off-gas system requiring several months of shutdown. The fuel off-gas line near the pump bowl had been rodded out and a removable section replaced. Several shutdowns were required because plugs in the off-gas system lines had not been cleared completely. Off-gas system valves and filters had been replaced. Based on the MSRE literature it seems that freeze-up of off-gas system lines continued until the MSRE was permanently shut down.

\subsection{Salt Drainage Systems}

The principal function of the fuel drainage system is the safe containment of the fuel salt following intentional drains or drains following accidents.

Examples for reasons for intentional drains are:

- maintenance work on pumps, IHX. etc.

- replacement of core graphite

Examples for drains during accidents are:

- failure of the primary system piping or vessel

- secondary coolant ingress

- loss of salt from primary system that leads to pump stoppage

- loss of coolant or circulation in the secondary system

- loss of heat removal capability in steam system (e.g., loss of feedwater)

- loss of power or mechanical failure of primary pumps

- inadvertent drainage valve opening

- accidental overpressurization of primary system

Coolant sait also needs to be drained occasionally either to facilitate repair and maintenance work, or to clean the salt. 
3.5.1 requirements for drainage systems

\subsubsection{1 fuel drainage system}

A preliminary set of requirements is the following:

- $\quad$ provide for sudden drainage within [TBD] minutes

- $\quad$ provide this drain via gravity forces alone

- $\quad$ provide surge volume from the primary pump bowl

- $\quad$ provide highly reliable cooling system capable of removing decay heat after a sudden drain from full power operation

- achieve high reliability through passive means with minimal reliance on electric power supplies

- $\quad$ keep maximum drain tank temperatures in safe operating range

- ensure minimal risk for freezing either fuel salt or coolant salt

- accidental leakage of coolant into fuel salt should not require chemical processing to prevent adverse nuclear or chemical effects

- $\quad$ provide for pumping and piping system to refill core/primary system

- $\quad$ provide for pumping and piping system to processing facility

\subsubsection{2 coolant drainage system}

- $\quad$ provide for sudden drainage within [TBD] minutes

- provide this drain via gravity forces alone

- $\quad$ provide surge volume from the secondary pump bowi

- achieve high reliability through passive means with minimal reliance on electric power supplies

- keep maximum drain tank temperatures in safe operating range

- ensure minimal risk for freezing either fuel salt or coolant salt

- in case of accidental leakage of fuel into coolant salt provide for separation of fuel from coolant salt, fuel salt cleanup and coolants alt disposal

- $\quad$ provide for pumping and piping system to refill secondary loop

- $\quad$ provide for pumping and piping system to processing facility 


\subsection{2 design options for drainage systems}

\subsubsection{1 fuel drainage system}

Different design options exist in regard to the drainage system configuration and the choice of coolant for the drainage system.

In the past several options were considered:

- $\quad$ storage of the salt in a long pipe with radiant heat transfer to cooled plates

- use of heat pipes to cool fuel-salt-filled tanks

- $\quad$ storage system with convective cooling (MSRE)

- storage of the salt in a tank having a coolant circulated by natural convection to a water-cooled heat exchanger (MSBR)

Among the heat transport fluids considered for the MSBR were:

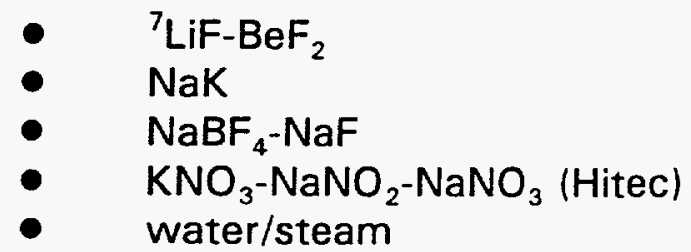

The final selection was $\mathrm{LiF}-\mathrm{BeF}_{2}$ because of its compatibility with the fuel salt. Table 3.4 summarizes the results of the evaluation that led to the selection of $\mathrm{LiF}_{-}-\mathrm{BeF}_{2}$ as coolant.

Not included in this evaluation is another alternate coolant, namely $\mathrm{NaF}^{7} \mathrm{LiF}_{-} \mathrm{BeF}_{2}$ (4522-33 mole \%) which is very similar to the MSRE coolant ${ }^{7} \mathrm{LiF}_{-} \mathrm{BeF}_{2}(66-34$ mole $\%)$ except that sodium is substituted for approximately two-thirds of the lithium ions ${ }^{10}$. The major advantages of this coolant are its compatibility with the fuel salt, low melting point and the greatly reduced cost. It was omitted from the table because its cost is very high (like the cost for the MSRE coolant that was listed because it had been proposed for the MSBR). 
TABLE 3.4:

EVALUATION OF COOLANTS FOR THE PRIMARY DRAIN TANK SYSTEM

\begin{tabular}{|c|c|c|}
\hline COOLANT & DESIRABLE FEATURES & UNDESIRABLE FEATURES \\
\hline $\mathrm{NaBF}_{4}-\mathrm{NaF}$ & $\begin{array}{l}\text { inexpensive } \\
\text { low viscosity } \\
\text { broad test data base available }\end{array}$ & $\begin{array}{l}\text { fuel processing required in case of } \\
\text { leak } \\
\text { high melting point } \\
\text { Hastelloy } N \text { required } \\
\text { cost and complexity of components } \\
\text { and equipment is medium to high }\end{array}$ \\
\hline NaK & $\begin{array}{l}\text { good for cooling and heating } \\
\text { low pressure } \\
\text { low corrosion } \\
\text { low cost } \\
\text { stable under irradiation } \\
\text { ease of instrumenting and control- } \\
\text { ling } \\
\text { works with stainless steel and Has- } \\
\text { telloy } N\end{array}$ & $\begin{array}{l}\text { avoid contact with air } \\
\text { cost and complexity of components } \\
\text { and equipment is medium to high } \\
\text { no data on fuel-NaK interaction }\end{array}$ \\
\hline${ }^{7} \mathrm{LiF}-\mathrm{BeF}_{2}$ & $\begin{array}{l}\text { no fuel processing required in case } \\
\text { of leak } \\
\text { least thermal shock on drain sys- } \\
\text { tem } \\
\text { extensive experience (MSRE) } \\
\text { Hastelloy } N \text { may not be required } \\
\text { no volume change on freezing }\end{array}$ & $\begin{array}{l}\text { very expensive } \\
\text { high melting point (concern about } \\
\text { freezing) } \\
\text { high viscosity } \\
\text { cost and complexity of components } \\
\text { and equipment is medium to high }\end{array}$ \\
\hline Hitec & $\begin{array}{l}\text { inexpensive } \\
\text { carbon steel can be used } \\
\text { low melting point }\end{array}$ & $\begin{array}{l}\text { doubtful stability at high tempera- } \\
\text { tures and in radiation field } \\
\text { alt processing required in case of } \\
\text { leak } \\
\text { cost and complexity of components } \\
\text { and equipment is medium to high }\end{array}$ \\
\hline water/steam & $\begin{array}{l}\text { least danger of freezing } \\
\text { lowest cost } \\
\text { used in MSRE drain tank } \\
\text { natural convection easily estab- } \\
\text { lished } \\
\text { cost and complexity of components } \\
\text { and equipment is low }\end{array}$ & $\begin{array}{l}\text { requires double barrier tubes (e.g., } \\
\text { bayonet) } \\
\text { large number of tubes required }\end{array}$ \\
\hline
\end{tabular}




\subsubsection{2 coolant salt drainage system}

The design of a coolant salt drainage system is much simpler than the design of the fuel drain system. There are no fission products and decay heat problems. However, while such a system has no heat removal capability it must be heated to keep the coolant liquid. Depending on the coolant, in case of a leak of fuel into sodium fluoroborate system, care must be exercised in treating the reaction products.

\subsection{Freeze Valves, Melt Plugs and Mechanical Valves}

The MSRE used only freeze valves where a flattened portion of a 2 -inch section was provided with external heaters and coolers. Under normal operating conditions, this section was cooled to keep the salt frozen and keep the "valve" shut. Stopping the cooling (and adding heating) would allow a thawing of the salt plug and open the valve.

For the MSBR, the same type of valve had been proposed realizing, however, that for a single fuel drain line with a 6-inch diameter, a sizeable refrigeration plant would be required to keep the valve shut.

Another option considered was a small shell-and-tube heat exchanger with the salt flowing through the tubes, that would provide for "valve" closure.

In still another option a mechanical-type valve with the seat chilled to provide positive shutoff had been considered.

The concept of a melt plug has also been proposed which assumes that a drain line is kept plugged by using a material whose melting point is above that for the salt, and that would melt in case of a salt overheating.

Which concept will ultimately be employed for opening and closing drain lines will depend on the reliability and reproducibility of the proposed valve opening and closure, the ease for its repair, maintenance and replacement. Freeze valves are simple in principle but get very complicated for large systems. A mechanical valve where the seat is chilled has certain advantages because it does not require to freeze largediameter pipes. A melt plug is simple in principle but requires in the fuel line a material, different from the fuel salt, that has a higher melting point. Resetting such a valve can be a very complex procedure, and fuel-melt plug material interactions could change the melt characteristics of such a configuration. 


\subsection{Fuel and Sait Processing}

Fuel processing facilities must be available to achieve the following goals:

- remove impurities such as corrosion products and reaction products

- remove rare earth trifluorides to extend fuel life (if found justifiable to add this functional requirement)

- clean the fuel at the end of its life to remove trifluorides and fission products, if deemed necessary

Before any design for such a facility can be developed its functions need to be defined more clearly.

Coolant salt processing facilities will also be available to remove impurities such as corrosion products, oxides and reaction products from coolant-fuel salt interactions in case of a leak.

\subsection{Approach to Shielding}

In the $A B C$ system, tons of fission products will be circulated in the primary system. All components in the primary loop will be exposed to fission products and a significant level of radionuclide deposition can be expected in addition to direct activation through neutron exposure.

Furthermore, the neutron beam, that will be directed into the target located inside the reactor vessel, has to be shielding so that structures and personnel are not exposed to high levels of radiation. Accelerator-related shielding issues will not be addressed in this report. However, it is important to note that the spallation neutrons produced in the target have on average much higher energies than the fission neutrons, and special shielding precautions might be required.

The shielding approach proposed for the ABC system would focus on shielding in the immediate proximity of the sources of radiation to protect both personnel and structures.

\subsection{1 maintenance personnel}

To protect maintenance personnel from radiation, thick concrete walls are required. In addition movable shield sections might be required depending on the mainte- 
nance/repair work that has to be performed.

\subsection{2 systems, structures and components}

Shielding has to begin inside the blanket vessel to protect the vessel from neutron damage. Furthermore, a reduction in neutron leakage is also required to keep as low as possible the fission rates in the pump bowl and IHX which would otherwise be a source for fast neutrons and gammas that need to be shielded against, as well as any direct activation of structures surrounding the blanket.

To achieve effective shielding one can either provide separate shielding structures or combine the reflector and shielding function by adding inelastic neutron scatterers and neutron poison to the outer regions of the reflector. 


\subsection{REFERENCES:}

1. "Technical Review of the ALMR Program", Englewood, CO, March 16-17, 1993 (Viewgraph collection); see also SECY-89-197, "Issuance of Draft Safety Evaluation Report (SER) for the Power Reactor Inherently Safe Module (PRISM)", September 12, 1987

2. Presentation to the JASON Panel by Charles D. Bowman, "ABC Target/Blanket Physics and Engineering", January 18, 1994

3. F. Venneri, "The Physics Design of Accelerator-Driven Transmutation Systems", International Conference on Accelerator-Driven Transmutation Technologies and Applications, July 25-29, 1994

4. see Chapter 10 in "APT Accelerator Topical Report", LA-CT-94-48, Vol. 1 Rev. 1, March 1994

5. "Accelerator Based Conversion ( $A B C$ ) Pu Disposition: Requirements Document", August 26, 1994, prepared by Barthold \& Associates, Inc.

6. R. C. Robertson (Editor), "Conceptual Design Study of a Single-Fluid Molten-Salt Breeder Reactor", ORNL-4541 (June 1971)

7. based on a memo by R. Bradbury, J. Longo, R. Strong, M. Hayes, "The Design Goals and Significant Features of the Safe Integral Reactor", published by Stone \& Wester, 1989

8. Westinghouse presentation to National Academy of Sciences Committee on Future Nuclear Power Development, August 22, 1989, and information provided by Westinghouse descriptive brochure on AP-600.

9. G. T. Mays, A.N. Smith, J.R. Engel, "Distribution and behavior of Tritium in the Coolant-Salt Technology Facility", ORNL-TM-5759 (April 1977)

10. A. D. Kelmers et al.:, "Evaluation of Alternate Secondary land Tertiary)Coolants for the Molten-Salt Breeder Reactor", ORNL/TM-5325 (April 1976) 


\subsection{RECOMMENDED REFERENCE CONFIGURATION}

The $A B C$ configuration proposed here is a 4-module pool design with intermediate loops separating the circulating fuel (primary loop) from the coolant-steam loops. Each module is operated separately from the others except that all modules are driven by one accelerator. Two modules share support systems such as the fuel drain and offgas systems. In the following sections, discussions will be presented on:

4.1 considerations for the selection of the reference configuration

4.2 primary system

4.3 secondary system

4.4 steam system

4.5 auxiliary systems

4.6 containment systems

\subsection{Considerations for the Selection of the Reference Configuration}

The proposed $A B C$ module size is $750 \mathrm{MWt}$ which yields a 3,000 MWt capacity for a four-module plant. Safety, reliability, and cost considerations guided the development of this $A B C$ plant layout. Specifically, the following features were considered desirable for the $A B C$ system and guided this design effort:

- low pressure systems throughout

The very low vapor pressure of molten salts even at high temperatures and the low pressure drop design of the primary system allow for a low operating pressure primary system. To fully benefit from this characteristic, the secondary and steam loop have to be operated at low pressures, too. This enhances passive and engineered safety, for example, through enhanced natural convection flow capability, design simplifications, increased system, component and structure reliability.

- no single systems, structure, or component will be relied upon excessively to ensure safe operation

Adopting the defense-in-depth concept requires to "spread the risk" by establishing multiple barriers to radionuclide releases. If only one barrier would be relied upon excessively, the defense in depth concept would be violated. 
- clear definition of flow paths through piping

In the classical pool concept a core is located inside a reactor vessel, together with a pump and IHX. Hot coolant outside the core is separated from the cold coolant by an interface that directs the hot coolant to flow through the pump and $\mathrm{IHX}$ back into the core inlet region without using piping. Such a configuration is not directly applicable to a liquid fuel reactor because it would increase significantly the system fissile inventory due to the large ex-core inventory. In an earlier $A B C$ design this problem was solved by placing large amounts of graphite inside the vessels and let gaps between graphite blocks identify the flow paths. As discussed in Chapter 3, this introduces potential problems in regard to the clear identification of flow paths and led to the design proposed here that connects different components through piping and uses the pool configuration to (1) contain any leaking fuel salt from the primary system, and (2) provide a large heat sink.

- natural convection flow is emphasized by using upflow cores and arranging core, $\mathrm{IHX}$ and steam generator at increasing elevations

There is no compelling reason to use a downflow corei. Upflow makes the establishment of natural convection flow easier.

A low-pressure-drop design together with staggered thermal centers for the primary, secondary and steam system will enhance natural convection flow to allow for easy passive decay heat transport/removal in case of a loss of forced flow.

- large heat sinks are provided in the pool to store the decay heat in case decay heat cannot be removed actively

(i) The main reason for coolant downflow in a pebble bed reactor is the requirement to avoid pebble levitation. The current MHTGR evolved from the pebble bed steel vessel design and, when the fuel form was changed from pebbles to prismatic fuel elements, the flow direction was not changed because the system design developed so far was for pebble fuel.

It should be noted that downflow vs upflow is not as critical an issue for gas-cooled reactors as for water-or sodium-cooled reactors because decay heat removal via natural circulation is not as effective in a gas-cooled reactor as in a liquid-cooled reactor. 
Providing large heat sinks will enhance passive safety to the extent that, under the best of circumstances, no operator action is required to keep intact the barriers to radionuclide releases in case the active external heat sink is lost (e.g., in case the steam generator is lost as a heat sink due to a loss of service water). At that time, a loss of heat sink would lead to a draining of the fuel into the drainage systems from where the decay heat can be removed passively. The use of a pool configuration permits the easy installation of passive decay heat removal system like the DRACS and IRACS of the ALMR, should this be necessary for the ABC system.

isolation of loops to facilitate ease in repair and replacement of systems and components and to mitigate the progression of accidents

Loop isolation is accomplished via:

- IHTS isolation valves to isolate the IHX from the steam generator, and

- MSIV valves to isolate the steam generator from (1) the IHX and auxiliary vessel and (2) the feedwater and turbine systems.

containment of radionuclides in the primary system, the secondary system, the steam system and the containment building through judicious selection of operating pressures

In the unlikely event that the primary system boundary is violated, radionuclides should be retained inside the primary system cell.

If, at the same time, the primary system boundary is violated inside the IHX (e.g., a tube rupture), the higher pressure on the secondary side would lead to coolant leakage into the fuel region followed by a loop isolation.

Should this loop isolation fail, radionuclides could enter the coolant side of the steam generator after primary and secondary side pressures equilibrated.

If a steam generator tube rupture would occur simultaneously, radionuclides would be retained in the secondary loop due to the higher steam pressure. Rapid-acting isolation valves would isolate the steam generator. 
Should this isolation also fail, radionuclides could enter the steam side but only after steam pressure and secondary side pressure had equilibrated. A second set of main steam isolation valves would also have been activated to isolate the steam generator.

Should then the external steam loop boundary be violated radionuclides would be released into the steam generator cell, which acts as a containment.

Radionuclide containment is provided through the primary system cell, the cell containing the IHTS isolation valves and secondary coolant pumps, and the cell containing the steam generator system. All three cells are safety-grade constructions and located under an additional containment structure. Attention is given to the penetrations from one cell into another to ensure that proper isolation can be done.

- elimination of the graphite moderator blocks in the core region

The presence of the graphite moderator in the MSBR ${ }^{1}$ ensured a wellmoderated neutron spectrum which was a prerequisite for effective breeding. However, the presence of moderator elements introduced problems in regard to (1) gaseous fission product adsorption, (2) neutron damage in graphite and the need for periodic replacements of graphite blocks/assemblies, (3) the need to dispose of highly radioactive graphite, and (4) the possibility for flow blockage accidents in case pieces of graphite break loose.

Because breeding of fuel is not desired in the $A B C$, all these problems can be eliminated by eliminating the use of a graphite moderator.

design simplicity and transparency is emphasized

Because of its liquid form, molten salt fuel permits a level of design simplicity that clearly distinguishes it from solid fuel reactors. Refueling does not require complex refueling machines, fuel rods and assemblies made within tight specifications, complex reactivity control systems and their backup, complex shutdown systems, fuel storage, and extensive and complex recovery procedures from, for example, refueling accidents or control rod withdrawal accidents. Because a molten salt system allows in principle for great design simplicity and transparency it is 
important to maintain this simplicity in the systems design."

- diverse, independent and redundant heat transfer systems are employed

The main heat transport system is capable of reliably removing the heat from full-power to decay-power levels.

Should this system fail and lead to an overheating of the primary system, the fuel salt will be automatically drained, through a freeze valve, by gravity from the primary system into a drain tank from where the heat is passively transferred to a molten salt (or other) coolant and from there to water/steam. Steam separators which are part of the fuel drainage system divert the steam to air-cooled condensers in a natural draft stack. The condensate is returned by gravity.

In case of a loss of active decay heat removal, there is sufficient time available from the time the main heat transport system is lost until the fuel is fully drained, due to the large heat capacity available inside the primary system cell.

- $\quad$ minimize material problems by proper shielding of vessels and judicious selection of operating conditions

The achievement of high plutonium destruction rates is related to high neutron fluxes which in turn are responsible for vessel material damage. To achieve both high plutonium destruction rates and low vessel damage requires sufficient shielding inside the reactor vessel, and the judicious selection of operating conditions.

It is known that adding boron to graphite will very effectively filter out any thermal neutrons. However, fast neutrons are not effectively eliminated by born. Furthermore, neutron moderation in a graphite system requires large distances over which the moderation would occur. If shielding would be done solely by graphite-boron configurations, this would lead to large vessels which are costly. Therefore, it has been suggested to add iron pins to a graphite reflector to use the inelastic scattering properties of iron to slow down the neutrons and then capture them in boron.

(ii) There were earlier $A B C / A T W$ designs that employed complex inlet plenum designs that were not in accordance with this requirement, and were eliminated for their complexity. 
Neutron flux and power density are closely correlated. A compromise has to be found between (1) the desire to use as high a power density as possible to reduce vessel cost and (2) neutron damage flux. Similarly, fuel salt temperatures have to be selected to extend vessel lifetimes.

- spatial separation of primary system components

Because all primary system components contain fuel salt, any neutron leakage into components outside the core have to be minimized because (1) they would create additional heat sources and (2) due to the fissions in those regions, fast neutron fluxes would be increased resulting in increased neutron damage and activation..

- low personnel doses by proper shielding and remote maintenance

Most if not all maintenance, repair, and replacement work on mainline systems, structures and components has to be done remotely. This work can be carried out from the (thick) concrete floor under which the mainline systems are located. Maintenance enclosures are provided to shield the areas in the vicinity of the maintenance work.

- ease of access to components for maintenance, repair, and replacement

All radioactive equipment is installed in containment cells. The overhead shielding is arranged in removable sections that permit access to those systems. The systems will be designed such that each component, its supports, instrumentation, etc. can be viewed from above and be accessible by remotely operated tools. Any removal of mainline systems must be carried out by straight push or pull operations and adequate space has to be provided for it.

Even though lifetime structures (e.g., reactor vessel, pump vessels, IHX shells, steam generator vessels, etc.) are generally not designed for replacement, the $A B C$ system being a first-of-a-kind system will allow for the replacement of those structures.

- $\quad$ minimize waste streams

Waste streams will be minimized by:

- $\quad$ reducing the activation of components via neutron irradiation 
- designing structures and components for the life of the plant

- $\quad$ eliminating graphite moderator assemblies

- $\quad$ keeping fission products in the fuel salt

- conservative operating conditions

Fuel and salt temperatures, flow rates, power densities, operating pressures in the primary system, intermediate system and steam generator system have to be selected based on previous experience with the MSRE, extended lab-scale experience with molten salt tests, and other operating reactors. The operating conditions have to support safety and reliability and should be prudent extrapolations from current experience.

- $\quad$ modules should share auxiliary systems

To reduce cost, auxiliary systems should be shared to the largest possible extent. Among those systems are the fuel salt drain system, off-gas system, chemical processing, hot cells, and storage facilities.

- placement of pumps to enhance safety, reliability and reduce cost

Pumps can be placed either in the hot leg or cold leg portion of a loop. The components immediately following the pump will be exposed to the highest pressure in the respective loop. The placement of the pump in a particular loop should enhance safety, reliability, and reduce cost.

- use of double-walled piping

The use of double-walled piping has significant advantages such as:

- inventory reduction

- $\quad$ reduced heating requirements

- $\quad$ reduced number of penetrations of containment walls

At this stage in the development of a preconceptual $A B C$ design, only limited use has been made of double-walled piping. In a next design iteration this issue needs to be explored more fully considering performance, safety, reliability, inspectability, maintainability, and cost issues.

In the following the major systems of the $A B C$ facility will be briefly described. 


\subsection{RECOMMENDED PRIMARY SYSTEM}

\subsubsection{Blanket}

Operating Conditions: There is no documented basis in support for the currently cited operating conditions selected for the ABC system. During 1994, different primary system operating conditions were published for the $A B C$ system, that sometimes even varied within a single viewgraph presentation (Table 4.1). For any design characterization it is important that only one set of operating conditions is used to eliminate the ambiguities that creep in when different ones are used.

TABLE 4.1: FUEL INLET AND OUTLET TEMPERATURES, ${ }^{\circ} \mathrm{C}\left({ }^{\circ} \mathrm{F}\right)$

\begin{tabular}{|c|c|c|c|c|c|}
\hline & \multicolumn{2}{|c|}{1994 JASON PRESENTATION } & \multirow{2}{*}{$\begin{array}{l}\text { July and } \\
\text { August }\end{array}$} & \multirow{2}{*}{$\begin{array}{l}\text { ORNL } \\
\text { ABCiv }\end{array}$} & \multirow[t]{2}{*}{ Proposed } \\
\hline & $\begin{array}{l}\text { based on } \\
\text { IHX data }\end{array}$ & $\begin{array}{l}\text { based on } A B C \text { Op- } \\
\text { erating Parameters }\end{array}$ & & & \\
\hline INLET & $598(1108)$ & $502(936)$ & $577(1070)$ & $566(1050)$ & $566(1050)$ \\
\hline OUTLET & $750(1382)$ & $698(1288)$ & $727(1340)$ & $705(1300)$ & $705(1300)$ \\
\hline RISE & $152(274)$ & $196(353)$ & $150(270)$ & $139(250)$ & $139(250)$ \\
\hline
\end{tabular}

The ORNL ABC operating condition data are the same as that for the MSBR design and ORNL's denatured molten salt reactor design of $1980^{2}$. A sound technical basis for these operating conditions still needs to be developed.

Recommendation: In the interim, the MSBR fuel salt operating conditions are recommended for further $A B C$ design studies until a comprehensive technical basis can be provided for any changed conditions.

Power Density and Power Level: A technical basis for the selection of power density and power level still has to be developed. Safety and reliability as well as cost considerations will play a major role.

(iii) based on Las Vegas Conference (July 94) and August 94 Overview of LANL Molten Salt $A B C$ Design viewgraphs

(iv) Based on ORNL ABC design presented November 30-December 1, 1994 
Recommendations: A fuel power density of $100 \mathrm{MW} / \mathrm{m}^{3}$ is recommended that, together with an assumed power level of $750 \mathrm{MWt}$ yield a fuel salt core inventory of $7.5 \mathrm{~m}^{3}$. At this time, these choices seem to be reasonable and do not seem to stretch the existing technology base (the MSBR had a peak power density in the core of $70.4 \mathrm{MW} / \mathrm{m} 3$ and a core size of $2250 \mathrm{MWt}$ ).

Fuel Salt Composition: The fuel salt compositions identified in Chapter 3 are all feasible compositions.

Recommendation: At this time, for further system studies, a fuel composition of ' $\mathrm{LiF}$ $\mathrm{BeF}_{2}-\mathrm{ZrF}_{4}-\mathrm{PuF}_{3}$ is recommended. However, for future work it is strongly recommended to evaluate a replacement of $\mathrm{LiF}$ by $\mathrm{NaF}$ that would, for all practical purposes eliminate the tritium problem - that led to the choice of sodium fluoroborate as coolant.

Core Configuration: In the center of the core is a $0.6 \mathrm{~m}$ diameter target region that extends from the top of the core region to just below the core midplane.

Recommendations: It is recommended that the fuel region not contain a graphite moderator. The core region has the shape of a square cylinder (height-to-diameter ratio of 1.01 . The core is surrounded axially and radially by $1.25 \mathrm{~m}$ thick graphite reflector/shield regions ${ }^{v}$ that are (1) intended to protect the vessel from neutroninduced damage, and (2) will also moderate the neutrons.

The use of a core barrel is recommended. The reflector/shield graphite is attached to such a core barrel that sits inside the core vessel. Between core barrel and core vessel is a small gap for "cold" fuel salt bypass flow to keep the core vessel at (or near) core inlet temperature. The core vessel is expected to be a lifetime structure and operating the vessel at a lower temperature is clearly beneficial.

It is recommended to have the outer half of the reflector region (i.e., the region next to the core barrell equipped with small boronated steel pins. The function of the iron is to slow down the neutrons (due to the high inelastic scattering cross section), and the function of the boron is to capture the slowed-down neutrons. Trade studies have to be performed to determine a quantitative basis for the thickness of the reflector/shield region and to determine the split between the "pure" graphite region and the thickness of the graphite region that contains the boronated steel pins. The elimination of a graphite moderator in the core also eliminates (or at the very least greatly mitigates) any graphite replacement issues due to excessive graphite material damage

(v) This recommendation is based on shielding analyses for the MHTGR and the need for the $A B C$ system to provide more effective shielding because of the higher neutron flux. 
coming from the exposure to high neutron fluxes. The neutron fluxes will be significantly lower at the reflector regions than in the center of the core.

The lower axial reflector has penetrations to allow the fuel salt flow to penetrate this region on its way to the core. The holes/channels in this lower axial reflector have to be arranged such that they do not permit a direct neutron exposure/shine (due to neutron streaming) of the vessel region. This can be accomplished by creating small plena regions inside the graphite block(s) from where offset flow channels emerge.

\subsubsection{Core Support Plate}

It is highly desirable to have clearly identifiable flow paths in the primary system (and elsewhere) and to provide support for internal structures.

Recommendation: A core support plate, made of Hastelloy N, should be used to support radial and lower axial graphite reflector regions. This support plate contains a suitable number of penetrations for the fuel salt flow into the core region. Below the support plate is the fuel salt inlet plenum. It needs to be determined whether or not there is a need for installing an additional shield region below the inlet plenum to better shield the lower part of the blanket vessel.

\subsubsection{Fuel and Coolant Salt Pumps}

Fuel salt pumps of the desired capacity are not available commercially. The MSRE fuel pump was driven by a $75 \mathrm{hp}$ motor and had a capacity of $1200 \mathrm{gpm}$. The $2240 \mathrm{MWt}$ MSBR design called for 4 pumps each with a capacity of $16,000 \mathrm{gpm}$. The ABC pump design ( 2 pumps per $750 \mathrm{MWt}$ module) has a capacity of approximately 11,000 $\mathrm{gpm}$. While this is smaller capacity than the MSBR pump, it is nearly a factor 100 higher than the MSRE pump.

Recommendation: The MSBR pump design should be used for $A B C$ design studies until a specific $A B C$ pump design has been developed. The lower portion of the pump (pump tank, impeller, casing, etc.) is located in the primary system cell, and the drive motor is located above the shielding in the primary and secondary system bay.

A pump tank provides a volume to accommodate the thermal expansion of the primary system due to temperature changes (normal, off-normal conditions). A diameter of $6 \mathrm{ft}$ is assumed. The pump bowl is also connected to the fuel drain tank which serves as a surge volume for salt overflowing from the primary system. 
It is recommended to use at this time the same basic pump design for both the fuel and coolant salt pumps.

It is recommended to place both fuel and coolant pumps in the hot-leg section of their respective loops at their highest locations.

\subsubsection{Gas Sparging System}

It still needs to be determined whether or not a gas sparging system is required for the Pu disposition task. According to Ref. 1, it was calculated that the $2250 \mathrm{MWt}$ MSBR would produce $1 \mathrm{~kg}$ of noble-gas fission products per day. About $15 \%$ of the gaseous fission products are relatively short-lived and will decay in the fuel-salt system. The remaining $85 \%$ are either stable or have half-lives which are long enough for them to be removed through a sparging system that injects helium into the primary system and removes fuel salt that is sent to a separator together with the helium carrier gas. Only lab experiments on components of such a system have been performed.

Recommendation: Should the incorporation of a sparging system be required it is recommended to use the MSBR design for such a system as a starting point until an $A B C$-specific system has been designed. The flow rate for the $A B C$ gas sparging system, however, would be lower than for the MSBR.

\subsubsection{Blanket Vessel}

The blanket vessel contains the core barrel, core region, radial and axial reflector and shield regions, as well as the inlet and outlet plena.

Recommendation: The blanket vessel is made of Hastelloy N. Fuel salt flow to and from this vessel comes through a double-walled pipe (pressure vessel) with the hot fluid being in the inner tube and the returning cold fluid being in the space between the inner and outer tube. Shortly after this double-walled tubes leaves the blanket vessel it branches off into a pipe transferring the hot fluid to the fuel pump and IHX inlet plenum, and another pipe bringing back the cold fluid from the IHX outlet plenum. The incoming cold fluid is directed into the inlet flow region created by the core barrel, between the core barrel and the vessel wall. The fuel salt outlet region is the region between the upper axial reflector and the core region.

The blanket vessel has two double-walled pipes. At the bottom of the vessel is a small fuel salt drainage pipe that, using the 6 inch-diameter drainage pipe of the MSBR 
as a reference point, would have a diameter of about 3.5 inches.

\subsection{SECONDARY SYSTEM}

Recommendation: At this time, for further system studies, a coolant composition of $\mathrm{NaBF}_{3}-\mathrm{NaF}$ should be assumed. Other coolant choices should still be considered, especially $\mathrm{NaF}-\mathrm{BeF}_{2}$ - LiF which is very suitable in case $\mathrm{NaF}-\mathrm{BeF}_{2}-\mathrm{ZrF}_{4}-\mathrm{PuF}_{3}$ is selected as fuel salt.

The recommended designs for $\mathrm{IHX}$, fuel drainage system, off-gas system and isolation valves will briefly be described. At this time it is assumed that the coolant pump design is identical to the fuel salt pump except that the motor strength might be somewhat different.

\subsubsection{IHX}

Two IHX's are located inside the blanket vessel. Based on the discussion in section 3.2.2 the following is recommended.

Recommendation: A vertical counterflow shell-and-tube-type heat exchanger is recommended for use in the $A B C$ system. Its basic layout is similar to that designed for the MSBR with the following differences:

- conventional tubes are proposed instead of the special tubing used for the MSBR IHX to improve heat transfer

The incentive for using special tubing in the MSBR came from the expected reduction in external fuel inventory which would tend to lower the fuel doubling time, even though the $\mathrm{IHX}$ cost would increase. Such an incentive does not exist for the $A B C$ system.

- piping for the primary and secondary salt will penetrate the $\mathrm{IHX}$ shell at the sides rather than enter from the top in form of double-walled piping for the secondary salt, as in the MSBR IHX design.

The U-type double-walled tubing used for the MSBR IHX would increase the height requirements for the $A B C I H X$ without clear benefits. The more conventional design of the $I H X$ (similar to the ALMR IHX) has. therefore, been adopted. 
Furthermore, the IHX is placed at a higher elevation than the core to enhance natural circulation.

\subsubsection{Coolant Drain System}

A coolant drain system is provided to drain the coolant from the secondary loop for maintenance work, coolant processing, or repair work on the secondary system. The control system has to ensure that coolant drain, if necessary, can only be done after the fuel has been drained from the primary system.

To facilitate the drain, drainage valves are required and suitable storage facilities.

Recommendation: A freeze valve is provided to drain the coolant from the secondary system into storage tanks. These tanks are heated and equipped with pumps to refill the secondary loop. These tanks are also connected to coolant salt processing facilities.

\subsubsection{Coolant Off-Gas System}

Recommendation: In the absence of (1) a final selection of the coolant salt, and (2) data on sodium fluoroborate coolant salt stability and required controls, no design recommendations are provided at this time on such a system. It is conceivable that ultimately a coolant off-gas system might very well be required should sodium fluoroborate be used as a coolant. The helium sweep gas in the pump bowl will carry with it $\mathrm{BF}_{3}$ that needs to be separated from the helium.

\subsubsection{Isolation Valves}

In case of an IHX tube failure, coolant will leak into the primary system until the pressures in the primary and secondary system are equalized. It is then possible that fuel salt can enter the secondary system and carry large amounts of fission products with it. To eliminate the transport of fuel and fission products from the primary system to the secondary system (or at the least lower significantly the probability from this to happen), the intermediate loop has to be isolated.

It is important to isolate the steam generator, for example, in case of a steam generator tube rupture. In this case, the (high pressure) steam generator needs to be isolated from (1) the $\mathrm{HHX}$ to avoid damage to the IHX, and (2) the feedwater and 
turbine system.

Recommendation: Quick-acting isolation valves are recommended for installation between the coolant pump suction line and $\mathrm{IHX}$ and $\mathrm{IHX}$ and steam generator. These valves will permit the isolation of the intermediate heat transport system and the steam system.

The Fuel Drainage System and the Off-Gas System are described in sections 4.5.1-2.

\subsection{STEAM SYSTEM}

From a safety point of view, leakage of fission products/fuel from the primary system to the secondary system can be delayed by operating the secondary system at a higher pressure than the primary system. Should there be a leakage of fuel/fission products into the secondary system, the probability for further leakage outward into the steam system would be greatly reduced by operating the steam system at a higher pressure than the secondary system.

However, IHX tube failures can lead to an overpressurization of the primary system and, dependent on the pressure differential between the two system, can potentially lead to damage in the primary system. Steam generator tube failures can lead to an overpressurization of the secondary system and, dependent on the pressure differential, can cause damage to components in the secondary system and potentially also in the primary system.

The desire to use low pressure differentials between the systems, the desire to take advantage of the low vapor pressure of molten salts at high temperatures and the possibility to operate molten salt systems at low pressures, competes with the desire for high thermal efficiencies that are helped by high steam pressures.

To properly balance the different incentives and their consequences is a complex process that has to be carefully evaluated. However, to further the ABC design certain recommendations will be made that at a later time need to be revisited.

Should sodium fluoroborate be used as intermediate coolant, there is a concern about the inleakage of steam. If there is a small leak only hat can be repaired in a short period of time, such a leak would not be harmful. However, large leaks will greatly increase metal corrosion and mass transfer. The reaction of sodium fluoroborate with steam leads to the formation of relatively insoluble corrosion products $\mathrm{Na}_{3} \mathrm{CrF}_{6}$ and 
$\mathrm{NaNiF}_{3}$ which could foul steam generator surfaces and/or restrict narrow coolant flow channels. Similar reaction products will form in case NaF-LiF-BeF 2 is used as a coolant.

It seems necessary to provide for coolant salt cleanup after such reactions take place. This issue will not be addressed here.

Recommendation: While many MSBR design features, especially those in the auxiliary systems, can easily be translated into $A B C$ design features, the MSBR steam cycle should be changed for the $A B C$. The $A B C$ system (as well as the MSBR) is a lowpressure system and this features is important for safety and cost considerations. It is recommended to maintain this important feature.

\subsubsection{Operating Conditions}

Recommendations: The steam pressure should stay below 1000 psi to greatly reduce the consequences of an overpressurization of the secondary system ${ }^{\text {vi }}$. The steam outlet temperature of $1000^{\circ} \mathrm{F}$ is acceptable; the feedwater inlet temperature of $700^{\circ}$ $F$ is consistent with the liquidus temperature for sodium fluoroborate which is $384^{\circ} \mathrm{C}$

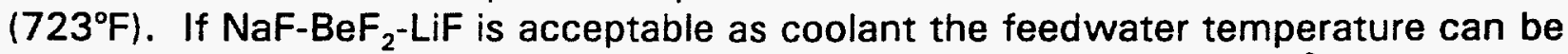
lowered because the liquidus temperature for this salt is $290^{\circ} \mathrm{C}\left(554^{\circ} \mathrm{F}\right)^{3}$. It should be noted that Reference 3 cites in addition to this liquidus temperature another value of $340^{\circ} \mathrm{C}\left(644^{\circ} \mathrm{F}\right)$. The lower value is taken from a Russian study published in 1957 , whereas the higher value is taken from a compilation of phase diagrams published in 1959.

\subsubsection{Steam Generator}

Recommendation: To be consistent with the enhancement of natural circulation flow throughout the heat transport systems, a vertical U-tube steam generator design is recommended with a capacity of $375 \mathrm{MWt}$, that is placed at a higher elevation than the IHX. Two of those steam generator modules will be used for each $750 \mathrm{MWt} A B C$ module.

(vi) It should be noted that ABB-CE's Safe Integral Reactor (SIR) has a primary system design pressure of 2800 psi, and an operating pressure of 2240 psi. The steam pressure is 800 psi. It is also noteworthy that the $320 \mathrm{MWt}$ SIR design employs 12 modular once-through steam generators, each $8.50 \mathrm{~m}$ long.

REVISION 0

$$
4-15
$$

MARCH 1995 
I also strongly recommend to consider small-sized straight-tube, once-through steam generators that are simple in design and can easily be replaced.

\subsubsection{Isolation Valves}

The need for loop isolation has been discussed earlier.

Recommendations: Two sets of isolation valves will be used to isolate the steam generator. One set of valves is installed between $\mathrm{IHX}$ and steam generator to isolate the steam generator from the intermediate coolant loop and any fission product transport coming from the primary loop. A second set of valves will isolate the steam generator from feedwater supply and steam flow to the turbine.

\subsection{Auxiliary Systems}

The following auxiliary systems will be addressed:

- fuel drainage system

- off-gas system

- fuel salt processing system

Other auxiliary systems like backup/emergency on-site power, cell heating, radioactive material disposal systems, storage systems, instrumentation, control and protection systems, etc. will not be addressed here.

\subsubsection{FUEL. DRAINAGE SYSTEM}

Whenever fuel salt has to be drained from the primary system this function has to be accomplished:

- through passive initiation,

- using only gravity forces all the fuel from the primary system has to be drained into a fuel drainage tank,

- with passive decay heat removal in the drain tank.

Recommendation: The fuel drainage system is designed for rapid drainage which provides for a positive emergency shutdown mechanism. The fuel drainage tank is a double-walled tank to ensure containment of radionuclides should a leak develop in the 
drainage tank.

Recommendation: A freeze valve has to be used to initiate fuel drainage from the primary system into the fuel drainage tank. The time required to melt the freeze plug and the time to drain the primary system need to be determined.

Recommendation: One fuel drainage system serves two $750 \mathrm{MWt} A B C$ modules. It is located underground and between two $A B C$ module banks. For a 4-module $A B C$ system, two drainage tanks are required. In addition, one backup container needs to be provided in case one of the drain tanks needs to be drained for repair.

Recommendation: The layout and elevations of the primary system have to facilitate complete fuel drainage via gravity from the primary system after the freeze valve opened.

Recommendation: A fuel drain tank with a convective cooling system is recommended. The fuel salt is stored in a tank. NaK is recommended as coolant; NaF-LiF$\mathrm{BeF}_{2}$ is recommended as backup. The coolant is circulated through the tank by natural convection to an air-cooled tank; a water-cooled heat exchanger is recommended for the backup coolant.

Recommendation: The drain tank is also used to:

- accommodate spill-over fuel from the fuel pump bowl

- serve as a holdup volume for off-gases

It needs to be determined whether or not this drain tank can hold gaseous fission products for longer periods of time and thus reduce the size of the charcoal beds in the off-gas system. Because of temperature limitations charcoal beds could not be placed into the drain tank.

\subsubsection{OFF-GAS SYSTEM}

According to the conceptual design report for the MSBR, for a $2250 \mathrm{MWt}$ off-gas system the gas flows are as follows:

$2.25 \mathrm{scfm}$ from each of the four pump loops $\quad \Rightarrow 9 \mathrm{scfm}$

$0.5 \mathrm{scfm}$ purge gas for each of the pump shafts $\Rightarrow 2 \mathrm{scfm}$ total helium carrier gas flow:

$11 \mathrm{scfm}$ 
Of the total $11 \mathrm{scfm}$ gas flow, the net flow of fission products and materials other than helium is about $0.1 \%$ or $0.01 \mathrm{scfm}$. During a $2 \mathrm{hr}$ period, a total of 0.6 scf of fission products and materials would have accumulated. The decay heat was estimated to $18 \mathrm{MWt}$ accounting for noble metals, radioactive gases and daughters.

For a two-module $A B C$ system with a total of $1500 \mathrm{MWt}$, this decay heat level is about $12 \mathrm{MWt}$.

It is assumed that the fuel drain tank serves as an efficient collector of particulates in the gas (noble metals, salt mist, non-gaseous daughters of the noble gases) and eliminates the use of a particle trap or filter unnecessary.

Recommendation: Two $750 \mathrm{MWt}$ ABC modules share one off-gas system. The main functions performed by the off-gas systems are:

- to allow for the decay of the fission gases $\mathrm{Kr}$ and $\mathrm{Xe}$, and their daughters that have not been removed in the fuel drain tank.

- to oxidize tritium and remove it in a gas cleanup system

- remove the decay heat

It needs to be determined whether there is a need to remove in the gas cleanup system also the stable noble gases and ${ }^{85} \mathrm{Kr}$ that decays with a half-life of 10 years. Furthermore, it needs to be determined how much of the tritium is lost on the way by diffusion through duct and vessel walls.

Recommendation: The off-gas system is similar to that for proposed for the MSBR with the following modifications:

- the holdup time in the drainage tank is increased to allow for more decay and a reduced heat load in the off-gas system

- no particle trap is used after the fuel salt drain tank

- the gases flow to a Xe holdup system for which the holdup time still needs to be determined

- from this holdup system, the gas is sent back to the primary system through a chemical trap and monitor, gas cleanup system, surge tank, compressor, and accumulator.

Recommendation: Double containment, or better, is used in all parts of the system where outleakage could cause a hazard to personnel. The pressures in various parts of the system have to prevent outleakage of hazardous material by, for example, using a high-pressure inert gas blanket in an annulus surrounding the radioactive gases. 


\subsubsection{Fuel Salt Processing}

The fuel processing requirements for the $A B C$ system would be similar to those for the denatured molten salt reactor with once-through fueling. ${ }^{4}$

The processing requirements for the $A B C$ system are far less than for the MSBR. For one, there is no need for the isolation of ${ }^{233} \mathrm{~Pa}$ because it is not present in the molten salt. There is no need for continuous fuel reprocessing to keep the fission product inventory low and instead, advantage can be taken of the high level of fission products that can be accommodated in the fuel salt. As in the MSBR, gaseous fission products are removed from the system and noble metal fission products are expected to plate out (or deposit) on metal surfaces where they do not affect the neutronic performance.

The main reason for fuel salt processing is the removal of trifluoride fission products that have a limited solubility in the fuel salt. Furthermore, it may be necessary to remove from the fuel salt impurities which may arise from corrosion or reaction with other materials. Furthermore, oxygen contamination needs to be removed.

Recommendation: A side stream of fuel salt should be drawn off the fuel drain tank for fuel processing. The processes used still need to be identified and optimized.

\subsection{CONTAINMENT SYSTEM}

The containment system proposed in the following is very robust and possibly overdesigned. However, at least a certain level of protection going beyond that used in conventional reactors seems justified because of the circulation of molten fuel that is laden with fission products.

Recommendation: Instead of a single containment building the $A B C$ containment consists of a series of containment cells for the (1) primary system, (2) IHTS isolation valves and secondary coolant pumps, (3) steam generators with MSIVs, (4) maintenance enclosures on top of the primary system cell and the cell containing the IHTS valves and coolant pumps, (5) one containment building over the primary system cell and the cell containing the IHTS valves and coolant pump and another containment building on top of the steam generator cell. The latter containment building has to be able to withstand a main steam line rupture.

Recommendation: The walls of the containment cells are $8 \mathrm{ft}$ thick and insulated. The 
insulation has to protect the concrete (biological) shielding from excessive temperatures and radiation damage while at the same time provide thermal insulation. The primary system cell which is lined with a Hastelloy $N$ structure, contains the blanket

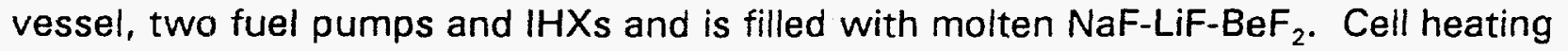
is required to bring the cell temperatures up to the high operating temperatures. Resistance heating can be used but other means to heat the cells might be possible, too. It must be possible to leak-test those structures and to monitor them during operation.

It needs to be determined whether the cell containing the IHTS valves and coolant pumps should also be filled with a molten salt.

Recommendation: Outside the steam generator cell, in the feedwater bay, are two MSIVs. The feedwater bay is not a safety-related structure.

Recommendation: The number of penetrations through containment structures should be kept low. 


\subsection{REFERENCES}

1. Roy C. Robertson (Editor), "Conceptual Design Study of a Single-Fluid Molten-Salt Breeder Reactor", ORNL-4541 (June 1971)

2. J. R. Engel et al.: "Conceptual Design Characteristics of a Denatured Molten Salt Reactor with Once-Through Fueling", ORNL-TM-7207 (July 1980)

3. A. D. Kelmers et al., "Evaluation of Alternate Secondary (and tertiary) Coolants for the Molten-Salt Breeder Reactor", ORNL/TM-5325 (April 1976).

4. J. R. Engel, et al.,"Conceptual Design Characteristics of a Denatured MoltenSalt Reactor with Once-Through Fueling", ORNL-TM-7207 (July 1980) 


\section{PRECONCEPTUAL ABC DESIGN DEFINITION AND SYSTEM CONFIGURATION LAYOUT APPENDIX A}

March 1995

Prepared by

Barthold \& Associates, Inc. 132 Seven Oaks Drive

Knoxville, TN 37922

$$
\text { for }
$$

Los Alamos National Laboratory

under Subcontract 2254V0015-3Y as Amended 


\section{PRECONCEPTUAL}

ABC DESIGN DEFINITION AND SYSTEM CONFIGURATION LAYOUT

\section{APPENDIX A}

March 1995

LIST OF CONTENT

A1: OPERATING CONDITIONS FOR THE STEAM-CYCLE ABC SYSTEM

A2: FLOW RATES AND COMPONENT DIMENSIONS

A3: DRAWINGS FOR THE ABC LAYOUT

A4: IMPACT OF CORE DESIGN PARAMETERS ON CONTAINMENT SIZE

Prepared by

Barthold \& Associates, Inc.

132 Seven Oaks Drive

Knoxville, TN 37922

for

Los Alamos National Laboratory

under Subcontract 2254V0015-3Y as Amended 


\title{
A1: $\quad$ OPERATING CONDITIONS FOR THE STEAM-CYCLE ABC SYSTEM
}

\author{
INTRODUCTION
}

While the MSBR is the point of reference and departure for the ABC system design, it is important to recognize that the design approach for the $A B C$ system differs significantly from that for the MSBR.

\section{Breeding vs Destruction of Fissile Material}

A careful review of the MSBR design shows that this system was a finely tuned breeder design. To achieve a high breeding gain, the carrier salt could only contain constituents with a very low neutron absorption cross section; furthermore, the carrier salt constituents had to promote neutron moderation. Beryllium was one constituent, and lithium another. However, lithium had to be enriched in ${ }^{7} \mathrm{Li}$ to $99.99 \%$ to be acceptable. Sodium was excluded because of its "high" neutron absorption cross section (the $2200 \mathrm{~m} / \mathrm{s}$ value for sodium is 50 times higher than for beryllium). A gas sparging system to effectively remove $\mathrm{Xe}$ and $\mathrm{Kr}$ from the fuel salt had a very high priority to keep low any breeding penalty. Fission products had to be removed continuously and ${ }^{233} \mathrm{~Pa}$ had to be isolated so as not to lose it due to neutron absorptions in the reactor.

All these issues are of low priority for an $A B C$ system whose mission it is to destroy as effectively as possible the fissile material inserted into the core without producing any new fissile material.

\section{Optimistic vs Realistic Expectations}

During the 1950's and 1960's it was expected that nuclear reactors would dominate the electricity-generating capacity that had to be added to the grid. Projections for the installed nuclear capacity by the year 2000 exceeded 2000 GWe. To install such a capacity and ensure fuel supplies for the life of the plants, and to meet a rapidly increasing demand for nuclear power, the ability to breed fuel in a reactor had a very high priority.

The MSBR of the late 1960's and early 1970's was in competition with the LMFBR for breeding and cost performance. Breeding gains for oxide- and metal fueled LMFBRs were expected to be in the range of $0.4-0.55$. Oxide- and metal-fuei LMFBRs were expected to have doubling times of 15 years and less than 10 years, 
respectively. However, during the 1980's those projected doubling times had risen to $25-30$ years, and 20 years, respectively.

Equally optimistic were the operating conditions for the breeders designed during the late 1960's and early 1970's. Mixed mean outlet temperatures were expected to be in the $1100-1150^{\circ} \mathrm{F}$ range, but dropped to the $875-930^{\circ} \mathrm{F}$ range during the $1980^{\prime} \mathrm{s}$ (the CRBRP had a mixed mean outlet temperature of $975^{\circ} \mathrm{F}$ ).

Thermal efficiencies of $40-45 \%$ were expected during the 1960's, but the ALMR thermal efficiency was projected to be in the $35-36 \%$ range. Fuel cycle cost was expected to be less than 0.5 mills $/ \mathrm{kWh}$, and capital cost was expected to be in the $\$ 100-120 / \mathrm{kWe}$ range (some PWR turn-key plants were sold at that time at a fixed capital cost of $\$ 85 / \mathrm{kWe}$ installed). We know today that fuel cycle cost are a factor 10 higher, and capital cost are a factor 20 and more higher.

It is, therefore, not surprising that the MSBR with a somewhat marginal breeding gain of only 0.06 and a projected doubling time of over 20 years, to be a successful competitor, had to have low capital cost. This was achieved by keeping fissile inventory cost very low through frequent reprocessing and reducing the out-of-pile inventory, and aiming for a very high thermal efficiency. Duplicating the Bull Run Steam Plant conditions promised a very high thermal efficiency of $44.5 \%$, however, at the expense of 3800 psi pressure ${ }^{1}$.

\section{Safety Then and Now}

During the 1960's and early 1970's, being able to shut down the reactor in case of an accident was the major safety concern. Safety reports from that time explained, for example, that fuel assembly melting could occur, albeit at a low probability. The reactor would then be shut down, the damaged assembly would be removed and after a short time, upon completion of repair and decontamination work, the reactor would be restarted.

Shutdown reliability is still a major design issue for today's reactors and assurance has to be provided that failure to shut down a reactor has to be an event that is outside the design basis. The major safety concerns today, however, are with reliable decay heat removal in case of an accident and, after the reactor is shut down, the availability of service water as the ultimate heat sink (or a cooling tower), the loss of coolant, and

(1) The MSBR designers were aware that using the Bull Run Steam Plant conditions would introduce design complications and that it might be worthwhile to be less aggressive in terms of steam pressure in favor of design simplification. 
overpower transients resulting from accidents. The early reactor designs showed little in terms of passive and inherent safety features which, today, are mandated for advanced reactors by the NRC. Economics is viewed in the context of safety and reactor availability.

Therefore, for the $A B C$ system design, safety came first, and $A B C$ systems economics has to be achieved within the safety constraints. 


\section{A1.0 Operating Conditions for the ABC Steam Cycle}

\subsection{ABC primary system operating conditions}

The operating conditions for the $A B C$ system are constrained by the carrier salt selections for the fuel and coolant.

\subsection{1 fuel salt compositions}

For molten salt reactors two chemical fuel forms have been considered, fluorides and chlorides. Fluoride salts have the ability to dissolve large amounts of thorium and uranium fluorides as well as fission product fluorides, show low viscosities and a low vapor pressure at high temperatures. Uranium can easily be separated from the salt in a fluoride volatility process that stems from the high volatility of $\mathrm{UF}_{6}$ (boiling point of less than $100^{\circ} \mathrm{C}$ ) and the low volatility of $\mathrm{UF}_{4}$ (boiling temperature over $1400^{\circ} \mathrm{C}$ ).

Chlorides are less well known than fluorides. Because chlorine is less reactive than fluorine, it is expected that not all fission products would be available in the melt in chloride form. Furthermore, as shown in Table 1, chlorides would have to use enriched chlorine because the neutron absorption cross section for natural chlorine is very high.

Therefore, only the fluoride form of salts has been pursued as a suitable form for reactor applications.

The following constituents for the fuel salt have to be considered:

$$
\begin{aligned}
& \mathrm{LiF} \\
& \mathrm{BeF}_{2} \\
& \mathrm{ZrF}_{4} \\
& \mathrm{NaF} \\
& \mathrm{PuF}_{3}
\end{aligned}
$$

Because the $\mathrm{PuF}_{3}$ concentration will be initially less than 0.05 mole \%, it is assumed that, at least initially, the material properties of the fuel salt are determined by the carrier salt. At one time bismuth fluoride had also been considered. However, because of its reduction by structural materials, it was removed from the list of contenders. 
The preferred configuration for molten salt fuel is a thermal neutron spectrum. This will result in a much lower fissile inventory than in a fast configuration. Thermal spectrum configurations can be achieved by either using an internal graphite moderator, or by surrounding an unmoderated core of small dimensions with a thick graphite reflector.

Table 1: Elements/Isotopes Suitable for High-Temperature Fuels

\begin{tabular}{|l|l||}
\hline MATERIAL & \multicolumn{1}{|c|}{$\sigma_{1}$} \\
& (barns at $2200 \mathrm{~m} / \mathrm{sec}$ \\
\hline \hline Nitrogen-15 & 0.000024 \\
Oxygen & 0.0002 \\
Deuterium & 0.00057 \\
Carbon & 0.0033 \\
Fluorine & 0.009 \\
Beryllium & 0.010 \\
Bismuth & 0.032 \\
Lithium-7 & 0.033 \\
Boron-11 & 0.05 \\
Magnesium & 0.063 \\
Silicon & 0.13 \\
Lead & 0.17 \\
Zirconium & 0.18 \\
Phosphorus & 0.21 \\
Aluminum & 0.23 \\
Hydrogen & 0.33 \\
Calcium & 0.43 \\
Sulfur & 0.49 \\
Sodium & 0.53 \\
Chlorine-37 & 0.56 \\
Tin & 0.6 \\
Cerium & 0.7 \\
Rubidium & 0.7 \\
Chlorine (nat.) & 33.8 \\
Lithium (nat.) & 71 \\
\hline
\end{tabular}

A fast spectrum is difficult to achieve with a molten salt based on fluorides. The German MOSEL project was based on uranium, sodium and beryllium fluorides and achieved only an epithermal spectrum. The MOSEL core was surrounded by a blanket fluid consisting of the same carrier salt but with thorium fluoride as the fertile material. 
For plutonium destruction a fast spectrum might not be optimal because of the solubility limits for $\mathrm{PuF}_{3}$. As fission products build up the plutonium inventory has to increase to maintain the same eigenvalue. The fissile inventory in a fast molten salt reactor would start out very high but then increase less steeply as in a thermal system because of the lower reactivity worth of fission products in such a spectrum. However, it is expected that the solubility limit for $\mathrm{PuF}_{3}$ (and the rare earth trifluorides) is reached earlier than in a thermal system.

The following mixtures of fluorides are candidates for fuel carrier salt:

$$
\begin{aligned}
& \text { LiF-BeF } \\
& \text { LiF-NaF-BeF }_{2} \\
& \text { NaF-BeF }_{2}
\end{aligned}
$$

Additions of $\mathrm{ZrF}_{4}$ have been considered to avoid fuel precipitation in the presence of oxidants.

Table 2 summarizes the material properties of these salts and two additional salts:

$$
\begin{aligned}
& \text { LiF-BeF } \\
& \text { LiF-NaF-BeF } \\
& \text { NaF-BeF }_{2} \\
& \text { LiF-BeF }_{2}-\text { ZrF }_{4}-\text { UF }_{4} \\
& \text { LiF-BeF }_{2}-\mathrm{ThF}_{4}-\mathrm{UF}_{4}
\end{aligned}
$$

The second to last salt is the MSRE fuel salt that was shown for comparison purposes and to illustrate the effect of a $\mathrm{ZrF}_{4}$ addition. The last salt is the MSBR salt shown for comparison only.

\section{Option 1: $\quad$ LiF-BeF $_{2}$}

This was the fuel carrier salt and coolant salt for the MSRE. The MSRE operation with partially enriched uranium produced about $500 \mathrm{~g}$ of plutonium and analyses of samples showed that all had stayed with the salt. This salt is well characterized. It was also the carrier salt for the MSBR fuel. This salt contains lithium that needs to be enriched in $\mathrm{Li}-7$ which is costly. Both $\mathrm{Li}-6$ and $\mathrm{Li}-7$ are the main sources for tritium production.

\section{Option 2: $\quad$ LiF-NaF-BeF $_{2}$}

This salt was not considered for the MSBR because it contains sodium which is a strong absorber. However, its liquidus temperature is $130^{\circ} \mathrm{C}$ lower than for the option 
1 carrier salt. This salt contains lithium that needs to be enriched which is costly. Lithium is the main source for tritium production.

\section{Option 3: $\quad$ NaF-BeF $_{2}$}

This salt was not considered for the MSBR because it contains sodium which is a strong neutron absorber. Its liquidus temperature is very close to that of the option 2 carrier salt. Its viscosity is higher (the viscosity of water at $600^{\circ} \mathrm{F}$ is $0.086 \mathrm{cp}$; at room temperature it is about $1 \mathrm{cp}$.). The are no significant differences in the other physical properties.

\section{Option 4: Either of the previous options with a $\mathrm{ZrF}_{4}$ addition}

Table 2 shows that the addition of a small amount of $\mathrm{ZrF}_{4}$ does not change properties significantly. The change in viscosity might very well reflect the reduction in $B_{2} F_{2}$ and to a lesser extent the addition of $\mathrm{ZrF}_{4}$.

\subsection{2 coolant salt compositions}

Commonly used in other reactors are either water, sodium or helium coolants. However, they are not suited for molten salt reactor applications.

Water leakage into the fuel would lead to the precipitation of fuel and the production of high-pressure steam, hydrogen and oxygen.

Sodium reacts with the fuel in that it would reduce all cations except lithium. Beryllium metal could alloy with structural metals. Pu could precipitate in the primary system and could later lead to an unacceptably high increase in reactivity. Sodium also reacts vigorously with water and steam and produces hydrogen, sodium hydroxide, and sodium oxide.

The use of helium would require a high operating pressure that would negate one of the advantages of the molten salt reactor, namely its low operating pressure characteristic. In case helium would leak into the fuel salt, unacceptably high power surges could result due to the positive reactivity coefficient for voids or bubbles.

Therefore, different types of coolants have to be investigated.

The following candidate compositions for coolant salt are shown in Table 3 and briefly discussed below: 


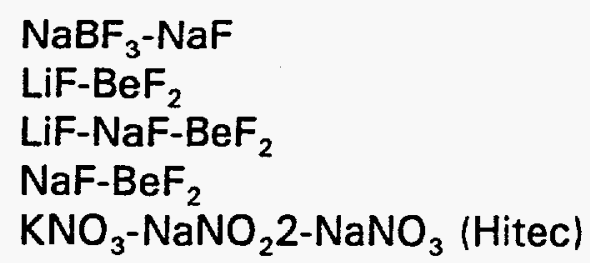

\section{Option 1: $\quad \mathrm{NaBF}_{3}-\mathrm{NaF}$}

The main reasons for selecting sodium fluoroborate instead of $\mathrm{LiF}_{-} \mathrm{BeF}_{2}$ as the MSBR coolant were:

1. avoiding the high cost for using enriched $\mathrm{Li}-7$

2. avoiding the high freezing point of the MSRE coolant

The principal advantages of sodium fluoroborate are the low cost, low viscosity, and its capability to trap tritium. There are claims that tritium would be completely trapped in this coolant, however, the experimental data available for review do not support this claim. In its pure form, it is not corrosive to all major or minor constituents of structural metal alloys.

The chief disadvantage of this coolant arises from its mixing with fuel salt during an accident. This leads to the generation of $\mathrm{BF}_{3}$ gas and probably a redistribution of fissile material between immiscible phases. Other disadvantages of this coolant salt are its thermal decomposition that produces $\mathrm{BF}_{3}$, and its reaction with steam. In case of steam inleakage, metal corrosion can be greatly increased. In case the coolant leaks into the steam system, the $\mathrm{pH}$ of water will be changed due to the formation of $\mathrm{HF}$ with fluoride-containing salts and the water will also contain ppm concentrations of fluorides. There is the potential for stress-corrosion cracking.

The decomposition of the coolant leaves most of the $\mathrm{BF}_{3}$ in the salt, but some of it can be swept out of the pump bowl by the required sweep gas. If $\mathrm{BF}_{3}$ is not added, the coolant will slowly change its composition and increase in freezing point. The $\mathrm{He}^{-\mathrm{BF}_{3}}$ mixture cannot be continuously discharged because of the toxicity and chemical reactivity of $\mathrm{BF}_{3}$ and the need to recover helium. If $\mathrm{BF}_{3}$ is released into the off-gas system, it may react with the charcoal beds.

\section{Option 2: $\quad{ }^{7}{ }_{\text {LiF-BeF }}$}

This salt is fully compatible with the fuel salt as demonstrated in the MSRE. Lithium is present in form of $\mathrm{Li}-7$ to prevent discarding all fuel salt in case of a leak of the 
coolant into the fuel salt.

In the MSRE, heat was transferred from the coolant at $546^{\circ} \mathrm{C}\left(1015^{\circ} \mathrm{F}\right)$ to a lowefficiency, air-cooled radiator. In the MSBR, the coolant has to transport the heat to portions of a steam system at much lower temperatures than $546^{\circ} \mathrm{C}$. For coolants with LiF contents of $60-67$ mole \%, the freezing points are between 440 and 460 ${ }^{\circ} \mathrm{C}$. To prevent this coolant salt from freezing in the steam-producing equipment would require an abnormally high feedwater temperature, resulting in a decrease in thermal efficiency. It had been estimated that about a $10 \%$ drop in thermal efficiency would occur in a supercritical steam cycle when the feedwater temperature would have to be increased from $700^{\circ} \mathrm{F}\left(371^{\circ} \mathrm{C}\right)$ to $800^{\circ} \mathrm{F}\left(426^{\circ} \mathrm{C}\right)$.

Furthermore, this coolant is ineffective in trapping tritium.

\section{Option 3: $\quad{ }^{7}$ LiF-NaF-BeF 2}

This coolant is compatible with the fuel salt. It has a low freezing point (that is even below that for sodium fluoroborate), and a low vapor pressure. In its pure form, it is not corrosive to all major or minor constituents of structural metal alloys.

Its disadvantages are its high cost due to the enrichment of Li, its increased corrosivity when mixed with steam (similar to that for sodium fluoroborate), and its inefficiency in trapping tritium.

\section{Option 4: $\quad{\underline{\mathrm{NaF}}-\mathrm{BeF}_{2}}$}

Based on material properties, this seems to be a very desirable coolant salt. It has not been pursued for MSBR applications, probably because (1) in case of a leak into the fuel, a complex cleanup would be required, and (2) NaF could not be present in a marginal breeder like the MSBR. Furthermore, its ability to trap tritium has not been investigated.

\section{Option 5: $\quad \underline{\mathrm{KNO}}_{3}-\mathrm{NaNO}_{2}{ }_{2-\mathrm{NaNO}_{3}}$ (Hitec)}

The main advantages for this coolant are (1) its low melting point, (2) it is inexpensive and (3) it allows the use of carbon steel up to $850^{\circ} \mathrm{F}$, and above this temperature stainless steel. It is also expected to trap tritium.

Its disadvantages are its violent reaction with graphite if a leak occurred in the IHX, its stability in a radiation field at high temperatures and the need for salt processing in case of a leak. 


\subsection{3 primary system options}

Because of its violent reaction with moderator or reflector graphite, Hitec is eliminated from any consideration in the primary system. The other fuel-coolant combinations are briefly characterized in Table 4.

For the characterization of the fuel-coolant combination the following issues have to be addressed:

- do fuel and coolant react when mixed?

- is tritium produced in the fuel?

- if tritium is produced, does the coolant trap the tritium?

- if coolant leaks into fuel, is fuel processing required?

- melting point of coolant

- cost of coolant and fuel carrier salts

- is the coolant salt stable?

- is the fuel salt a strong neutron absorber?

These topics are briefly summarized in Table. 4.

\subsection{4 proposed primary system operating conditions}

Based on the evaluation of the different fuel-coolant salt combinations, at this time, it would be prudent to use:

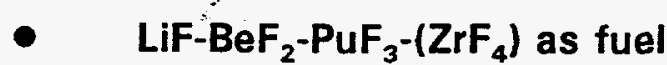 \\ - $\mathrm{NaBF}_{3}-\mathrm{NaF}$ as coolant}

These two salts have been investigated extensively under the MSBR Program. They are, by and large, well characterized. However, these choices are less than optimal for a Pu destroyer.

It is recommended to investigate also:

$$
\begin{aligned}
& \text { - } \quad \mathrm{NaF}_{-}-\mathrm{BeF}_{2}-\mathrm{PuF}_{3} \text { as fuel } \\
& \text { - } \quad \mathrm{NaF}-\mathrm{BeF}_{2} \text { as coolant. }
\end{aligned}
$$

This combination has the following advantages: 
1. for all practical purposes, no tritium is produced

2. the melting point for this fuel is $220^{\circ} \mathrm{F}$ lower than for the LiF-BeF ${ }_{2}$-based fuel

3. the melting point of this coolant is slightly lower than that for the sodium fluoroborate coolant

4. fuel and coolant are fully compatible

5 the coolant is thermally stable

6. the cost for the carrier salt is low; no enrichment services are required

Potential disadvantages are:

1. sodium is a much stronger neutron absorber than lithium

2. the neutron spectrum is slightly harder than for the LiF-BeF2 carrier salt which requires a slightly higher Pu inventory, but results in slightly lower negative reactivity worth of the fission products

However, it is conceivable that the advantages of the NaF-BeF ${ }_{2}$-based salts can far outweigh the disadvantages. In regard to inventory requirements, later in life, the fissile inventory requirements are governed by the accumulated fission products in the core. I.e., the hardening of the spectrum due to the substitution of $\mathrm{Li}$ by $\mathrm{Na}$ has little effect. 
PRECONCEPTUAL ABC DESIGN DEFINITION AND SYSTEM CONFIGURATION LAYOUT

Table 2: Properties of Different Fuel Carrier Salts

\begin{tabular}{|c|c|c|c|c|c|}
\hline $\begin{array}{l}\text { Composition } \\
\text { (mole \%) }\end{array}$ & $\begin{array}{ll}\text { LiF* } & (65) \\
\text { BèF2 } & (29.1) \\
\text { ZrF4 } & (5) \\
\text { UF4 } & (0.9)\end{array}$ & $\begin{array}{ll}\mathrm{LiF} & (66) \\
\text { BeF2 } & (34)\end{array}$ & $\begin{array}{ll}\text { LiF } & (23) \\
\text { NaF } & (41) \\
\text { BeF2 } & (36)\end{array}$ & $\begin{array}{ll}\text { NaF } & (57) \\
\text { BeF2 } & (43)\end{array}$ & $\begin{array}{ll}\text { LiF** } & (71.7) \\
\text { BeF2 } & (16) \\
\text { ThF4 } & (12) \\
\text { UF4 } & (0.3)\end{array}$ \\
\hline Liquidus Temperature, $\mathrm{C}(\mathrm{F})$ & $434(813)$ & $458(856)$ & $328(622)$ & $340(634)$ & $500(932)$ \\
\hline \multicolumn{6}{|l|}{ Physical Properties at $850 \mathrm{~F}(454 \mathrm{C})$} \\
\hline Density $(\mid \mathrm{b} / \mathrm{ft} 3)$ & 141 & 125.5 & 136 & 139 & 206 \\
\hline Heat Capacity, (Btu-lb-1- F-1) & 0.47 & 0.57 & 0.47 & 0.44 & 0.33 \\
\hline Viscosity (centipoise) & 10 & 40.4 & 40 & 65 & 12 \\
\hline Vapor Pressure at $1125 \mathrm{~F}(607 \mathrm{C})$ in $(\mathrm{mm})$ & negligible & negligible & negligible & negligible & negligible \\
\hline Thermal Conductivity, (watts/ C-cm) & 0.01 . & 0.01 & 0.01 & 0.01 & 0.008 \\
\hline
\end{tabular}

* MSRE fuel salt; cited because it shows the effect of the $\mathrm{ZrF} 4$ addition on properties

* MSBR fuel salt composition is shown for comparison only 


\section{PRECONCEPTUAL ABC DESIGN DEFINITION AND SYSTEM CONFIGURATION LAYOUT}

Table 3: Properties of Different Coolant Salts

\begin{tabular}{|c|c|c|c|c|c|}
\hline $\begin{array}{l}\text { Composition } \\
\text { (mole \%) }\end{array}$ & $\begin{array}{ll}\text { NaBF3 } & (92) \\
\text { NaF: } & (8)\end{array}$ & $\begin{array}{ll}\text { Lif } & (66) \\
\text { BeF2 } & (34)\end{array}$ & $\begin{array}{ll}\mathrm{LiF} & (23) \\
\text { NaF } & (41) \\
\text { BeF2 } & (36)\end{array}$ & $\begin{array}{ll}\text { NaF } & (57) \\
\text { BeF2 } & (43)\end{array}$ & $\begin{array}{l}\text { KNO3 (53) } \\
\text { NaNO2 (40) } \\
\text { NaNO3 (7) }\end{array}$ \\
\hline Liquidus Temperature, $\mathrm{C}(\mathrm{F})$ & $385(725)$ & $458(856)$ & $328(622)$ & $340(634)$ & $109(228)$ \\
\hline \multicolumn{6}{|l|}{ Physical Properties at $850 \mathrm{~F}(454 \mathrm{C})$} \\
\hline Density (lb/ft3) & 121 & 125.5 & 136 & 139 & 108 \\
\hline Heat Capacity, (Btu-lb-1- F-1) & 0.36 & 0.57 & 0.47 & 0.44 & 0.37 \\
\hline Viscosity (centipoise) & 2 & 40.4 & 40 & 65 & 3.1 \\
\hline Vapor Pressure at $1125 \mathrm{~F}^{\prime}(607 \mathrm{C})$ in $(\mathrm{mm})$ & $200^{*}$ & negligible & negligible & negligible & negligible \\
\hline Thermal Conductivity, (watts/ C-cm) & 0.005 & 0.01 & 0.01 & 0.01 & 0.33 \\
\hline
\end{tabular}

* pressure of $\mathrm{BF}_{3}$ in equilibrium with this melt composition 
PRECONCEPTUAL ABC DESIGN DEFINITION AND SYSTEM CONFIGURATION LAYOUT

Table 4: Primary System Options Characteristics

\begin{tabular}{|l|l|l|l||}
\hline FUEL & COOLANT & ADVANTAGES & DISADVANTAGES \\
\hline \hline LiF-BeF2-PuF3 & LiF-BeF2 & $\begin{array}{l}\text { extensive MSRE experience } \\
\text { compatibility } \\
\text { no processing required in case of leaks }\end{array}$ & $\begin{array}{l}\text { high cost fuel and coolant } \\
\text { high melting point } \\
\text { tritium production } \\
\text { no tritium trapping }\end{array}$ \\
\hline LiF-BeF2-PuF3 & NaBF3-NaF & $\begin{array}{l}\text { extensive fuel experience } \\
\text { low coolant melting point } \\
\text { tritium trapping in coolant } \\
\text { low cost coolant }\end{array}$ & $\begin{array}{l}\text { high cost fuel and coolant } \\
\text { fuel-coolant reaction } \\
\text { thermal decomposition of coolant } \\
\text { handling of BF3 } \\
\text { tritium production } \\
\text { fuel processing in case of leaks }\end{array}$ \\
\hline LiF-BeF2-PuF3 & NaF-BeF2-LiF & $\begin{array}{l}\text { extensive fuel experience } \\
\text { fuel/coolant compatibility } \\
\text { low coolant melting point } \\
\text { high cost for 7Li }\end{array}$ & $\begin{array}{l}\text { high cost fuel and coolant } \\
\text { tritium production } \\
\text { no tritium trapping } \\
\text { fuel processing in case of leaks }\end{array}$ \\
\hline LiF-BeF2-PuF3 & NaF-BeF2 & $\begin{array}{l}\text { extensive fuel experience } \\
\text { fuel/coolant compatibility } \\
\text { low cooląt melting point } \\
\text { low coolant cost }\end{array}$ & $\begin{array}{l}\text { high cost fuel and coolant } \\
\text { tritium production } \\
\text { no tritium trapping } \\
\text { fuel processing in case of leaks }\end{array}$ \\
\hline NaF-BeP2-LiF-PuF3 & LiF-BeF2 & $\begin{array}{l}\text { part of LiF is replaced by NaF } \\
\text { lower cost, less tritium production) } \\
\text { fuel/coolant compatible } \\
\text { no processing required in case of a leak }\end{array}$ & $\begin{array}{l}\text { high melting point coolant } \\
\text { high cost coolant } \\
\text { tritium production } \\
\text { no tritium trapping }\end{array}$ \\
\hline
\end{tabular}




\section{PRECONCEPTUAL ABC DESIGN DEFINITION AND SYSTEM CONFIGURATION LAYOUT}

\begin{tabular}{|c|c|c|c|}
\hline NaF-BeF2-LiF-PuF3 & NaBF3-NaF & $\begin{array}{l}\text { part of LiF is replaced by } \mathrm{NaF} \\
\text { (lower cost, less tritium production) } \\
\text { low melting point coolant } \\
\text { tritium trapping in coolant } \\
\text { low cost coolant }\end{array}$ & $\begin{array}{l}\text { fuel-coolant reaction } \\
\text { thermal decomposition of coolant } \\
\text { handling of BF3 } \\
\text { tritium production } \\
\text { fuel processing in case of leak }\end{array}$ \\
\hline NaF-BeF2-LiF-PuF3 & NaF-BeF2-LiF & $\begin{array}{l}\text { part of LiF is replaced by } \mathrm{NaF} \\
\text { (lower cost, less tritium production) } \\
\text { low melting point coolant } \\
\text { low cost coolant } \\
\text { fuel/coolant compatible }\end{array}$ & $\begin{array}{l}\text { high cost coolant } \\
\text { tritium production } \\
\text { no tritium trapping }\end{array}$ \\
\hline NaF-BeF2-LiF-PuF3 & $\begin{array}{c}\text { NaF-BeF2 } \\
\vdots \\
\vdots\end{array}$ & $\begin{array}{l}\text { part of LiF is replaced by } \mathrm{NaF} \\
\text { (lower cost, less tritium production) } \\
\text { low melting point coolant } \\
\text { fuel/coolant compatible }\end{array}$ & $\begin{array}{l}\text { tritium production } \\
\text { no tritium trapping }\end{array}$ \\
\hline NaF-BeF2-PuF3 & LiF-BeF2 & $\begin{array}{l}\text { low melting point fuel } \\
\text { no tritium production } \\
\text { fuel/coolant compatible } \\
\text { low cost fuel. }\end{array}$ & $\begin{array}{l}\text { high cost coolant } \\
\text { high melting point coolant } \\
\text { sodium absorptions } \\
\text { fuel processing in case of leaks }\end{array}$ \\
\hline NaF-BeF2-PuF3 & NaBF3-NaF & $\begin{array}{l}\text { low melting point fuel } \\
\text { no tritium production } \\
\text { low cost fuel } \\
\text { low cost coolant }\end{array}$ & $\begin{array}{l}\text { fuel/coolant reaction } \\
\text { thermal decomposition of coolant } \\
\text { handling of BF3 } \\
\text { fuel processing in case of leaks }\end{array}$ \\
\hline NaF-BeF2-PuF3 & NaF-BeF2-LiF & $\begin{array}{l}\text { low melting point fuel } \\
\text { no tritium production } \\
\text { low cost fuel } \\
\text { fuel/coolant compatible }\end{array}$ & $\begin{array}{l}\text { high cost coolant } \\
\text { sodium absorptions }\end{array}$ \\
\hline
\end{tabular}


PRECONCEPTUAL ABC DESIGN DEFINITION AND SYSTEM CONFIGURATION LAYOUT

\begin{tabular}{|l|l|l|l|}
\hline NaF-BeF2-PuF3 & NaF-BeF2 & $\begin{array}{l}\text { low melting point fuel } \\
\text { low melting point coolant } \\
\text { no tritium production } \\
\text { low cost fuel } \\
\text { low cost coolant } \\
\text { fuel/coolant compatible }\end{array}$ & \\
\hline
\end{tabular}




\section{2 evaluation of steam cycle conditions}

At the time different breeder options were considered (i.e., the late 1960's), the LMFBR fuel cycle required a large centrally located reprocessing and refabrication plant that served between 25-50 GWe of installed capacity. This lowered the unit cost for reprocessing and refabrication and was one of the reasons why an EBR-II-type breeder with metallic fuel and an integrated fuel cycle was eliminated. Not unlike the EBR-II-type breeder, the MSBR was proposed as a breeder with its own reprocessing plant. To offset any cost penalty coming from the larger capital investment, the MSBR designers aimed for as high a thermal efficiency as possible to reduce power cost.

\subsubsection{MSBR supercritical steam cycle}

The MSBR copied the steam conditions for the Bull Run Steam Plant, a very large coalfired electricity generating plant just outside of Oak Ridge, $\mathrm{TN}^{2}$. Table 5 shows the steam conditions and steam generator design for the MSBR.

When applied to the MSBR this supercritical steam cycle yielded a net plant thermal efficiency of $44.4 \%$.

However, there were particular requirements for the MSBR. The feedwater supplied to the steam generator had to be at a temperature high enough to avoid coolant-salt freezing. Tentatively, this temperature had been set at $700^{\circ} \mathrm{F}\left(371^{\circ} \mathrm{C}\right)$. It was also assumed that the cold reheat steam must be preheated to $650^{\circ} \mathrm{F}$ before it enters the reheaters. These constraints led to the selection of a system in which the final stage of feedwater heating is by direct mixing with high-pressure steam. This process established the need for pressure-booster pumps in the feedwater line, because after the feedwater is heated to about $700^{\circ} \mathrm{F}$ in the mixing chamber, its pressure must be raised to that of the steam generator inlet pressure of about 3800 psia.

The MSBR required that about $5.1 \times 10^{6} \mathrm{lb} / \mathrm{hr}$ of $551^{\circ} \mathrm{F}$ steam leaving the highpressure turbine exhaust be preheated to about $650^{\circ} \mathrm{F}$ before it enters the reheaters. The arrangement that had been proposed is to reheat the steam by heat exchange with steam at steam generator exit conditions of 3600 psia and $1000^{\circ} \mathrm{F}$. The flowsheet for the supercritical-pressure cycle with feedwater heated by mixing is shown in Fig. 1.

2 This $950 \mathrm{MWe}$ plant supplies steam at $3500 \mathrm{psia}$ and $1000 \mathrm{~F}$ to the turbine throttle, with a reheat to $1000 \mathrm{~F}$. 
It is not clear whether the use of reheat and its improvement in thermal efficiency is sufficiently cost-effective to offset the added complexity and cost for this system. If reheat is not used, external moisture separators are required to prevent excessive moisture in the last stages of the low-pressure turbines. For the MSBR it was tentatively concluded that reheat provides for a somewhat better turbine performance than moisture separation. However, ORNL-4541 makes reference to an LMFBR study of a $2400 \mathrm{psig}, 900^{\circ} \mathrm{F} / 900^{\circ} \mathrm{F}$ steam cycle, comparing moisture separation and steam reheat that concluded that the economic gain for reheat was not sufficient to offset the added complexities and reduction in plant availability.

It is recommended to investigate the reheat cycle in more detail because its elimination would lead to a substantial system simplification through the elimination of the reheaters, the reheat steam preheaters, and the flow proportioners that divide the coolant salt flow between the steam generators and the reheaters, the latter ones being large heat exchangers with coolant salt on the shell side and steam on the tube side.

\subsubsection{MSBR subcritical steam cycle}

During the design of the MSBR it was recognized that the supercritical steam cycle with 3800 psig pressure might be too high for a nuclear power plant, especially for a low-pressure system like the MSBR. A subcritical steam system was investigated for the MSBR with the following results ${ }^{3}$ :

\begin{tabular}{|c|c|c|}
\hline$\therefore$ & $\begin{array}{l}\text { Supereritical } \\
\text { Cycle }\end{array}$ & $\begin{array}{l}\text { Subcritical } \\
\text { Cycle }\end{array}$ \\
\hline Nominal feed temperature to steam generator, ${ }^{\circ} \mathrm{F}$ & & \\
\hline Mixing pressure, nominal & 3500 & 2600 \\
\hline $\begin{array}{l}\text { Booster pump or steam compressor discharge } \\
\text { pressure, psia }\end{array}$ & 3800 & 2900 \\
\hline $\begin{array}{l}\text { Booster pump or steam compressor power } \\
\text { requirements, } \mathrm{MWe}\end{array}$ & 7.4 & 52 \\
\hline Steam flow through steam generator, $\mathrm{lb} / \mathrm{hr}$ & $9.5 \times 10 E+6$ & $19 \times 10 E+6$ \\
\hline Overall thermal efficiency, \% & 44.5 & 41.1 \\
\hline
\end{tabular}


The subcritical steam cycle is a modified Loeffler cycle shown in Fig. 2. Both cycles use preheating of the cold steam and subsequent reheat. The difference comes from the heating of the feedwater in a subcritical-pressure cycle where the water is being converted to superheated steam in the drum and then compressed and blown into the steam generator that, in essence, is used as a superheater. Instead of the booster pumps used in the supercritical cycle, steam compressors are required to raise the steam pressure.

For both the supercritical and subcritical cycles, other ways to heat the feedwater need to be explored. Among them the use of a high-pressure heat exchanger the heat the feedwater to $700^{\circ} \mathrm{F}$.

The effect of feedwater temperature on performance of the supercritical steam cycle for the MSBR has also been investigated with the following results ${ }^{4}$ :

\begin{tabular}{clll}
$\begin{array}{l}\text { Nominal Feed } \\
\text { Temperature, }{ }^{\circ} \mathrm{F}\end{array}$ & $\begin{array}{l}\text { Booster Pump } \\
\text { Work, MWe }\end{array}$ & $\begin{array}{l}\text { Steam Generator } \\
\text { Flow Rate, lb/hr }\end{array}$ & $\begin{array}{l}\text { Net Plant } \\
\text { Efficiency, \% }\end{array}$ \\
\hline 580 & none required & $\begin{array}{l}7.4 \times 10 \mathrm{E}+6 \\
9.5 \times 10 \mathrm{E}+6\end{array}$ & 44.9 \\
700 & 7.4 & $28 \times 10 \mathrm{E}+6$ & 44.5 \\
800 & 87 & 41.3 \\
\hline
\end{tabular}

The case with a feedwater temperature of $580^{\circ} \mathrm{F}$ assumes that this is about the highest feed water temperature that can be attained by regenerative feed water heating. In this case, no special mixer or booster pump would be required, and it was assumed that the reheat steam would not require preheating. For the 700 and $800^{\circ} \mathrm{F}$ feedwater cases, the feedwater is heated by mixing with steam from reheat steam preheaters. The higher the feedwater temperature has to be raised, the higher are the power requirements for the booster pumps and the steam generator flow rates, but the lower are the net plant thermal efficiencies.

4 Table 5.4 taken from ORNL 4541 (June 1971) 


\subsection{3 other steam cycle conditions}

Table 5 summarizes the steam cycle conditions for the CRBRP, the ALMR, CANDU 3 and CANDU Pickering. Among those listed, only CANDU Pickering has been in operation. It is noteworthy that the advanced reactors have by far the largest steam generator capacities.

The size of the MSBR steam generator was prudently selected. It was realized that about 3750 psia fluid pressure on the inside of the tubes imposes very severe environments on the heads and tube sheets. This led to the decision to keep the shell diameter at 18 inches to keep stresses within more tolerable limits. For the otherwise very advanced steam cycle (and because of it), the steam generator size was kept at $121 \mathrm{MW}$, which is the smallest of all the sizes listed.

\subsection{4 proposed steam cycle conditions for the ABC}

Instead of a horizontal U-tube steam generator design, a vertical U-tube design is proposed similar to that used in CANDU (see Fig. 3)

The following steam cycle conditions are proposed:

intermediate coolant

inlet temperature, ${ }^{\circ} \mathrm{F} \quad 1150$

outlet temperature, ${ }^{\circ} \mathrm{F} \quad 850$

feedwater/steam

inlet temperature, ${ }^{\circ} \mathrm{F} \quad 700$

outlet temperature, ${ }^{\circ} \mathrm{F} 1000$

steam pressure, psia $\quad 1000$

These are tentative conditions mostly dictated by safety considerations. Unless it can be justified, no reheat should be employed.

The steam pressure most likely has to be raised, perhaps even significantly (like to 2400 psia) to achieve a high plant efficiency. However, the safety implications should be assessed carefully. The moiten salt system is attractive because of the low vapor pressure of the salt even at very high temperatures that allows for a low operating pressure. This leads to a simplified primary and secondary system design. While the selection of 1000 psia as steam pressure is arbitrary, analysis should support increases to ensure the low-pressure characteristics of the molten salt system is maintained. 
TABLE 5: CHARACTERISTICS OF SOME STEAM GENERATOR DESIGNS

\begin{tabular}{|c|c|c|c|c|c|}
\hline FEATURE & MSBR & ALMR-REF & $\begin{array}{l}\text { ALMR- } \\
\text { MODB }\end{array}$ & CANDU 3 & $\begin{array}{c}\text { CANDU } \\
\text { Pickering }\end{array}$ \\
\hline Type & $\begin{array}{c}\text { horizontal } \\
\text { U-tube }\end{array}$ & helical coil & helical coil & $\begin{array}{l}\text { vertical U- } \\
\text { tube }\end{array}$ & $\begin{array}{l}\text { vertical } \\
\text { U-tube }\end{array}$ \\
\hline $\begin{array}{l}\text { capacity, MW } \\
\text { intermediate coolant } \\
\text { inlet temperature, F } \\
\text { outlet temperature, F } \\
\text { feedwater/steam } \\
\text { inlet temperature, F } \\
\text { outlet temperature, F } \\
\text { feedwater pressure, psia } \\
\text { SG outlet pressure, psia } \\
\text { tube bundle length, ft } \\
\text { \# tubes } \\
\text { overall HT surface, ft-2 } \\
\text { steam flow, } 10 \mathrm{E}+6 \mathrm{lb} / \mathrm{hr} \\
\text { efficiency, \% }\end{array}$ & $\begin{array}{r}121 \\
1150 \\
850 \\
700 \\
1000 \\
3752 \\
3600 \\
76.4 \\
393 \\
3929 \\
0.633 \\
44.4\end{array}$ & $\begin{array}{r}477 \\
864 \\
573 \\
\\
380 \\
830 \\
2072 \\
1800 \\
27 \\
495 \\
31,102 \\
1.6 \\
35.1\end{array}$ & $\begin{array}{r}850 \\
890 \\
619 \\
\\
420 \\
850 \\
2520 \\
2200 \\
40 \\
612 \\
64,089 \\
3.0 \\
36.1\end{array}$ & $\begin{array}{r}689.7 \\
587 \\
514 \\
369 \\
500 \\
667 \\
740 \\
\\
\\
\\
2.74 \\
32.65\end{array}$ & $\begin{array}{r}138 \\
560 \\
480 \\
340 \\
485 \\
593 \\
\\
2600 \\
0.53 \\
29.1\end{array}$ \\
\hline
\end{tabular}




\section{A2.0 Flow Rates and Component Dimensions}

At this time, not a single $A B C$ component or system has been designed. However, to better sketch out a plant layout, an attempt was made to determine flow rates and component dimensions, at the least as rough estimates that help to define a basic layout for the $A B C$ system.

The following basic assumptions were made:

\begin{tabular}{|c|c|}
\hline $\begin{array}{l}\text { module size: } \\
\text { average core power density } \\
\text { \# of coolant loops per module } \\
\text { \# of IHX per module } \\
\text { \# of steam generators per module } \\
\text { fuel salt constituents } \\
\text { coolant salt } \\
\text { fuel inlet temperature } \\
\text { fuel outlet temperature } \\
\text { moderator fraction in core } \\
\text { core length/diameter ratio } \\
\text { fuel region diameter } \\
\text { fuel flow area in core } \\
\text { axial/radial reflector thickness: } \\
\text { core barrel thickness: } \\
\text { gap between core barrel/vessel } \\
\text { vessel wall thickness } \\
\text { vessel diameter } \\
\text { inner diameter of inner outlet pipe } \\
\text { wall thickness of inner pipe } \\
\text { inner diameter of outer pipe } \\
\text { wall thickness outer pipe } \\
\text { outer diameter of outlet/inlet pipes } \\
\text { flow area in inner/outer pipe }\end{array}$ & 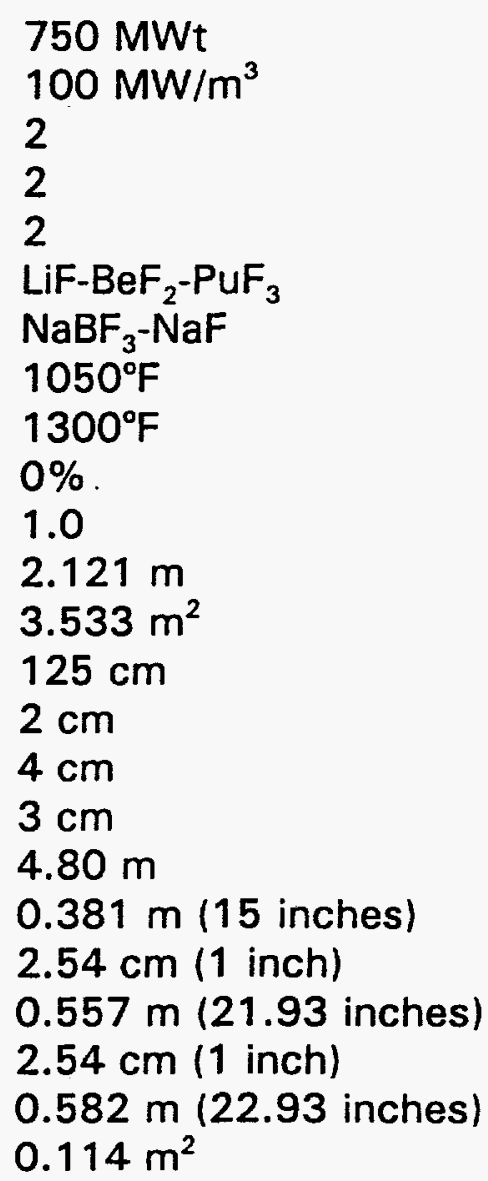 \\
\hline
\end{tabular}

Use was made of double-walled piping for the fuel leaving and returning to the core. The physical properties for the fuel ${ }^{5}$ were those for $\mathrm{BeF}_{2}$ - $\mathrm{LiF}$ because it is assumed that at the least initially the Pu content is close to 0.05 mole $\%$ which is too small to affect physical properties.

5 taken from "Physical Properties of Molten-Salt Reactor Fuel, Coolant, and Flush Salts", by S. Cantor, ORNL-TM-2316 (August 1968), 


\section{1 primary system}

Fuel flow rates were calculated according to:

$P($ power) $=F R$ (flow rate) $x \mathrm{cp}$ (specific heat) $x d T$ (temperature rise)

$7.5 \times 10 E+8=F R \times 2385 \mathrm{~J} / \mathrm{kg}-\mathrm{C} \times 138.9 \mathrm{C}$

or

Flow Rate $=2264 \mathrm{~kg} / \mathrm{s}$

The average core flow velocity is calculated from the correlation:

$F R=$ fuel density $(\mathrm{kg} / \mathrm{m} 3) \times$ fuel flow area $(\mathrm{m} 2) \times$ fuel velocity $(\mathrm{m} / \mathrm{s})$

$2264 \mathrm{~kg} / \mathrm{s}=1947 \mathrm{~kg} / \mathrm{m} 3 \times 3.533 \mathrm{~m} 2 \times$ fuel velocity

or

fuel velocity $=0.329 \mathrm{~m} / \mathrm{s}$

The volumetric flow rate is calculated from the correlation:

$F R=$ VFR (volumetric flow rate, $\mathrm{m} 3 / \mathrm{s}) \times$ density $(\mathrm{kg} / \mathrm{m} 3)$

or

volumetric flow rate $=1.163 \mathrm{~m}^{3} / \mathrm{s}$

The fuel travel time through the core region is $6.4 \mathrm{~s}$.

The outlet flow is conducted through two double-walled pipes, each with a flow of $1132 \mathrm{~kg} / \mathrm{s}$. Using the above-cited correlations, the average fuel velocity in either the outer or inner pipe is $5.18 \mathrm{~m} / \mathrm{s}(17 \mathrm{ft} / \mathrm{s})$.

As shown in section 3, the two pipes separate shortly after leaving the vessel. Heat transfer from the hot to cold fluid should be minimal. 


\section{2 secondary system}

Table 6 compares the MSBR IHX with that for the CRBRP. It is noteworthy that the smaller-capacity IHX for the CRBRP has less than half the tubes of comparable length but is housed in a vessel over twice the height and over $50 \%$ larger diameter than the MSBR IHX. The CRBRP IHX already passed licensing review whereas the MSBR IHX has never been reviewed by the NRC.

The IHX for the ABC system is a scaled-down version of the MSBR IHX design. However, it is assumed that inlet and outlet plena are reached from the sides to eliminate the need for the space on top of the $\mathrm{IHX}$ to accommodate the inverted $\mathrm{U}$ shaped outlet/inlet secondary flow arrangement.

For scaling purposes it was assumed that the same MW per meter of tube length applies, and that the tube length is $3.5 \mathrm{~m}$. This leads to the following IHX characterization:

$\begin{array}{lll} & \text { ABC } & \text { MSBR } \\ \text { power, MW } & 375 & \\ \text { central downcomer diameter, } \mathrm{m} & 0.4 & 556.3 \\ \text { tube length, m } & 3.5 & 0.508 \\ \text { number of tubes } & 8315 & 7.44 \\ \text { tube diameter, in. } & \text { same } & 5803 \\ \text { tube pitch, in. } & \text { same } & 0.375 \\ \text { shell diameter, m } & 2.0 & 0.75 \\ \text { overall height, m } & 5.0 & 1.717 \\ & & 7.2 \\ \text { Tube side conditions } & \text { fuel salt } & \\ \text { inlet temperature, }{ }^{\circ} \mathrm{F} & 1300 & \text { fuel salt } \\ \text { outlet temperature, }{ }^{\circ} \mathrm{F} & 1050 & 1300 \\ \text { mass flow rate, } \mathrm{kg} / \mathrm{s}\left(\mathrm{lb} / \mathrm{hr} \times 10^{6}\right)^{6} & 1164(9.24) & 1050 \\ \text { Shell side conditions } & \text { coolant salt } & 2955(23.4) \\ \text { inlet temperature, }{ }^{\circ} \mathrm{F} & 850 & 850 \\ \text { outlet temperature, }{ }^{\circ} \mathrm{F} & 1150 & 1150 \\ \text { mass flow rate, } \mathrm{kg} / \mathrm{s}\left(\mathrm{lb} / \mathrm{hr} \times 10^{6}\right)^{7} & 1495(11.9) & 2218(17.6)\end{array}$

6 The MSBR flow rate cannot be scaled-down because the fuel salt for the $A B C$ is essentially LiF-BeF2 whereas the MSBR fuel salt is LiF-BeF2-ThF4-UF4.

7 Because the same coolant is used, the MSBR flow rates were scaled down to obtain the $A B C$ flow rates. 


\section{3 steam system}

The only available steam generator design data for a molten salt steam generator are those for the small $121 \mathrm{MW}$ horizontal U-tube, U-shell heat exchanger for the MSBR that employs a supercritical steam cycle with $1000^{\circ} \mathrm{F}$ steam at $3500 \mathrm{psia}$. The tube length for this steam generator is $23.29 \mathrm{~m}(76.4 \mathrm{ft})$, and the inner shell diameter is $0.464 \mathrm{~m}$ (18.25 inches). For illustration purposes this steam generator will be scaled up to $375 \mathrm{MW}$ but limiting the shell diameter to $1.50 \mathrm{~m}$.

Using the MSBR $121 \mathrm{MW}$ steam generator as reference, the total length of tubing for a $375 \mathrm{MW}$ ABC steam generator is:

$$
(375 / 121) \times 393 \times 23.29 \mathrm{~m}=28,366 \mathrm{~m} \text {. }
$$

The number of tubes that can be accommodated in a $1.5 \mathrm{~m}$ diameter shell in relation to the 393 tubes accommodated in the $0.464 \mathrm{~m}$ shell is:

$$
393 \times(1.5 / 0.464)^{2}=4115 \text { tubes. }
$$

The tube length for the $A B C$ steam generator is then:

$$
28,366 / 4115=6.893 \mathrm{~m} .
$$

The overall length of the steam generator has to account for the curvature and the height of the plena. The tube length consist of two straight sections and one curved section. Assuming an average curvature radius of $0.6 \mathrm{~m}$, the length of the straight sections is $2.5 \mathrm{~m}$, and the height of the bundle is $3.1 \mathrm{~m}$. Assuming a radius of 0.75 $\mathrm{m}$ for the inlet and outlet plena, respectively, yields an overall height for the steam generator of $4.6 \mathrm{~m}$.

For the supercritical steam cycle of the MSBR steam reheaters had been added which were sizeable structures (603 tubes, $13.2 \mathrm{ft}$ long tubes, shell ID of 20.25 inches, and overall height of $15 \mathrm{ft}$ ).

Using a different steam cycle without reheat requires a new design. It is proposed to look closer at a vertical U-tube design (like CANDU) that would include primary and secondary moisture separators and may yield a height of $15 \mathrm{~m}$ for the $A B C$ system. It is also proposed to evaluate a helical coil steam generators. 
The steam generator design and estimate of flow rates is fairly complex. To illustrate some of these difficulties properties of superheated steam at $900^{\circ} \mathrm{F}$ are cited for 2400 and 3500 psia.

\section{0 psia 3500 psia}

Thermal conductivity, Btu/(hr-ft- F)

Viscosity, $\mathrm{lb} / \mathrm{ft}^{2} \times 10^{6}$

0.052

63

0.062

Specific volume, $\mathrm{ft}^{3} / \mathrm{lb}$

0.285

67

Specific heat, Btu/( $\left(\mathrm{b}-{ }^{\circ} \mathrm{F}\right)$

0.74

0.176

Relative film resistance to heat transfer

1.9

0.91

1.0

This illustrates why the high-pressure supercritical cycle has such an attraction from a heat transfer perspective. The film coefficient for heat transfer in the 3500 psia system is about twice that in the 2400 psia system and, therefore, the surface area required would be significantly less. 
TABLE 6: IHX FEATURES FOR THE MSBR AND CRBRP

\begin{tabular}{||l|l|l|}
\hline \hline IHX FEATURES & MSBR & CRBRP \\
\hline \hline thermal duty, MW & 556.5 & 325 \\
overall length, $\mathrm{ft}$ & 24 & 52.1 \\
shell diameter, $\mathrm{ft}$ & 5.7 & 8.8 \\
tube length, $\mathrm{ft}$ & 24.4 & 25.8 \\
\# of tubes & 5803 & 2850 \\
overall heat transfer area, $\mathrm{ft}^{2}$ & 13.916 & 11,810 \\
overall heat transfer coefficient, Btu/hr-F- $\mathrm{ft}^{2}$ & 784.8 & 1,374 \\
primary flow, $10^{6} \mathrm{lb} / \mathrm{hr}$ & 23.4 & 13.82 \\
intermediate flow, $10^{6} \mathrm{lb} / \mathrm{hr}$ & 17.8 & 12.78 \\
primary system & 1300 & 995 \\
hot leg temperature, ${ }^{\circ} \mathrm{F}$ & 730 \\
cold leg temperature, ${ }^{\circ} \mathrm{F}$ & 1050 & 936 \\
intermediate system & & 651 \\
hot leg temperature, ${ }^{\circ} \mathrm{F}$ & 1150 & \\
cold leg temperature, ${ }^{\circ} \mathrm{F}$ & 850 & \\
\hline
\end{tabular}




\section{A3.0 Drawings for System and Component Layouts ${ }^{8}$}

A series of drawings has been prepared to better illustrate the $A B C$ system design concept.

Not addressed here are the accelerator-molten salt system interface and the accelerator with the target assembly. Cited often as a complication for an ABC system are the penetrations required for the beam tube and target assembly. However, the penetration through the vessel to install the target assembly is in principle not different from the penetrations required for control rods drive lines in a reactor.

What should help greatly in the design of the target assembly and especially the target window, as well as the seals for the penetrations is the very low operating pressure for the primary system. The primary system operating pressure is affected by two considerations, (1) the need for a high pressure to avoid fuel boiling, and (2) the primary system pressure drop.

Because the vapor pressure of molten salts is very low even at high temperatures, a pressurization of the primary system is not required to delay fuel boiling.

The pressure drop in the core and piping should be minimal. Assuming the same tubing dimensions and layout as in the MSBR IHX should more than cut in half the pressure drop in the IHX to less than 50 psi because the $A B C \mathrm{IHX}$ tubing is less than half the length for the MSBR IHX. Further reductions, if desired, can be obtained by opening up the pitch and increasing the tube diameter. Under those conditions it is conceivable that the primary system pressure is significantly less than 100 psia which greatly simplifies not only the target design but also the primary system design and should also result in significant cost savings.

These benefits, however, can only be realized if the secondary and steam system pressures are not excessively high so that any tube rupture in these two system does not lead to damage in the primary system. This is an illustration for the correctness of the safety-first design approach. The scope in the design has to cover not only success and reliability of operation under normal operating conditions, but also safety under accident conditions.

8 Extensive use will be made of the work reported in "Preconceptual ABC Design Definition and System Configuration Layout" and submitted to LANL in March 1995. 
Drawings for the blanket system, intermediate system, steam system, gas sparging system, off-gas system, fuel drainage system, containment system and overall plant layout have been prepared. The drawings are roughly on scale. At the preconceptual design level it was not considered meritorious to tie down dimensions to be within 10 or $20 \%$ of the final dimensions because not a single component has been designed yet.

Fig. 4 shows the flow sheet for the ABC NSSS. Fig. 5 shows schematically the heat transport system hydraulic profile with its staggered thermal centers.

\section{1 core}

Fig. 6 shows a schematic drawing of the $A B C$ blanket configuration/module in a reflected system. Cold fuel coming from the $\mathrm{IHX}$ enters, through the outer of two concentric pipes, the gap between core barrel and vessel, thus keeping both structures at inlet temperature. The fuel flows downward, passes through holes in the lower core support plate to enter the inlet plenum. From here the fuel flows upward through holes in the lower axial reflector/shield into the core region. The hot fuel proceeds through a gap formed by the radial reflector and the upper axial reflector/shield to the inner of the concentric pipes on its way to the IHX. Each of the modules has two outlet/inlet pipes. At the bottom of the vessel is a drainage hole that is kept closed by a freeze plug located underneath that is not shown in the figure.

\section{2 primary and intermediate system}

Fig. 7 shows the Inside of the primary system cell that contains the blanket module, two fuel pumps and two IHXs. To better illustrate the elevations and sizes of the components they were rotated such that a single train core-pump-IHX is visible. In reality, these components are not fully visible in a side view as shown in Fig. 18.

The arrangement is such that each component can be withdrawn from this cell in a straight-pull motion. Not shown is the drainage line for the coolant from the IHX that facilitates complete drainage by gravity. Fuel drainage by gravity is complete and from the bottom drain line in the core vessel. The fuel pump is in the hot leg at the highest elevation. The fuel pump motor is located outside the containment. The fuel pump bowl is about $1.80 \mathrm{~m}$ in diameter. The concrete shielding surrounding the cell is about $2.50 \mathrm{~m}$ thick. This cell is a safety-related structure. The inside of this concrete structure contains a Hastelloy $\mathrm{N}$ (or steel) liner with insulation material between the liner and the concrete. The cavity is filled with $\mathrm{NaF}^{-L i F-B e F_{2}}$ molten salt. Should NaF- 


\section{PRECONCEPTUAL ABC DESIGN DEFINITION AND SYSTEM CONFIGURATION LAYOUT}

$\mathrm{BeF}_{2}$ become the carrier salt for the fuel, it would be both coolant salt and also the salt in the cavity.

Fig. 8 shows the cell containing the IHTS isolation valves and the secondary (coolant salt) pump. It needs to be determined whether it is necessary to fill this cell with a salt like NaF-BeF ${ }_{2}$ to contain leaks, should there be any, and serve as a heat sink. The pump and IHTS valves can be removed from this cell in straight-pull motions.

Underneath this cell is a salt storage area that has not been specifically defined yet. This cell, like all the others is surrounded by a $2.5 \mathrm{~m}$ thick concrete wall. It is a safety-related structure. The walls are stainless-steel-clad and heavily insulated. Should the cell be filled with salt, the use of Hastelloy $\mathrm{N}$ will be considered.

On top of the primary and secondary system cell and the IHTS and coolant pump cell is a containment building that contains maintenance enclosures and a polar crane together with an auxiliary crane.

\section{3 steam system}

The steam system is schematically shown in Fig. 9. The steam generator, a drain tank, and a set of MSIV are contained in a separate containment that has $2.5 \mathrm{~m}$ thick walls. It is a safety-related structure. Next to this containment building is the feedwater heating bay that contains another set of MSIV and feedwater heating equipment. The Feedwater Heating Bay is built to high industry standards. It is not a safety-related structure.

It needs to be determined whether another set of isolation devices is required to protect the IHX in case of a steam generator tube rupture. The MSBR used rupture disks that were located at the secondary-salt outlet of each steam generator. Furthermore, quick-acting block valves at the inlet and outlet of each steam generator were used to isolate the steam generator.

At present, one set of MSIV is placed inside the steam generator cell, and another set is located in the feedwater bay area. This might very well be an overdesign where one set of valves could be saved. The intent here was to provide a very high reliability through redundancy to isolate the steam generator to significantly lower the probability that radionuclides could leak from the primary system into the secondary system, from there into the steam system and ultimately the into the feedwater bay area. 
On top of the steam generator cell is the steam generator bay that provides a work area for the components inside the steam generator cell.

\section{4 gas sparging system}

Fig. 10 shows a schematic flow diagram for a gas sparging system, including both the bubble generation and removal bypass. This figure describes the MSBR system as shown in Fig. 3.37 of ORNL-4541. Because gas sparging has less importance for the $A B C$ system than the MSBR, a less complex system can most likely be used for the $A B C$ system.

\section{5 off-gas system}

Fig. 11 shows a schematic flow diagram of the MSBR off-gas system, as shown in Fig. 7.1 of ORNL-4541. Several options were considered for the ABC system. Option 1 shown in Fig. 12 eliminates the bubble generator system and the long-delay Xe holdup beds. The off-gas leaves the pump bowl through an entrainment separator and proceeds to the fuel drain tank. After a $2 \mathrm{hr}$ holdup, the off-gas enters the $47-\mathrm{hr} \mathrm{Xe}$ holdup system and then returns through a chemical trap and monitor to the primary system.

Fig. 13 shows a second option that maintains the bubble generator system shown in Fig. 11 but eliminates the long-term $X e$ holdup. After the gases leave the fuel salt drain tank they pass through a filter to remove particulate matters. After the 47-hr holdup all gases are returned to the primary system.

Fig. 14 shows the recommended off-gas system. It is very similar to option 2 shown in Fig. 13 but eliminates the particle trap and leaves open the holdup times in the fuel drain tank and in the Xe holdup system.

Fig. 15 shows a cross section of one bank of Xe holdup charcoal beds similar to the MSBR. Hairpin tubes are filled with chareoal through which the off-gases are directed. The heat is rejected to water that converts to $230 \mathrm{~F}$ steam which is condensed in a condenser and the condensate is directed back into the holdup bed. 


\section{6 fuel drainage system}

Fig. 16 shows a schematic flow diagram for the $A B C$ primary drain and heat removal system using $\mathrm{NaF}-\mathrm{BeF}_{2}-\mathrm{LiF}$ as coolant. The decay heat produced in the fuel drain tank is passively removed by a coolant salt and transported to a water-salt heat exchanger. The heated water is transported passively to a water-air heat exchanger located in a heat reject stack.

In case $\mathrm{NaK}$ is used as coolant in the fuel drain tank, the ultimate heat sink, according to a design study for the MSBR could be a water tank where, not unlike in case of the charcoal beds, water is brought to a boil and then either returned after passing through a condenser, or released to the outside and makeup water is supplied.

\section{7 containment system}

The containment system is shown in Figs. 17 and 18. Fig. 17 shows the relation to each other of the mainline systems. To show core vessel, pump and IHXs, those components had to be rotated out of their position because otherwise they would not have been all visible. Fig. 18 shows a top view of the mainline systems. The dimensions are:

$\begin{array}{ll}\text { core vessel diameter: } & 4.80 \mathrm{~m} \\ \text { core diameter: } & 2.10 \mathrm{~m} \\ \text { reflector thickness: } & 1.25 \mathrm{~m} \\ \text { IHX vessel diameter: } & 2.00 \mathrm{~m} \\ \text { pump bowl diameter: } & 1.80 \mathrm{~m} \\ \text { containment wall diameter: } & 2.50 \mathrm{~m} \\ \text { approximate primary cell outer diameter: } & 16 \mathrm{~m} \\ \text { approximate primary cell inner diameter: } & 11 \mathrm{~m} \\ \text { approximate primary cell height: } & 9 \mathrm{~m}\end{array}$

approximate building height on top of cells: $12 \mathrm{~m}$

At this stage of the $A B C$ design development no attempt was made to optimize the design and layout. Basic design analyses and decisions still have to be made that will affect the sizing of the cells and perhaps even their relationship to each other, as well as permissible module size, power density and system requirements. It is most likely that the reactor building wall thicknesses (the structure on top of the cells) can be significantly reduced, perhaps even to less than the MSBR building dome/wall thickness that was $3.5 \mathrm{ft}$. Inside the concrete building structure is a $1 \mathrm{~cm}$ thick liner made of carbon steel which acts as a sealing membrane to permit the achievement of 
less than one inventory loss per year. (The requirement for the MSBR was $0.1 \%$ per 24-hr period. A confinement building such as that proposed for the MHTGR had an expected leakage rate of one inventory per day).

It should be noted that none of the cell or building dimensions are excessive. For example, the MSBR reactor cell (inner) diameter was $22 \mathrm{~m}$ which is twice the diameter for the $A B C$ cell. All MSBR structures were above ground with a containment building height of $57 \mathrm{~m}$. The total height above ground for the $A B C$ containment building can be less than $8 \mathrm{~m}$.

It is assumed that the accelerator beam will enter the reactor building below grade. How far below grade it has to be directed has to be based on well-justified requirements because it will affect building cost.

The primary system cell and the cell containing the IHTS isolation valves and coolant pumps are under the primary and secondary system containment bay which is another containment structure. On top of the two cells is a maintenance enclosure. This enclosure is a thin-walled containment vessel designed primarily to contain airborne contaminants during maintenance operations. It has access ports over the vessel, pumps and IHXs.

As shown in Fig. 18, the primary system cell, IHTS-coolant pump cell and steam generator cell are safety-related structures. The feedwater heater bay requirement is to be built in accordance with high quality industrial standards.

\section{8 overall plant layout}

Fig. 17 and 18 already showed a single train configuration. Fig. 19 shows how two modules will share one off-gas system and one fuel drain system. Off-gas system and fuel drain system are placed next to each other. Shown is also the stack area assuming the coolant in the drain system is a molten salt.

No attempts was made at this stage of the design development to show hot cells, offices, areas for salt processing and storage, etc. These are not critical areas in regard to design viability albeit the cost for these facilities is not insignificant. 
A4.0 Impact of Power Density and Module Power on Containment Size

To assess the impact of changes in power density, power level and also height-todiameter (L/D) ratio, parametric studies were done with the following assumptions:

power density varies between $75-300 \mathrm{~kW} / \mathrm{l}$

module power was varied between 500 and $1000 \mathrm{MWt}$

L/D ratio was varied between 0.6 to 1.3

reflector thickness of $125 \mathrm{~cm}$

core barrel thickness of $2 \mathrm{~cm}$

gap between barrel and vessel wall of $4 \mathrm{~cm}$

vessel thickness of $3 \mathrm{~cm}$

\section{1 impact of power density}

Fig. 20 shows the relationship between power density and vessel diameter assuming a $750 \mathrm{MWt}$ module power level and an L/D ratio of 1.0. Increasing the power density by $400 \%$ decreases the vessel diameter by less than $20 \%$. Increasing the power density from $100 \mathrm{~kW} / /$ to $150 \mathrm{~kW} / \mathrm{l}$ decreases the vessel size from $4.80 \mathrm{~m}$ to $4.53 \mathrm{~m}$, or by $27 \mathrm{~cm}$.

This is too small a change to be reflected in the containment size.

\section{2 impact of module size}

Fig. 21 shows the relationship between vessel diameter and power level assuming a power density of $100 \mathrm{~kW} / /$ and an L/D ratio of 1.0 . Doubling the module power level increases the vessel diameter from $4.53 \mathrm{~m}$ at $500 \mathrm{MWt}$ to $5.01 \mathrm{~m}$ at $1000 \mathrm{MWt}$. Going from $750 \mathrm{MWt}$ to $1000 \mathrm{MWt}$ in module power increases the vessel diameter from $4.80 \mathrm{~m}$ to $5.01 \mathrm{~m}$, or by a mere $21 \mathrm{~cm}$.

This is too small a change to be reflected in the containment size.

\section{3 impact of $L / D$ ratio}

Fig. 22 show the relationship between vessel diameter and $L / D$ ratio, assuming a module power of $750 \mathrm{MWt}$ and a power density of $100 \mathrm{~kW} / \mathrm{l}$. Flattening the core from an L/D os 1.0 to an $L / D$ value of 0.6 increases the vessel diameter from $4.80 \mathrm{~m}$ 
to $5.19 \mathrm{~m}$, or by $39 \mathrm{~cm}$. Increasing the core height so that the L/D ratio increases from 1.0 to 1.3 , decreases the vessel diameter from $4.80 \mathrm{~m}$ to $4.62 \mathrm{~m}$.

These changes are too small to be reflected in the containment size. This means that the L/D ratio should be determined largely based on physics considerations. 


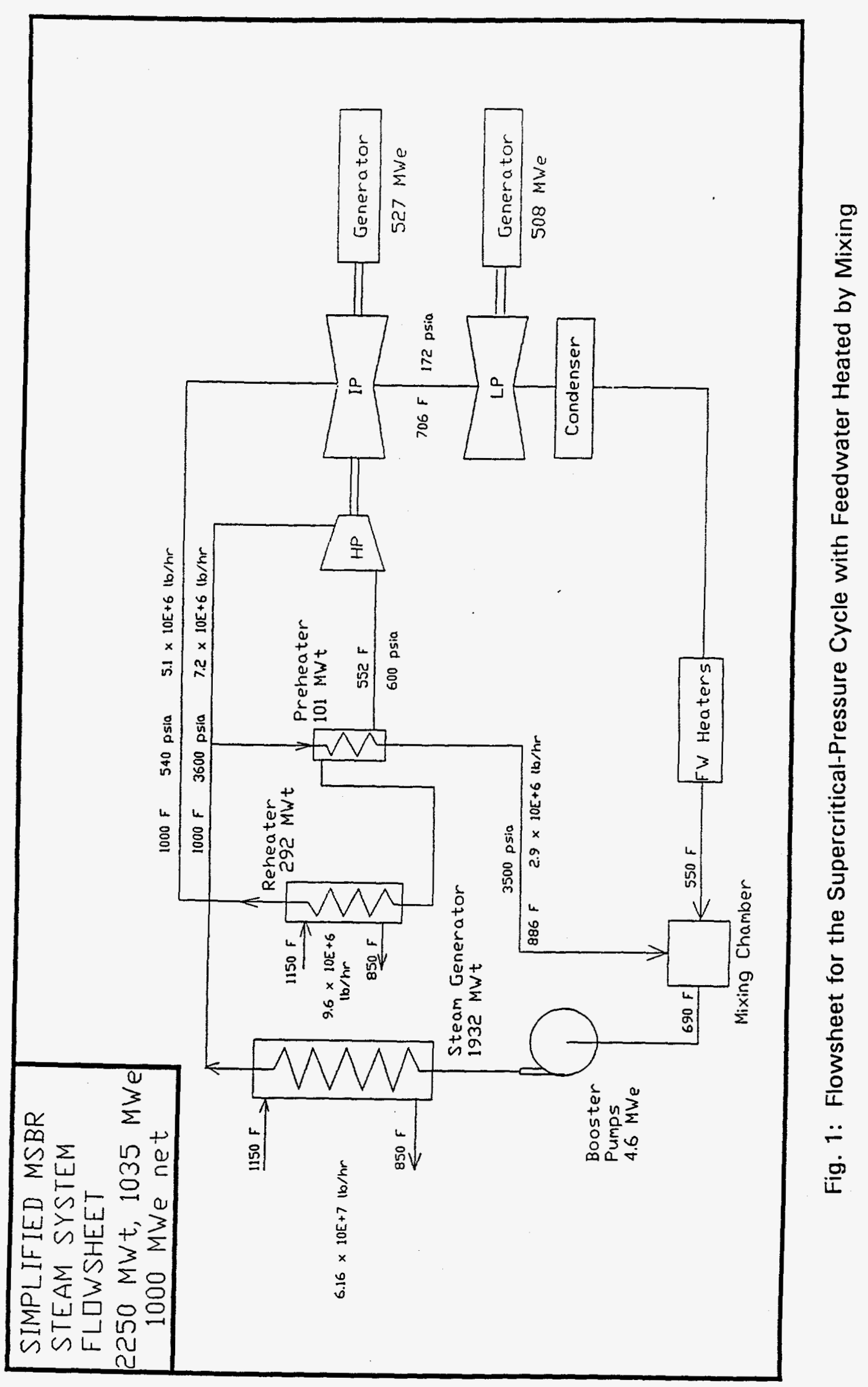




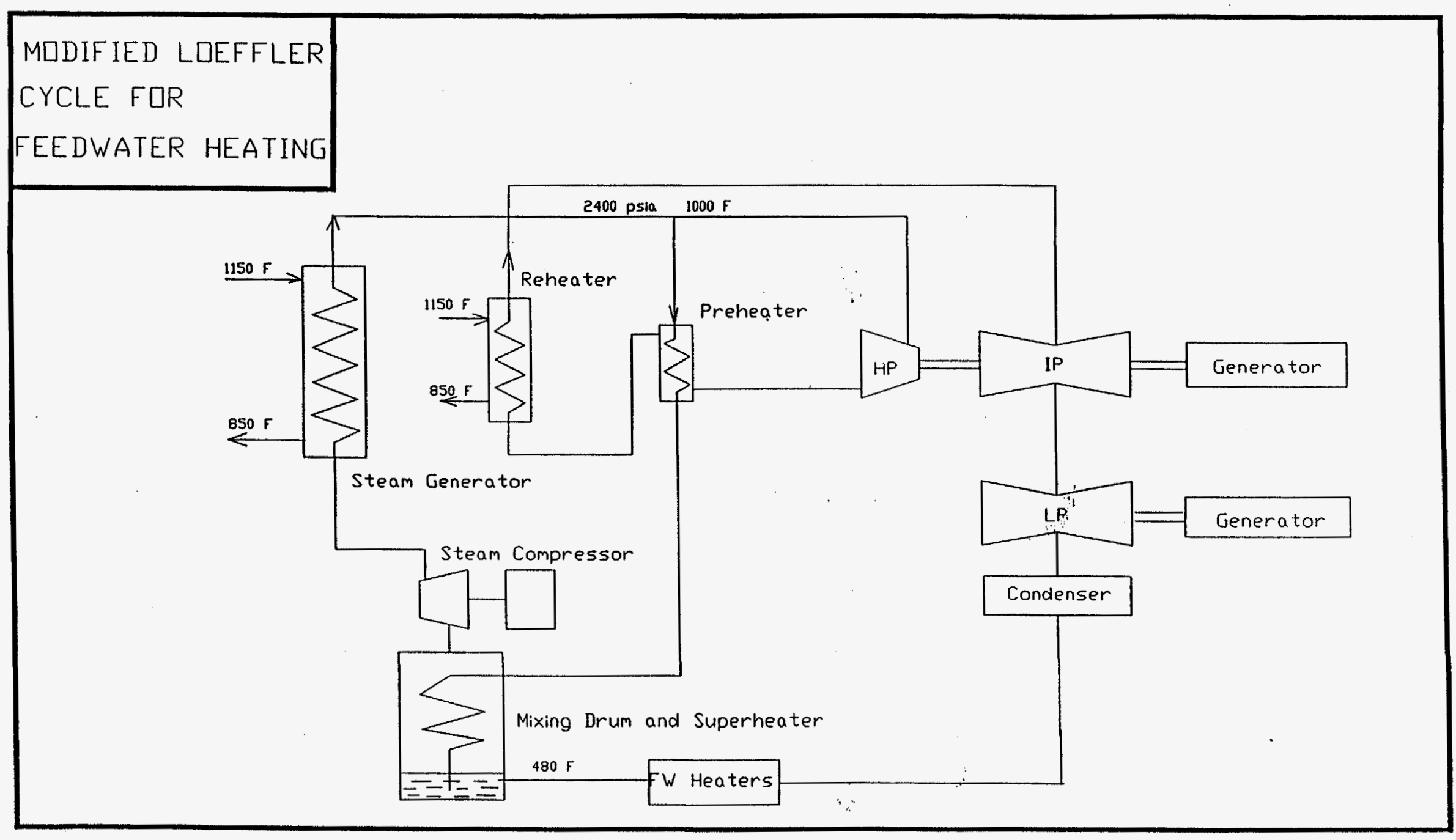

Fig. 2: Modified Loeffler Cycle for Feedwater Heating 
Fig. 3: Vertical U-Tube Steam Generator Similar to CANDU

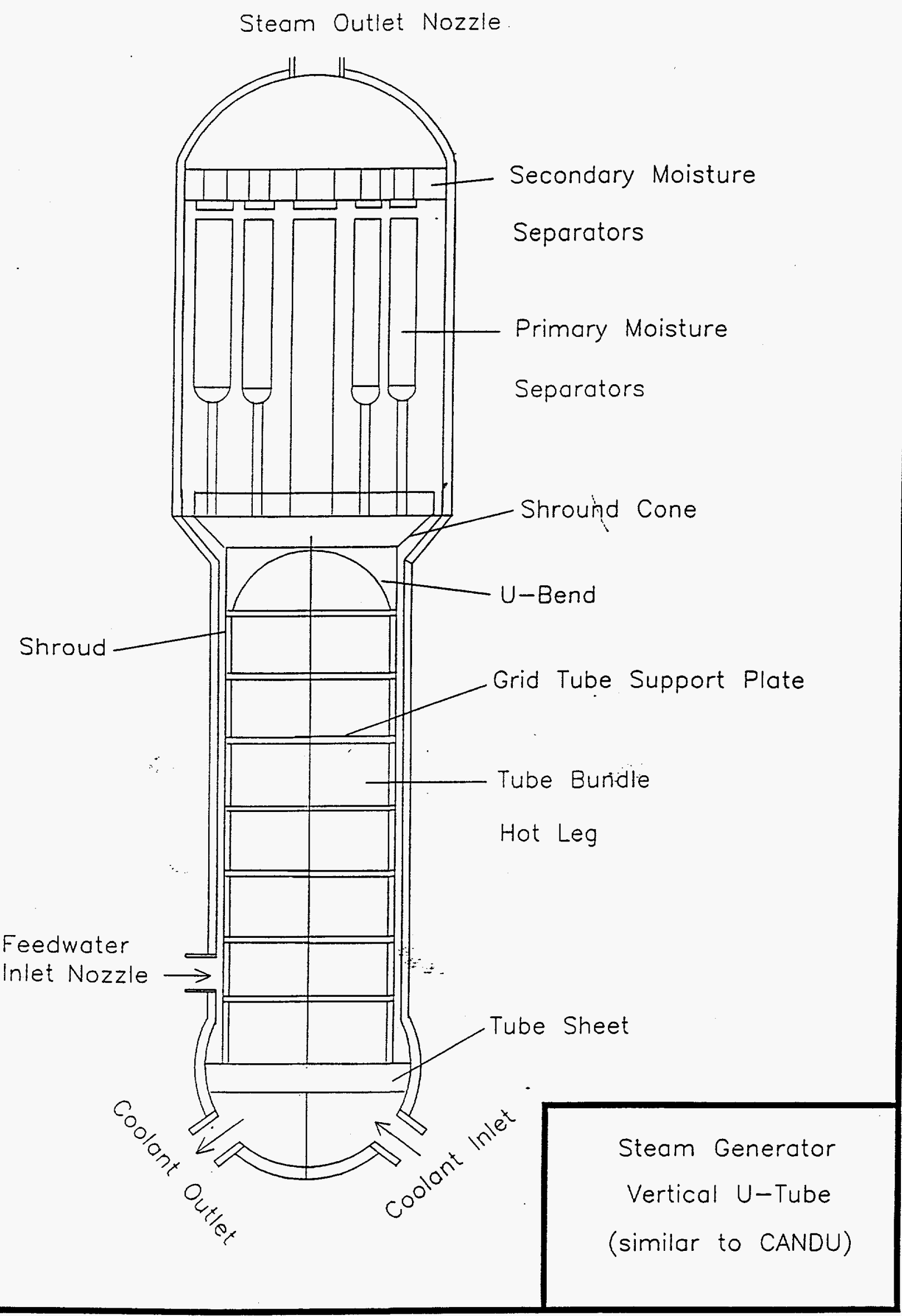




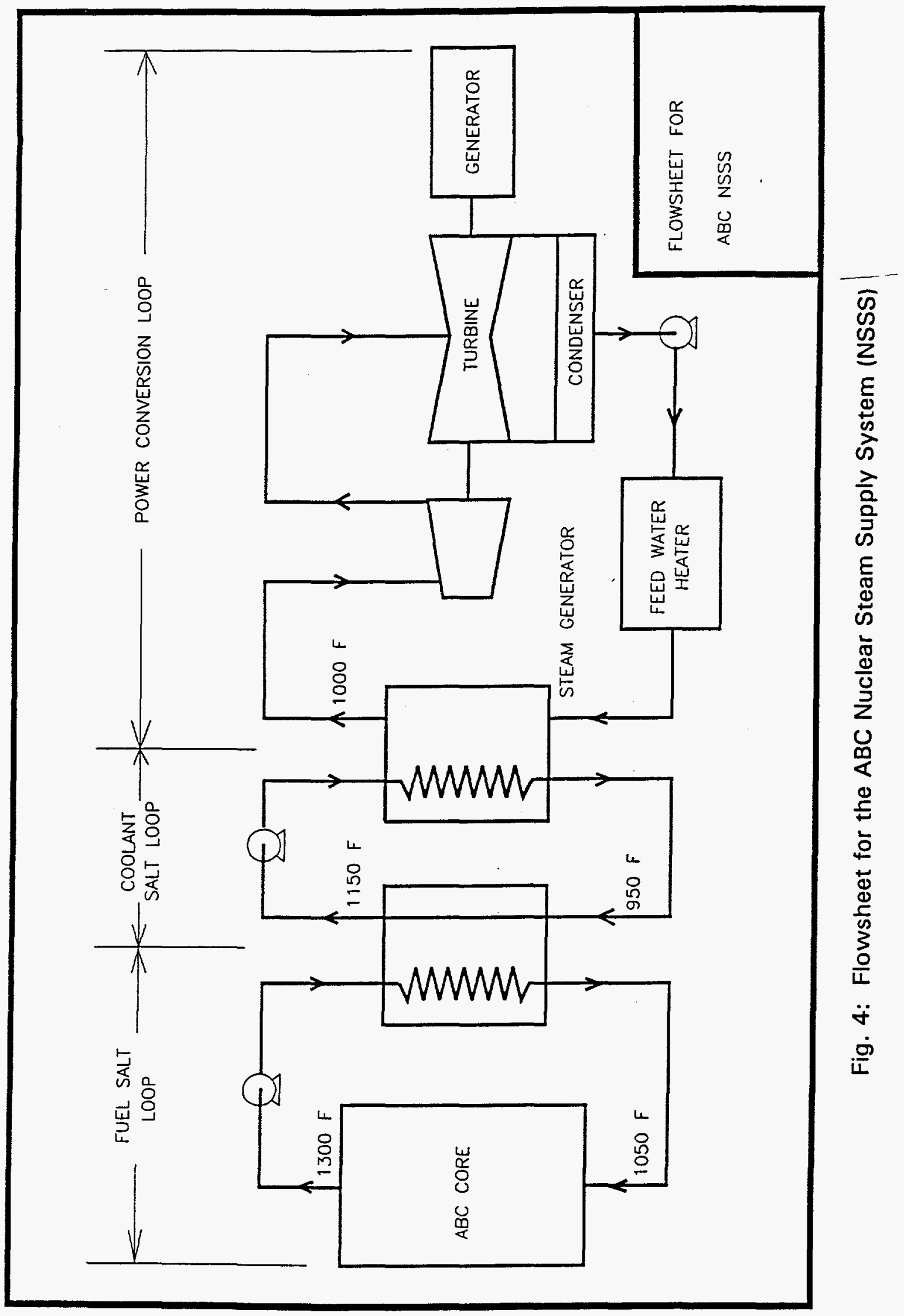




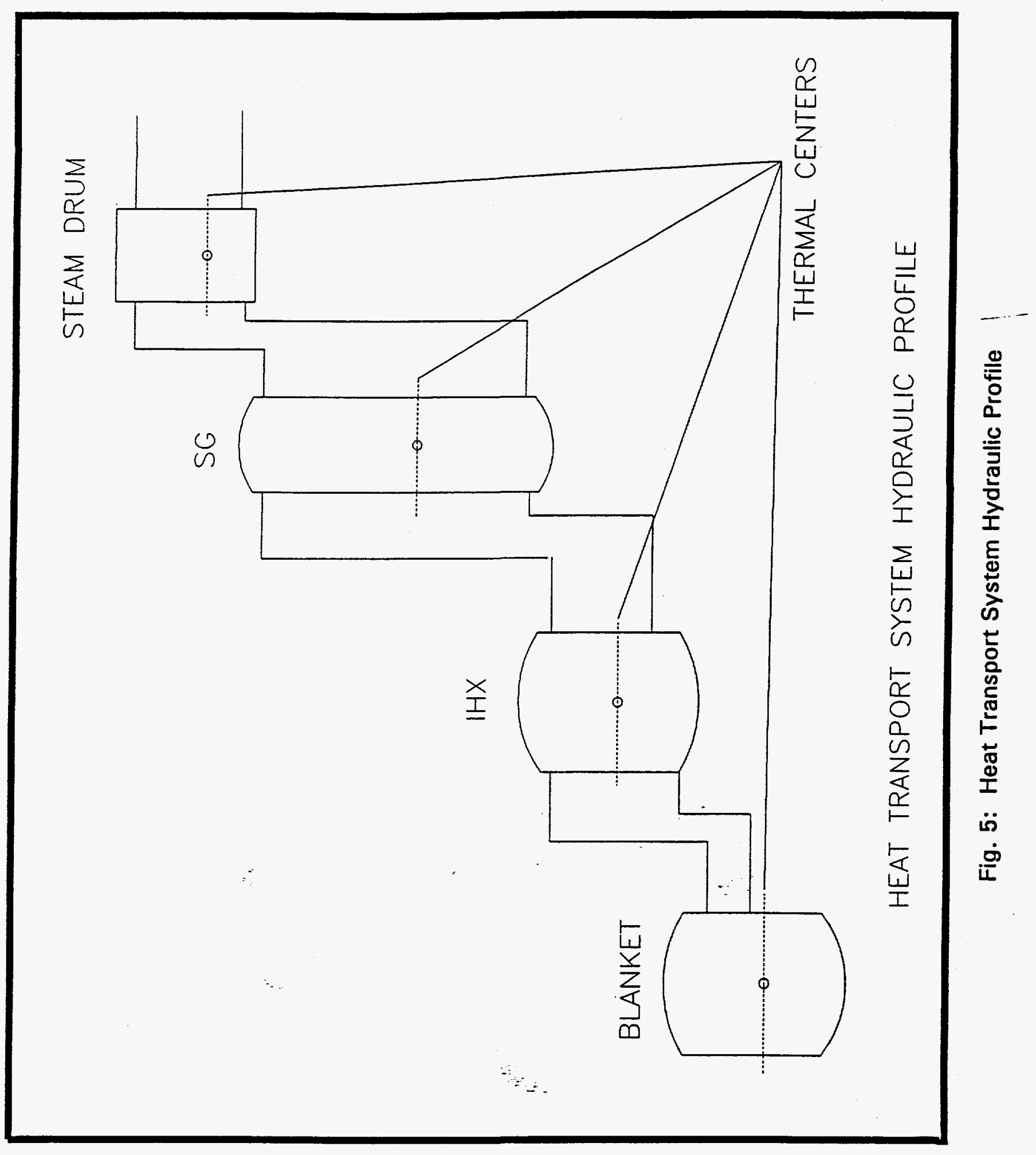




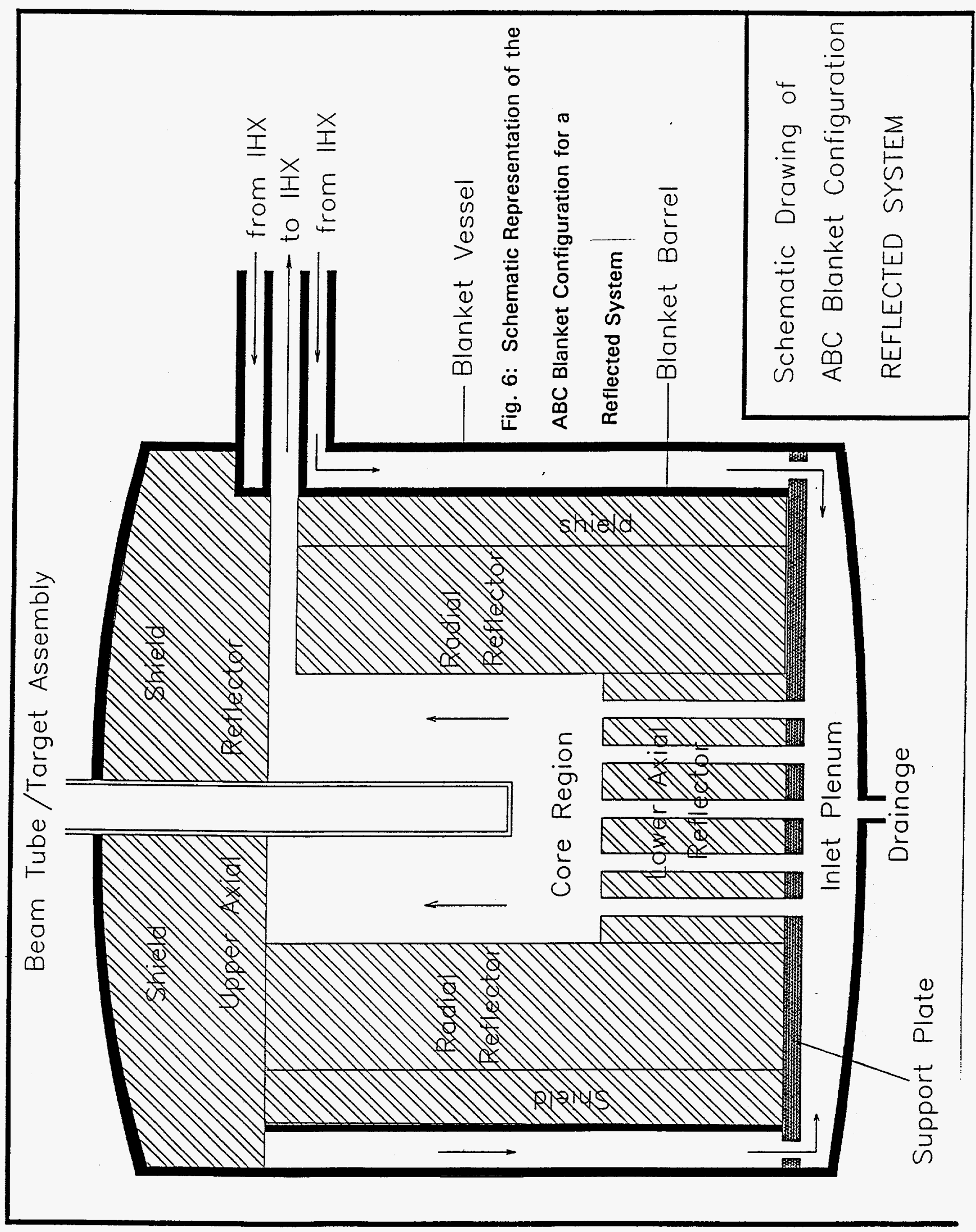




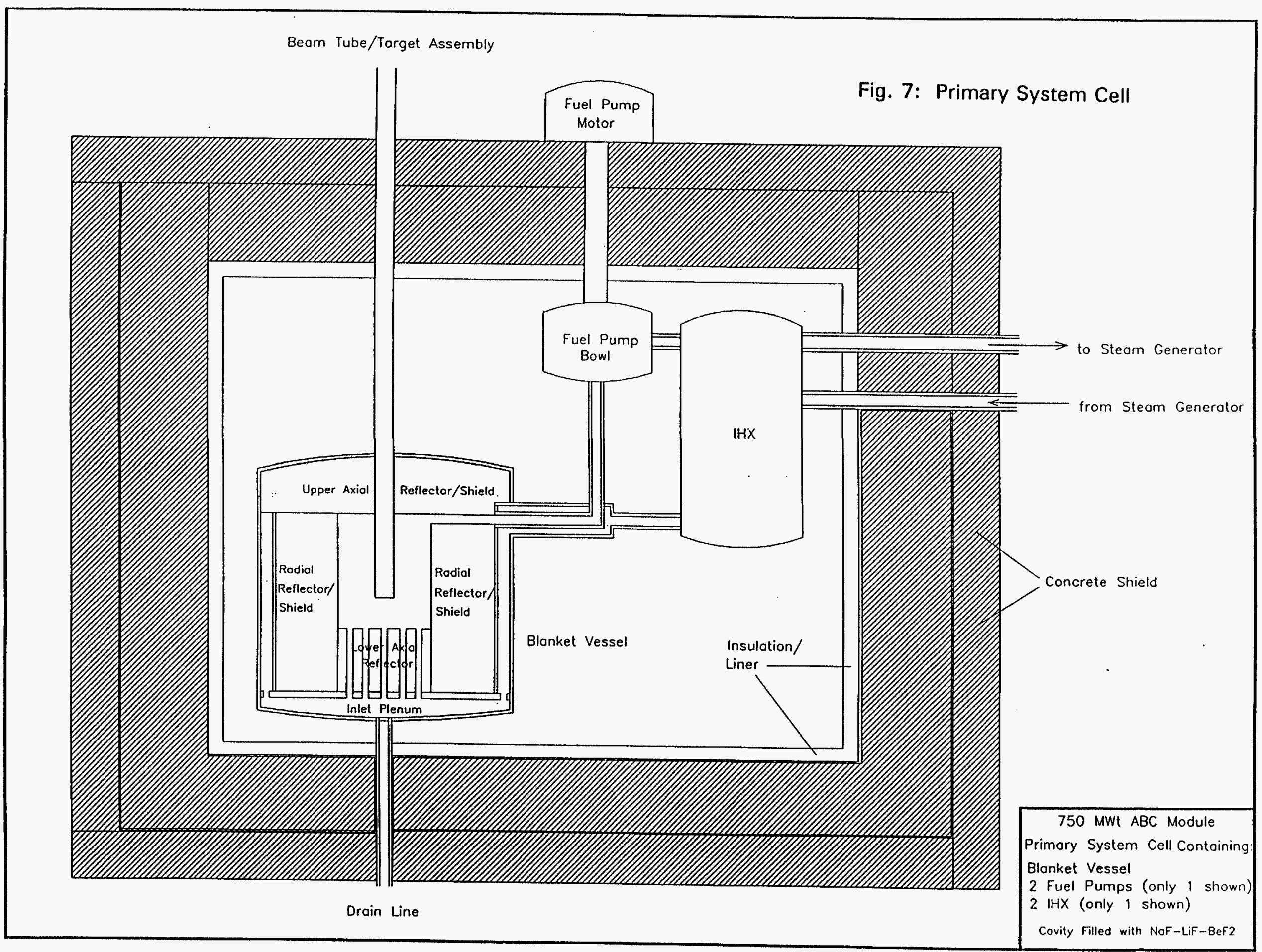




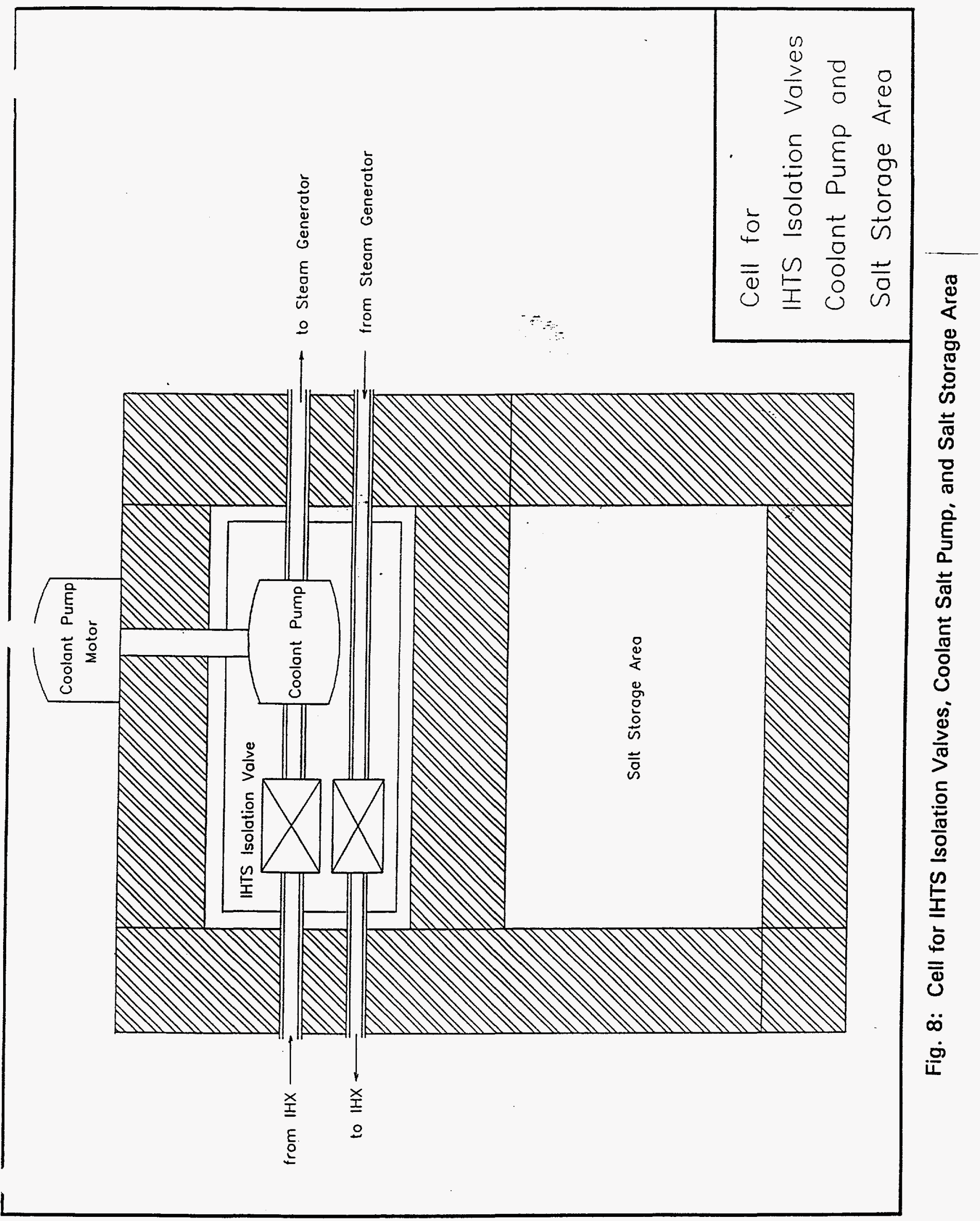




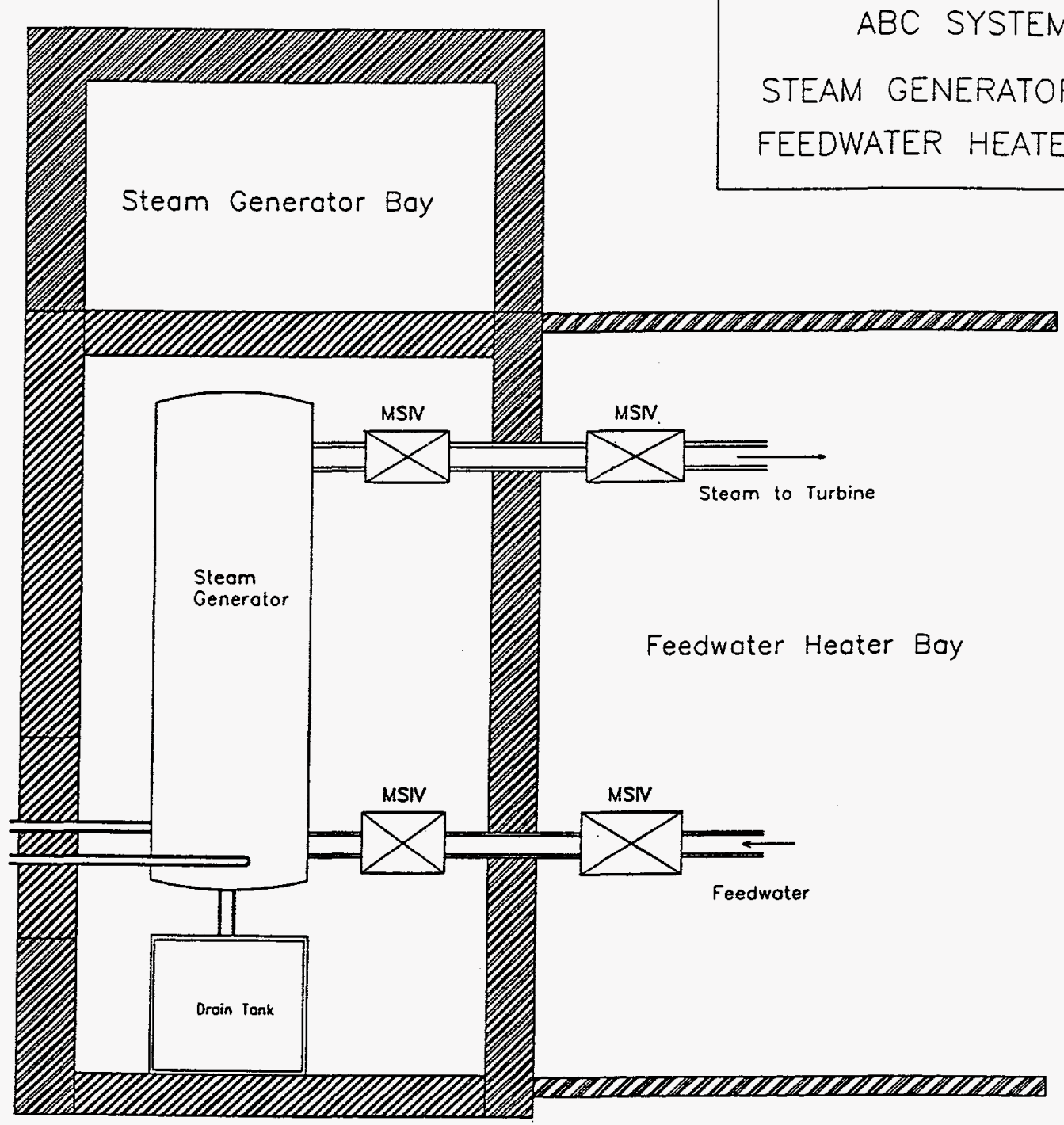

Fig. 9: Steam Generator Cell and Feedwater Bay 


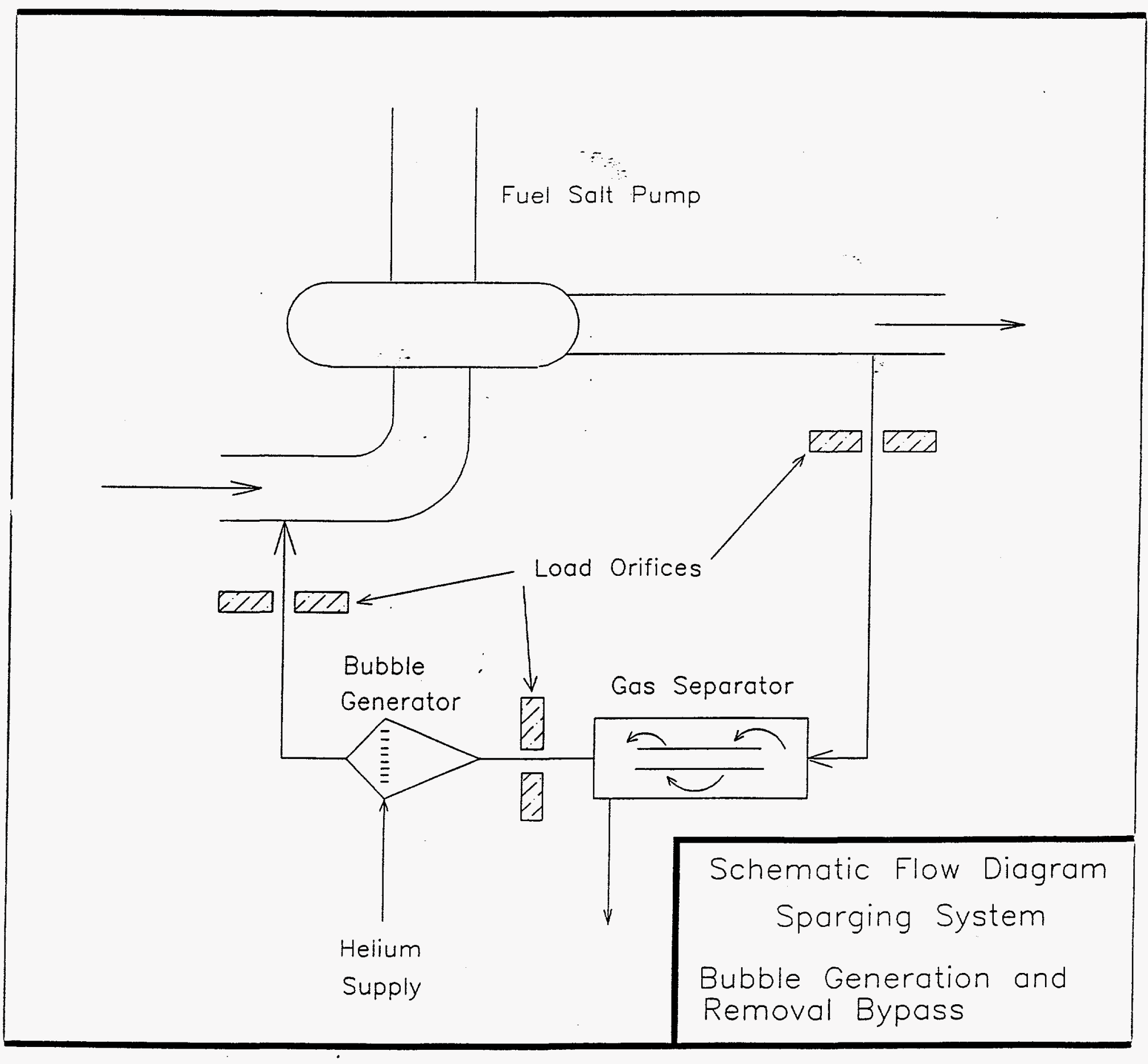

Fig. 10: Schematic Flow Diagram for the Sparging System 


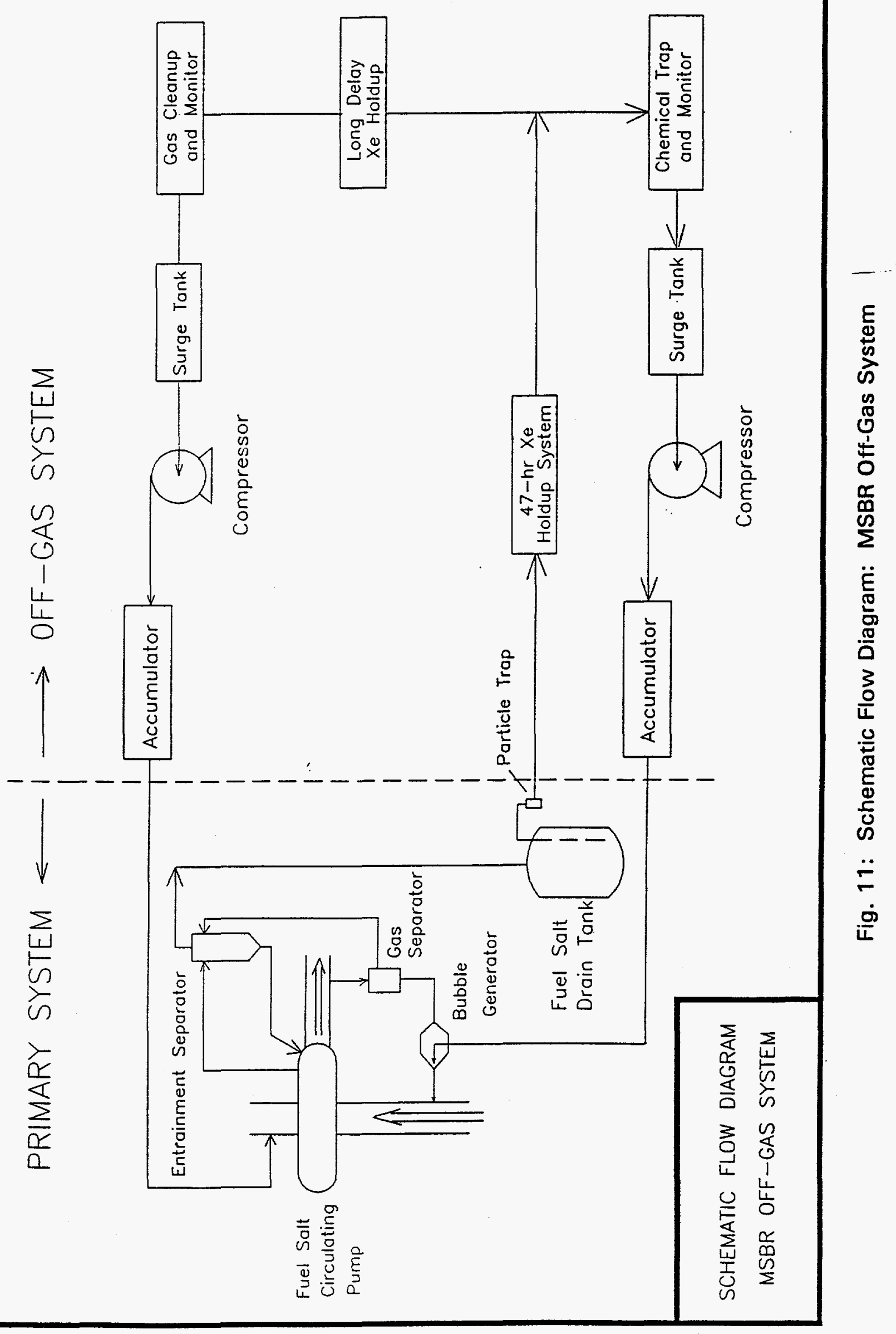




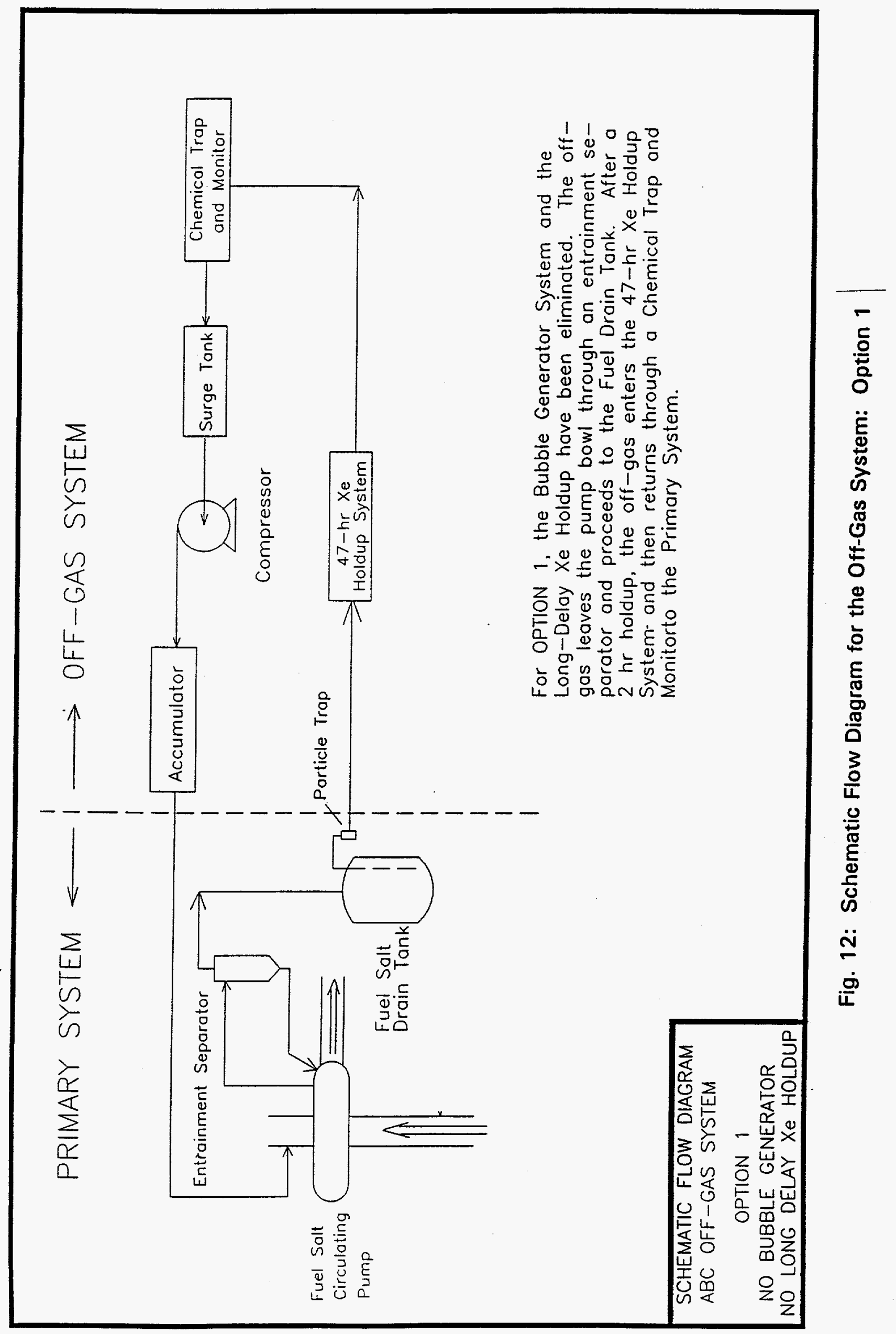




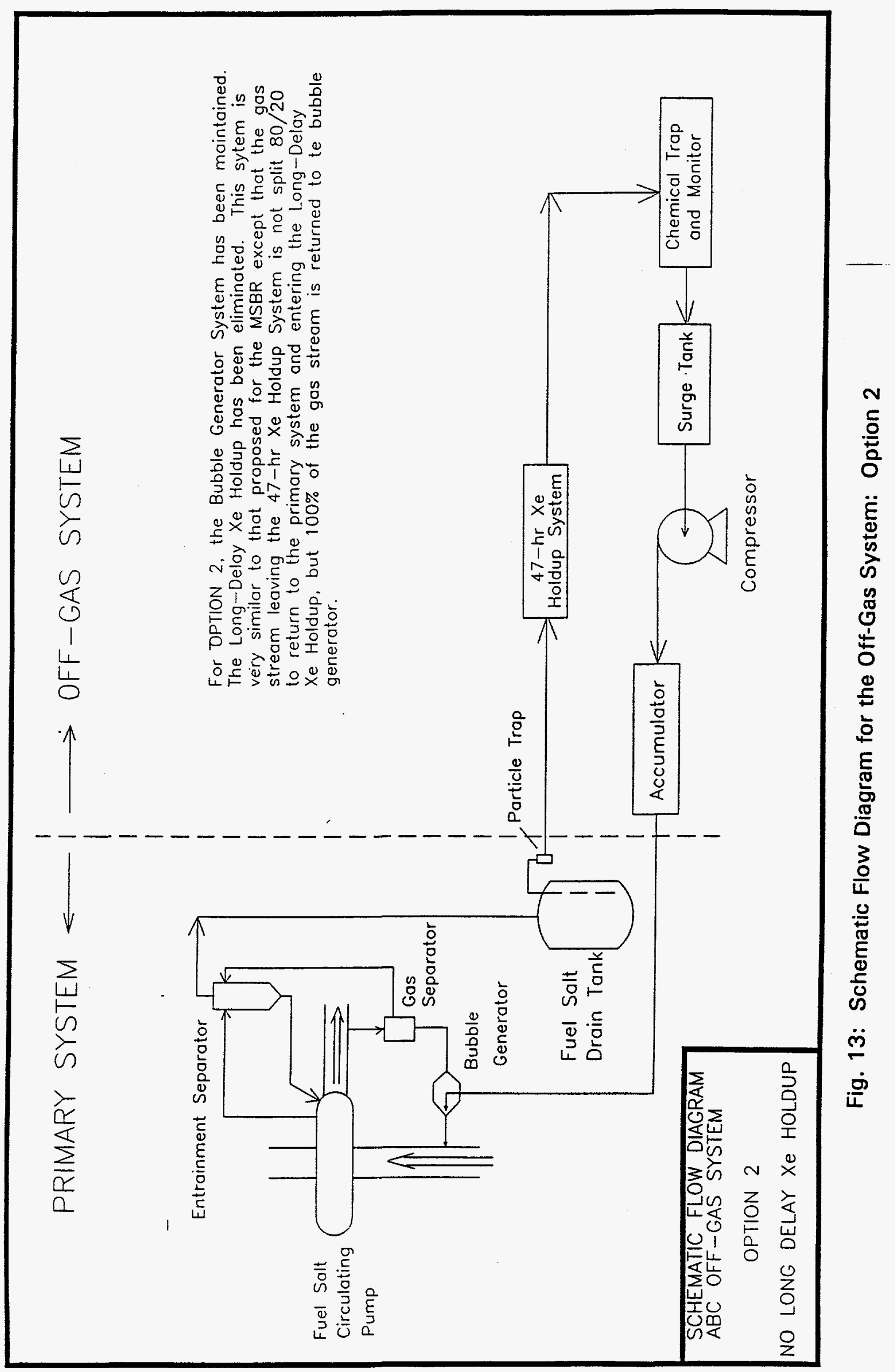




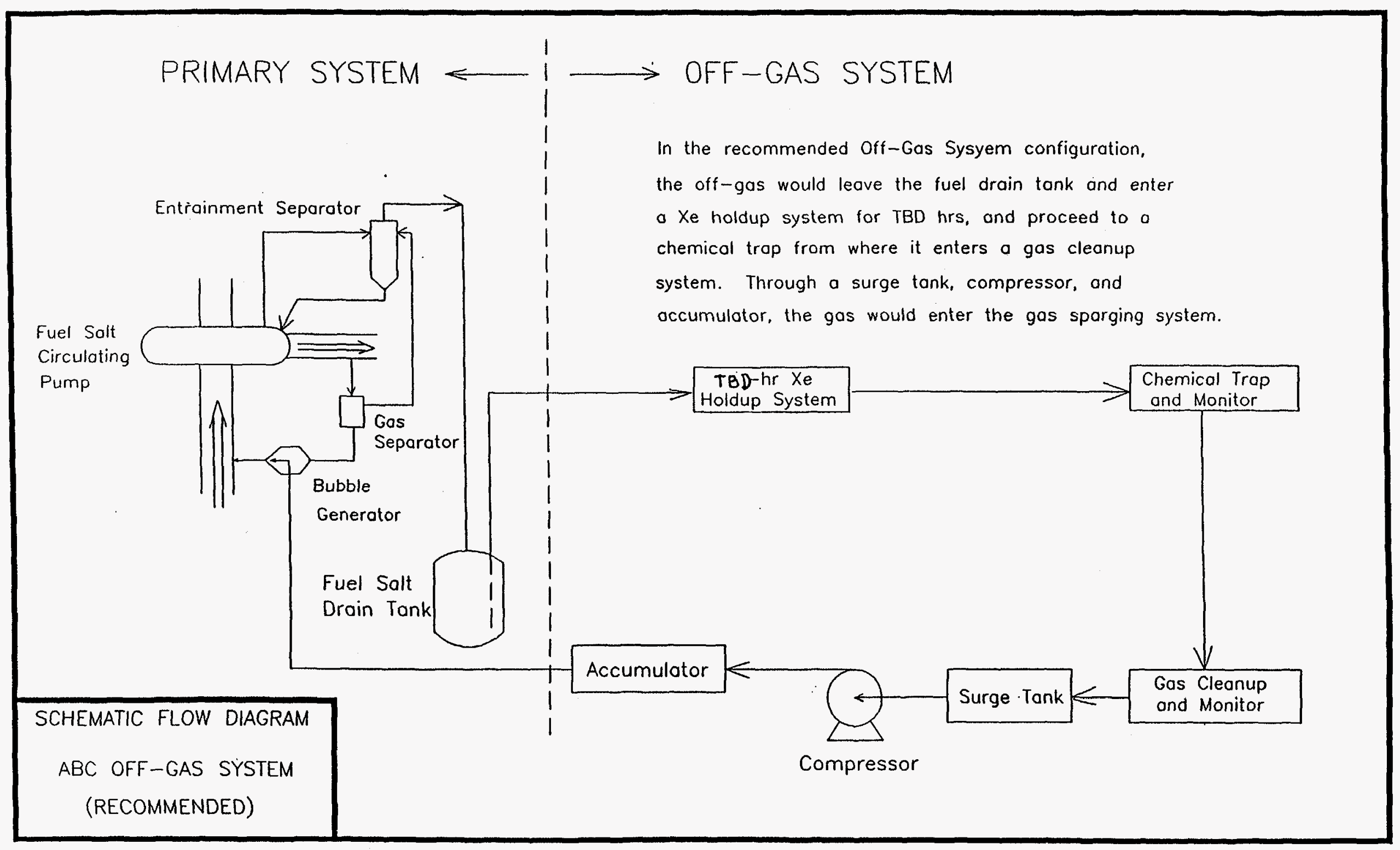

Fig. 14: Schematic Flow Diagram for the Recommended ABC Off-Gas System 


\section{ABC OFF-GAS SYSTEM}

Cross Section of one Bank of 47-hr Xe Holdup Charcoal Bed Similar to MSBR

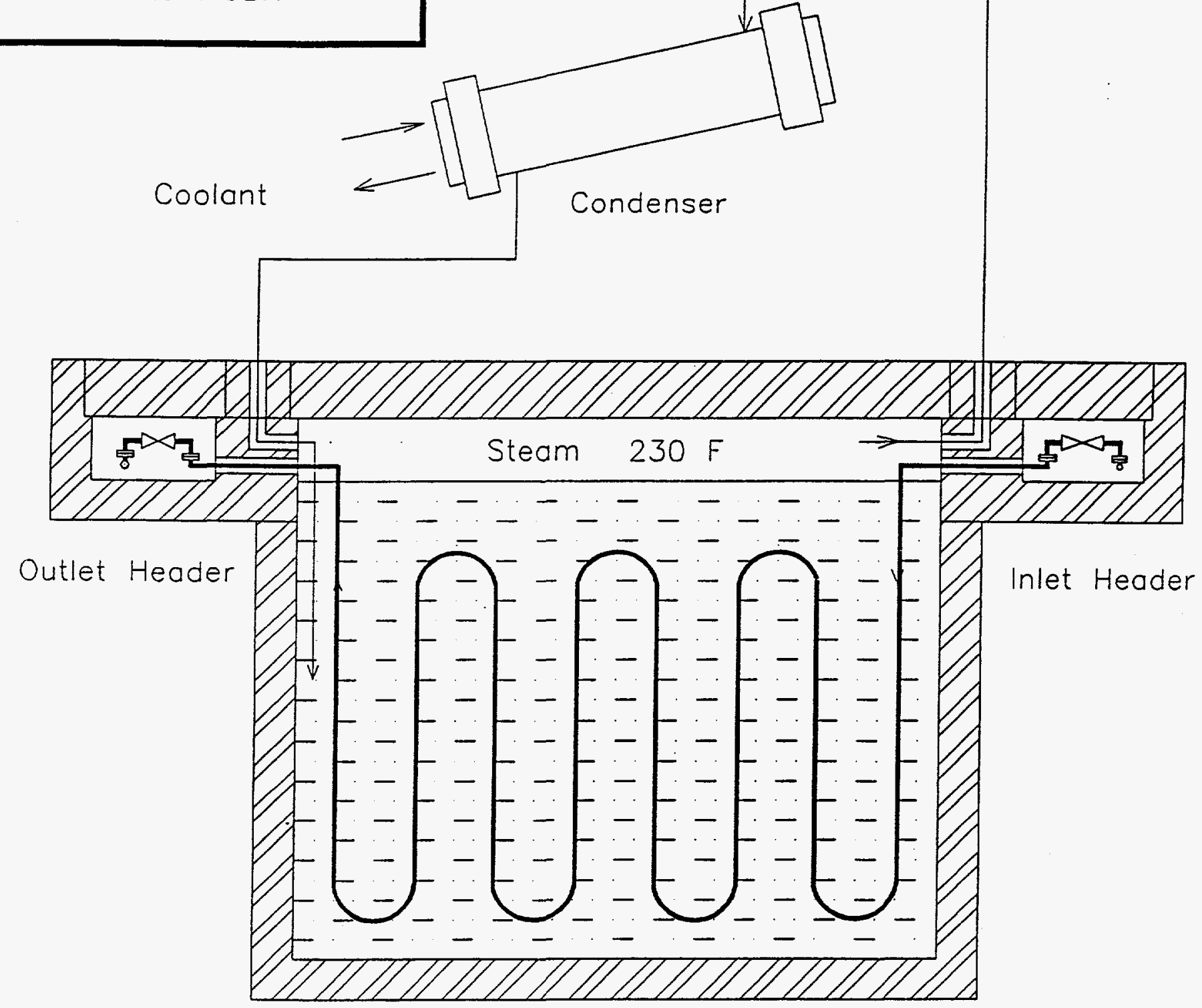

Fig. 15: Off-Gas System Charcoal Bed 


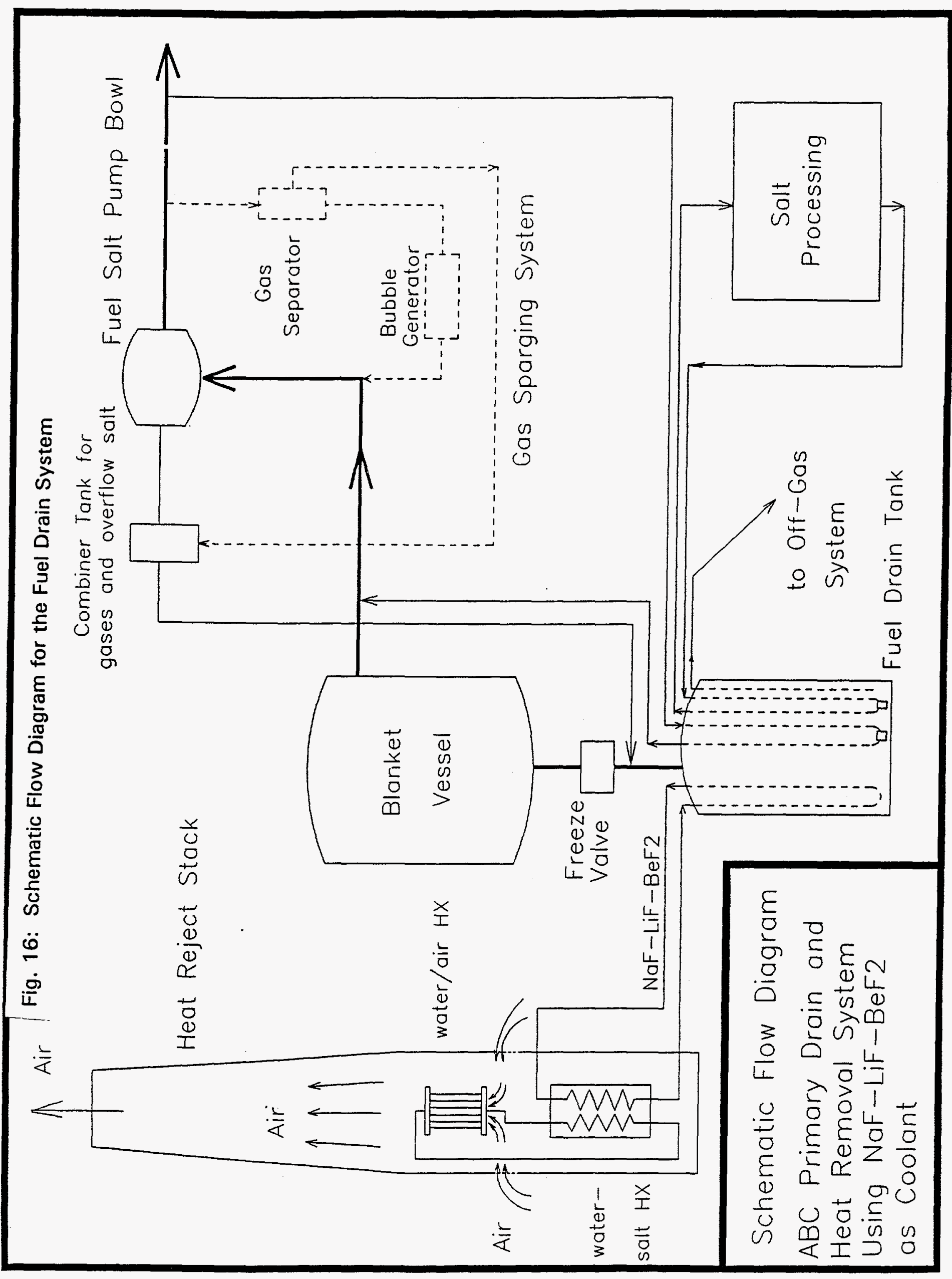




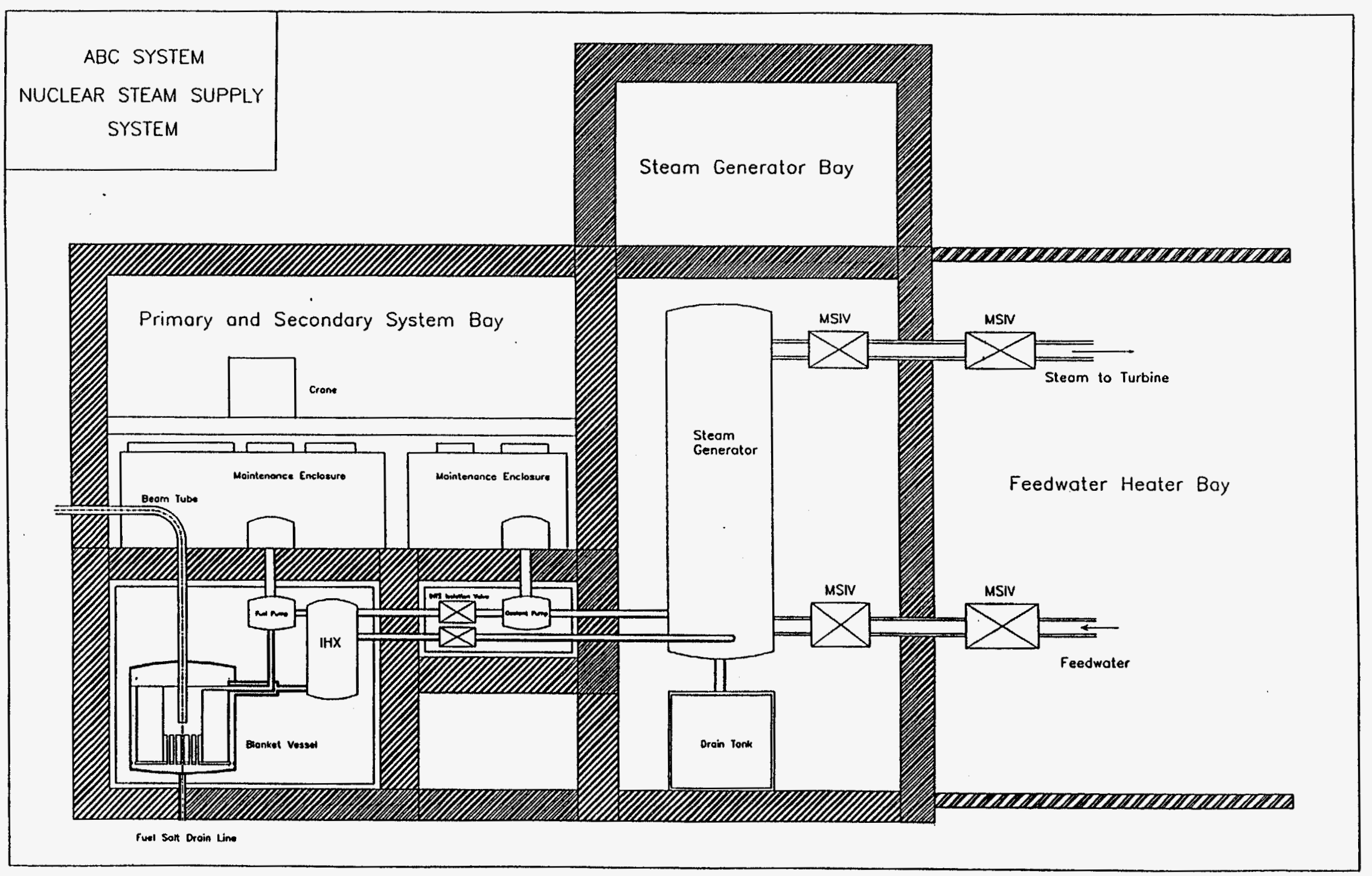

Fig. 17: ABC System Nuclear Steam Supply System 


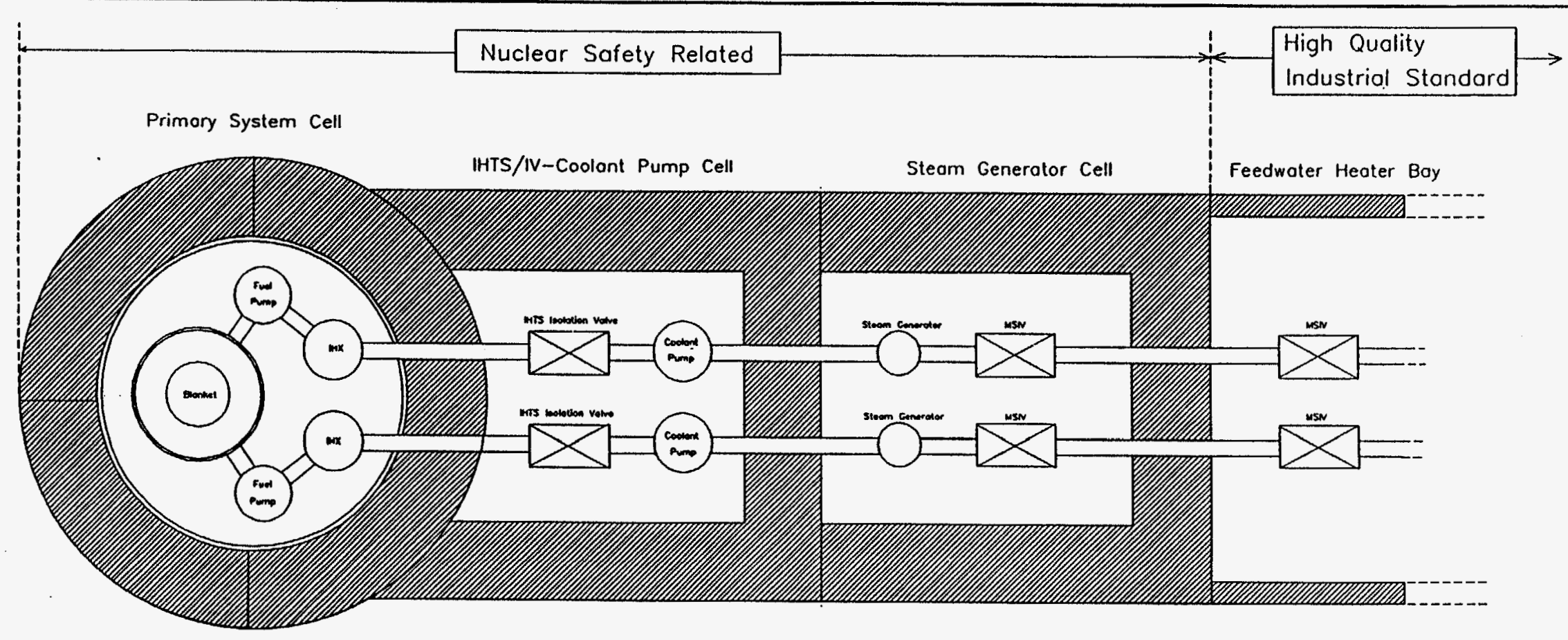

Plan View of 750 MWt $A B C$ Module Plant Blanket Vessel, IHX and Fuel Pump are Contained in Primory System Vessel

Separate Cell for IHTS IV and Coolant Pump Seporate Cell for MSIV and Steam Generator Separate Feedwoter Heoter Building

Fig. 18: Plan View of $750 \mathrm{MWt} A B C$ Module Train 


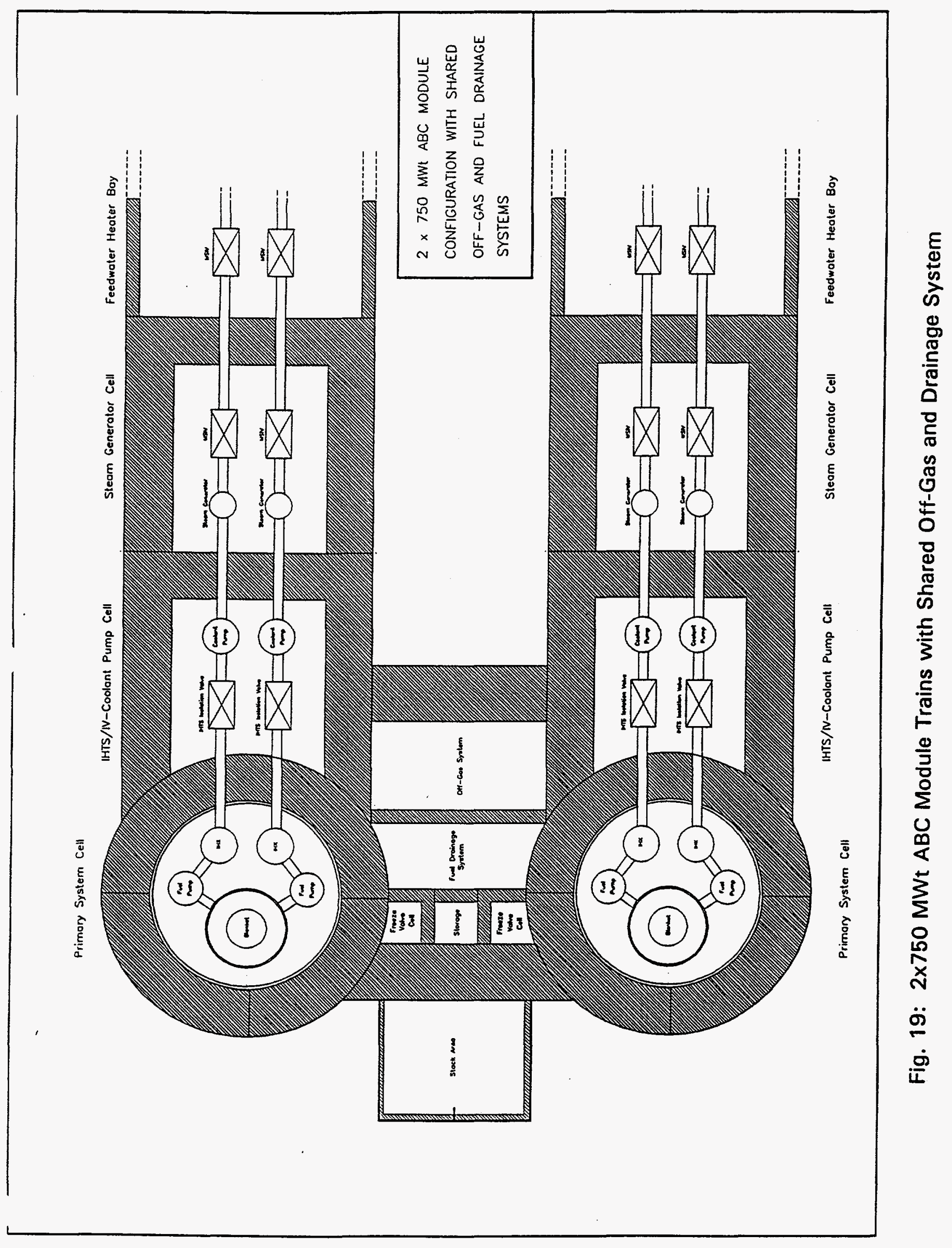




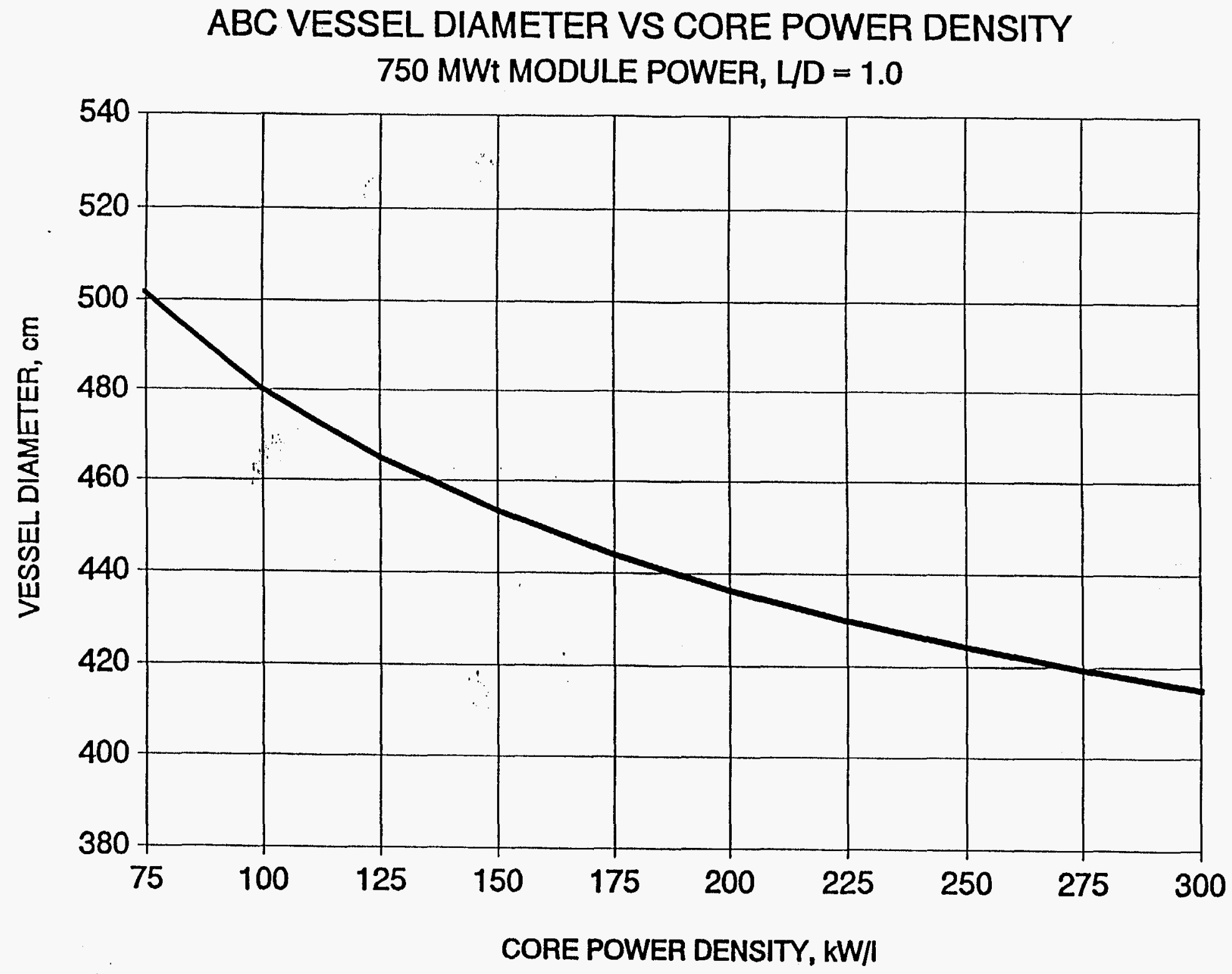

Fig. 20: $A B C$ Vessel Diameter as a Function of Core Power Density 


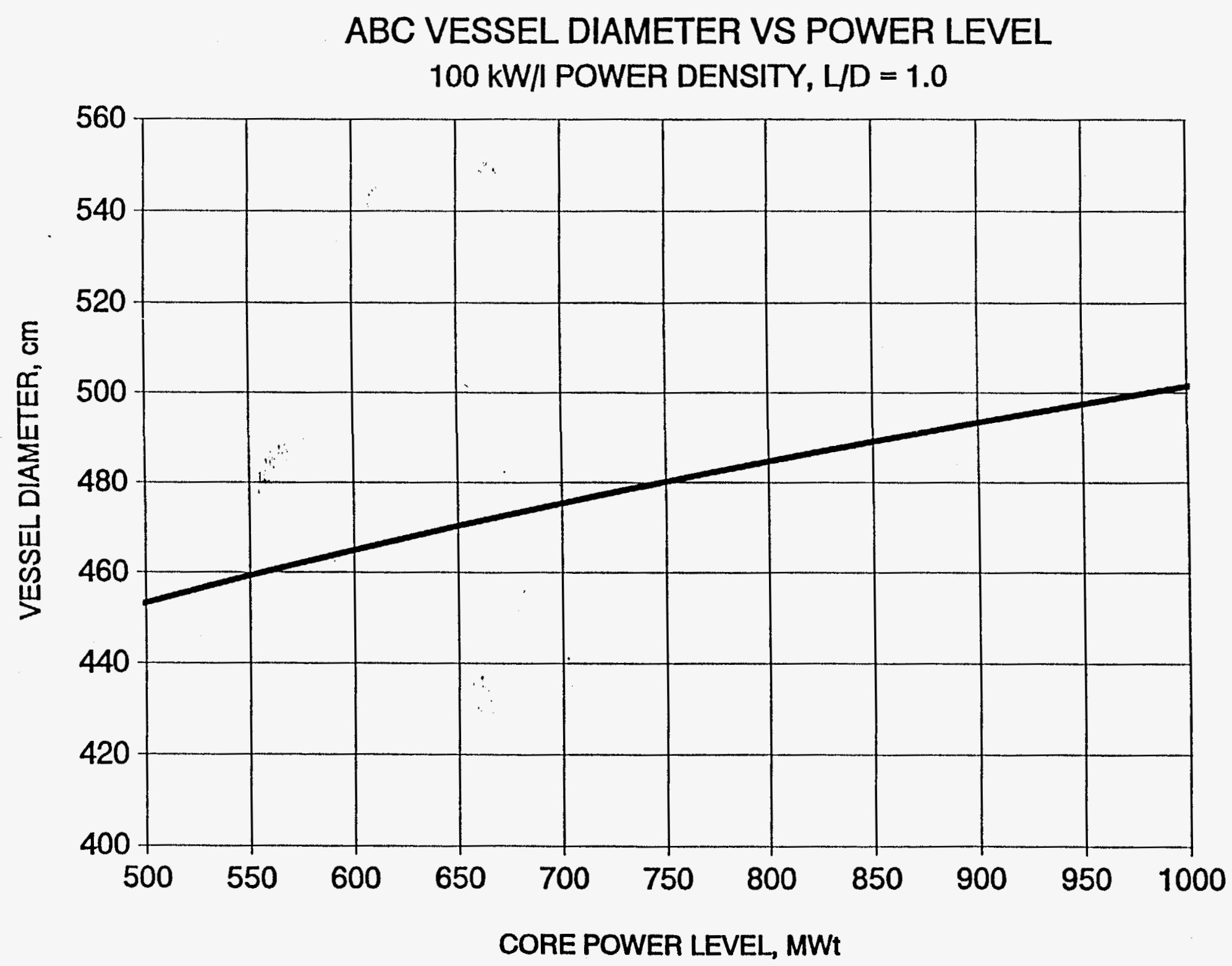

Fig. 21: $A B C$ Vessel Diameter as a Function of Power Level 


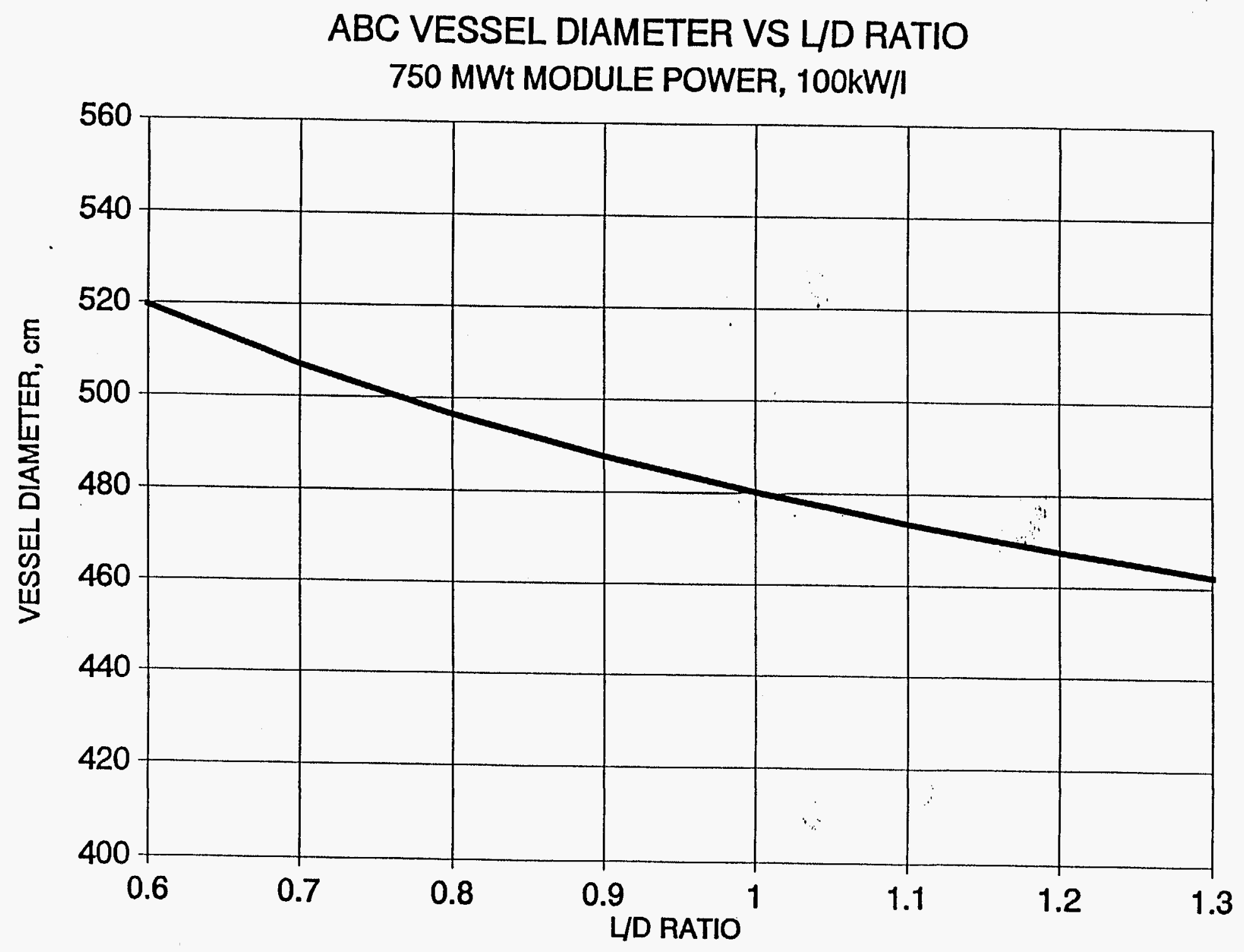

Fig. 22: $A B C$ Vessel Diameter as a Function of $L / D$ Ratio 